\title{
Colon Carcinogenesis: The Interplay Between Diet and Gut Microbiota
}

\section{OPEN ACCESS}

Edited by:

Frederic Antonio Carvalho, INSERM U1107 Douleur et Biophysique Neurosensorielle (Neuro-Dol), France

Reviewed by:

Océane C. B. Martin,

Université de Bordeaux, France Wei-Hua Chen,

Huazhong University of Science and

Technology, China Antonio Biondi,

University of Catania, Italy Joel B. Mason,

Tufts University School of Medicine, United States

Raaj Mehta,

Massachusetts General Hospital and Harvard Medical School, United States

*Correspondence:

Ming Tsuey Chew mtchew@sunway.edu.my

Specialty section: This article was submitted to Microbiome in Health and Disease,

a section of the journal

Frontiers in Cellular and Infection Microbiology

Received: 08 September 2020

Accepted: 28 October 2020

Published: 08 December 2020

Citation:

Loke YL, Chew MT, Ngeow YF, Lim WWD and Peh SC (2020) Colon

Carcinogenesis: The Interplay

Between Diet and Gut Microbiota. Front. Cell. Infect. Microbiol. 10:603086.

doi: 10.3389/fcimb.2020.603086

\author{
Yean Leng Loke ${ }^{1}$, Ming Tsuey Chew ${ }^{1 *}$, Yun Fong Ngeow ${ }^{2,3}$, Wendy Wan Dee Lim ${ }^{4}$ \\ and Suat Cheng Peh ${ }^{5,6}$
}

${ }^{1}$ Centre for Biomedical Physics, School of Healthcare and Medical Sciences, Sunway University, Petaling Jaya, Malaysia, ${ }^{2}$ Faculty of Medicine and Health Sciences, Universiti Tunku Abdul Rahman, Kajang, Malaysia, ${ }^{3}$ Centre for Research on Communicable Diseases, Universiti Tunku Abdul Rahman, Kajang, Malaysia, ${ }^{4}$ Department of Gastroenterology, Sunway Medical Centre, Petaling Jaya, Malaysia, ${ }^{5}$ Ageing Health and Well-Being Research Centre, Sunway University, Petaling Jaya, Malaysia, ${ }^{6}$ Department of Medical Sciences, School of Healthcare and Medical Sciences, Sunway University, Petaling Jaya, Malaysia

Colorectal cancer (CRC) incidence increases yearly, and is three to four times higher in developed countries compared to developing countries. The well-known risk factors have been attributed to low physical activity, overweight, obesity, dietary consumption including excessive consumption of red processed meats, alcohol, and low dietary fiber content. There is growing evidence of the interplay between diet and gut microbiota in CRC carcinogenesis. Although there appears to be a direct causal role for gut microbes in the development of CRC in some animal models, the link between diet, gut microbes, and colonic carcinogenesis has been established largely as an association rather than as a cause-and-effect relationship. This is especially true for human studies. As essential dietary factors influence CRC risk, the role of proteins, carbohydrates, fat, and their end products are considered as part of the interplay between diet and gut microbiota. The underlying molecular mechanisms of colon carcinogenesis mediated by gut microbiota are also discussed. Human biological responses such as inflammation, oxidative stress, deoxyribonucleic acid (DNA) damage can all influence dysbiosis and consequently CRC carcinogenesis. Dysbiosis could add to $\mathrm{CRC}$ risk by shifting the effect of dietary components toward promoting a colonic neoplasm together with interacting with gut microbiota. It follows that dietary intervention and gut microbiota modulation may play a vital role in reducing $\mathrm{CRC}$ risk.

Keywords: colorectal cancer, colon carcinogenesis, diet, gut microbiota, protein, fat, carbohydrate, bacteria interaction

\section{INTRODUCTION}

Colorectal cancer (CRC) is the third most commonly diagnosed cancer and the second most deadly cancer in the world, with about 1.8 million new cases and almost 881,000 deaths in 2018, comprising $5.8 \%$ of all cancer deaths that year (Rawla et al., 2019). The CRC global burden is expected to increase by $60 \%$ by 2030 , to approximately 2.2 million new cases and 1.1 million deaths per annum (Rawla et al., 2019). CRC incidence is three to four times higher in developed countries than developing countries, reflecting the state of $\mathrm{CRC}$ as a marker of socioeconomic development (Bray et al., 2018). The known risk factors are low physical activity; overweight and obesity; dietary habits including excessive consumption of red, processed meats and alcohol, and low dietary fibers (World Cancer Research Fund/American Institute for Cancer Research, 2018). The rapid rise of CRC 
incidence among individuals younger than 50 years old especially in high-income countries (Araghi et al., 2019; Siegel et al., 2019; Vuik et al., 2019) coupled with the fact that most CRC incidents arise sporadically (Yang and $\mathrm{Yu}, 2018$ ) further point to the influence of lifestyle factors on CRC development.

Human gut microbiota is dominated by three primary phyla, namely Firmicutes (30-50\%), Bacteroidetes (20-40\%), and Actinobacteria (1-10\%) (Gagnière et al., 2016). Strict anaerobes such as Bifidobacterium, Fusobacterium, Bacteroides, Eubacterium, Peptostreptococcus, and Atopobium are the major groups of bacteria in the human gut, whereas facultative anaerobes such as Lactobacilli, Enterococci, Streptococci, and Enterobacteriaceae are present in numbers that are 1,000-fold lower (Davis and Milner, 2009). The gut microbiota changes swiftly in terms of variety and composition during the first year of birth and remains relatively constant upon adulthood. Nevertheless, the composition of the resident microbiota may be altered due to environmental factors, predominantly, by the influence of diet (Chassaing et al., 2017; Jahani-Sherafat et al., 2018; Yang and Yu, 2018). It is increasingly apparent that when dietary components change the gut microbial composition and its diversity, the balance between beneficial and detrimental gut microbiota could be disrupted, and the resulting impaired gut homeostasis can set the stage for cancer development (Davis and Milner, 2009; Yang and Yu, 2018; De Almeida et al., 2019). Indeed, many studies have revealed a consistent link between colorectal carcinogenesis and gut microbiota. Fusobacterium nucleatum (Kostic et al., 2013; Tahara et al., 2014; Fukugaiti et al., 2015; Viljoen et al., 2015; Li et al., 2016; Mima et al., 2016; Tunsjø et al., 2019), Streptococcus gallolyticus (Abdulamir et al., 2010; Butt et al., 2016; Corredoira et al., 2017; Kumar et al., 2017; Kwong et al., 2018), Clostridium difficile (Fukugaiti et al., 2015; Zheng et al., 2017), Clostridium septicum (Corredoira et al., 2017; Kwong et al., 2018), Enterococcus faecalis (Zhou et al., 2016; Rezasoltani et al., 2018; Geravand et al., 2019), Escherichia coli (Buc et al., 2013; Bonnet et al., 2014; Kohoutova et al., 2014; Dejea et al., 2018), Peptostreptococcus stomatis (Zeller et al., 2014; Yu et al., 2017), and Bacteroides fragilis (Boleij et al., 2015; Zhou et al., 2016; Purcell et al., 2017; Dejea et al., 2018; Kwong et al., 2018; Haghi et al., 2019) are differentially enriched in the fecal or colonic mucosa samples of CRC patients relative to healthy individuals, or in the CRC patient's tumor tissue relative to adjacent healthy tissue, wherein in some cases, CRC disease status is associated with the abundance of CRC-associated gut microbiota. CRC risk is also associated with the seroprevalence of Helicobacter pylori antibodies (Zhang et al., 2012; Epplein et al., 2013; Teimoorian et al., 2018; Butt et al., 2019; ChangxiChen et al., 2019). Table 1 summarizes the common gut microbiota associated with CRC risk obtained from CRC patients' and healthy subjects' mucosa, blood, and stool. This is not an exhaustive summary.

In this article, an overview of the dietary components of various food classes that have been implicated in the pathogenesis of CRC, the mediating roles of gut microbiota and the different mechanisms involved in CRC initiation or progression are deliberated.

\section{THE INTERACTIONS BETWEEN DIET, GUT MICROBIOTA, AND COLORECTAL CANCER}

\section{Protein}

\section{Red Meat and Processed Meat}

Epidemiological studies have linked excessive processed meat, and to a lesser extent red meat, consumption to increased risk of CRC (Cross et al., 2010; Oostindjer et al., 2014; Demeyer et al., 2016). Reports published by the Word Cancer Research Fund in 2007 and 2018 indicated a strong evidence that a consumption of red and processed meat can increase CRC risk (World Cancer Research Fund/American Institute for Cancer Research, 2018). Processed meat has been classified as group I carcinogen by the World Health Organization's International Agency for Research on Cancer (2015), that is similar to the risk category of cigarettes and alcohol. Red meat was classified as Group 2A carcinogen, dictating its probable carcinogenicity (Bouvard et al., 2015). In a meta-analysis published in 2017, a 16 and $22 \%$ increment of CRC risk was reported for every 100 and 50g/ day additional intake of red meat and processed meat, respectively (Zhao et al., 2017). Several mechanisms have been purported to expound the disease-promoting effect of red and processed meat.

\section{N-Nitroso Compounds}

$\mathrm{N}$-Nitroso compounds (NOCs) consist of a nitroso group attached to a nitrogen atom and are formed by the reaction of a nitrite compound with amines or amides. NOCs comprise two major chemical classes, namely nitrosamines and nitrosamides. Humans are exposed to the highly mutagenic NOCs either by exogenous or endogenous means. The main source of exogenous NOCs includes meats that have been processed, smoked or cured (Bouvard et al., 2015). Alternatively, NOCs can be produced endogenously in the human gut from the intake of nitrite: amino acids are converted to amines via bacterial decarboxylation, followed by $n$-nitrosation in the presence of nitrite as nitrosating agent to generate NOCs (Parnaud et al., 2000; Fahrer and Kaina, 2013).

NOCs are multi-site carcinogens that can form DNA adducts - the outcome of covalent binding between reactive electrophilic species and the nucleophilic sites in DNA (Ewa and Danuta, 2017). Malignant transformation is initiated when $\mathrm{N}$-nitrosamines form diazomethane by the activation of $\mathrm{p} 450$ isoenzymes (CYP2E1), resulting in the formation of $\mathrm{O}^{6}$ carboxymethyl guanine $\left(\mathrm{O}^{6}-\mathrm{CMG}\right)$ and $\mathrm{O}^{6}$-methylguanine $\left(\mathrm{O}^{6}-\mathrm{MeG}\right)$ DNA adducts, which, when unrepaired, could induce $\mathrm{G}: \mathrm{C} \rightarrow \mathrm{A}: \mathrm{T}$ transition mutation that is typically detected in the $\mathrm{K}$-ras gene associated with human CRC (Fahrer and Kaina, 2013). Red meat was shown to be able to stimulate the production of $\mathrm{O}^{6}-\mathrm{CMG}$ (Lewin et al., 2006; Hemeryck et al., 2016) and $\mathrm{O}^{6}-\mathrm{MeG}$ (Le Leu et al., 2015). The formation of DNA adducts may account for the association between dietary NOC intake and rectal cancer (Loh et al., 2011; Zhu et al., 2014). 
TABLE 1 | Gut microbiota associated with colorectal cancer (CRC) risk.

\begin{tabular}{|c|c|c|c|c|c|c|}
\hline \multicolumn{3}{|c|}{ Bacteria } & \multirow[t]{2}{*}{ Sample type } & \multirow{2}{*}{$\begin{array}{c}\text { Method of } \\
\text { bacterial analysis }\end{array}$} & \multirow[t]{2}{*}{ Association } & \multirow[t]{2}{*}{ References } \\
\hline Phylum & Genus & Species & & & & \\
\hline \multirow[t]{8}{*}{ Fusobacteria } & Fusobacterium & - & $\begin{array}{l}\text { Rectal mucosa, } \\
\text { colorectal tissue }\end{array}$ & qPCR & $\begin{array}{l}\text { Significantly higher in CRA patients than in healthy controls, and in tumor tissue than in } \\
\text { adjacent normal tissue }\end{array}$ & (McCoy et al., 2013) \\
\hline & & & Stool sample & $\begin{array}{l}16 \mathrm{~S} \text { rRNA } \\
\text { pyrosequencing }\end{array}$ & Significantly higher in CRC patients than in healthy controls & (Wu et al., 2013) \\
\hline & & nucleatum & $\begin{array}{l}\text { Colorectal tissue, stool } \\
\text { sample }\end{array}$ & QPCR & Significantly higher in CRA and CRC patients than in healthy controls & (Kostic et al., 2013) \\
\hline & & & Stool sample & qPCR & Significantly higher in CRC patients than in healthy controls or patients with polyps & (Tunsjø et al., 2019) \\
\hline & & & Stool sample & qRT-PCR & Significantly higher in CRA patients than in healthy controls & (Fukugaiti et al., 2015) \\
\hline & & & Colonic mucosa & qPCR & Significantly higher in tumor tissue than in adjacent normal tissue & $\begin{array}{l}\text { (Tahara et al., 2014; } \\
\text { Viljoen et al., 2015) }\end{array}$ \\
\hline & & & Colorectal tissue & qPCR & Higher abundance was associated with significantly higher CRC-specific mortality & (Mima et al., 2016) \\
\hline & & & Colorectal tissue & FQ-PCR, FISH & $\begin{array}{l}\text { Significantly higher in tumor tissue than in adjacent normal tissue; overabundance was } \\
\text { significantly associated with lymph node metastasis }\end{array}$ & (Li et al., 2016) \\
\hline \multirow[t]{21}{*}{ Firmicutes } & Streptococcus & gallolyticus & Blood & Blood culture test & $\begin{array}{l}\text { Patients with history of S. gallolyticus bacteremia had significantly higher CRC risk than } \\
\text { those without }\end{array}$ & (Kwong et al., 2018) \\
\hline & & & Blood & Multiplex serology & $\begin{array}{l}\text { Antibody response to pilus protein Gallo2039, Gallo2178 and Gallo2179 was significantly } \\
\text { associated with CRC risk }\end{array}$ & (Butt et al., 2016) \\
\hline & & & Blood & Blood culture test & $62.7 \%$ of 204 patients with S. gallolyticus bacteremia had concurrent CRN & (Corredoira et al., 2017) \\
\hline & & & $\begin{array}{l}\text { Colorectal tissue, fecal } \\
\text { sample }\end{array}$ & PCR, ISH & Significantly higher in CRC patients than in healthy controls & (Abdulamir et al., 2010) \\
\hline & & & Colorectal tissue & qPCR & Significantly higher in tumor than in adjacent normal tissue & (Kumar et al., 2017) \\
\hline & Clostridium & difficile & Fecal sample & qRT-PCR & Significantly higher in CRA patients than in healthy controls & (Fukugaiti et al., 2015) \\
\hline & & & Fecal sample & Multiplex RT-PCR & Significantly higher in CRC patients with lymph node metastasis than those without & (Zheng et al., 2017) \\
\hline & & septicum & Blood & Blood culture test & $45.2 \%$ of 42 patients with C. septicum bacteremia had concurrent CRN & (Corredoira et al., 2017) \\
\hline & & & Blood & Blood culture test & $\begin{array}{l}\text { Patients with history of } C \text {. septicum bacteremia had significantly higher CRC risk than } \\
\text { those without }\end{array}$ & (Kwong et al., 2018) \\
\hline & Enterococcus & faecalis & Stool sample & qRT-PCR & Significantly higher in CRC patients than in healthy controls or patients with polyps & (Geravand et al., 2019) \\
\hline & & & Stool sample & qRT-PCR & Higher abundance significantly correlated with dysplasia grade & (Rezasoltani et al., 2018) \\
\hline & & & Colorectal tissue & qRT-PCR & Significantly higher in tumor tissue than in adjacent normal tissue & (Zhou et al., 2016) \\
\hline & Escherichia & coli & Colonic tissue & PCR & $\begin{array}{l}\text { E. coli of phylogenetic group B2 was significantly higher in CRC patients than in } \\
\text { diverticulosis patients }\end{array}$ & (Buc et al., 2013) \\
\hline & & & Colorectal tissue & PCR & $\begin{array}{l}\text { E. coli of phylogenetic group D was significantly higher in CRC patients than in healthy } \\
\text { controls; E. coli of phylogenetic group B2 was significantly higher in patients with } \\
\text { advanced CRA than in patients with non-advanced CRA }\end{array}$ & (Kohoutova et al., 2014) \\
\hline & & & Colonic tissue & PCR & $\begin{array}{l}\text { Significantly higher in colon cancer tumors than in diverticulosis mucosa and adjacent } \\
\text { normal tissue, and in colon cancer patients of stages III/IV than those of stage I }\end{array}$ & (Bonnet et al., 2014) \\
\hline & & & Colonic mucosa & $\mathrm{FISH}$ & Significantly higher pks+ E. coli in FAP patients than in healthy controls & (Dejea et al., 2018) \\
\hline & Peptostreptococcus & stomatis & Stool sample & $\begin{array}{l}16 \mathrm{~S} \text { rRNA } \\
\text { sequencing }\end{array}$ & Significantly higher in CRC patients than in healthy controls & (Zeller et al., 2014) \\
\hline & & & Stool sample & qPCR & Significantly higher in CRC patients than in healthy controls & (Yu et al., 2017) \\
\hline & Helicobacter & pylori & Blood & ELISA & $\begin{array}{l}\text { Significantly higher seroprevalence of } H \text {. pylori antibodies in CRC patients than in healthy } \\
\text { controls }\end{array}$ & (Zhang et al., 2012) \\
\hline & & & Blood & ELISA & $\begin{array}{l}\text { Significantly higher seroprevalence of } H \text {. pylori antibodies in patients with CRC and } \\
\text { adenomatous polyps than in healthy controls }\end{array}$ & (Teimoorian et al., 2018) \\
\hline & & & Blood & Multiplex serology & $\begin{array}{l}\text { Seropositivity of antibodies against VacA was associated with over 2-fold increase in colon } \\
\text { cancer risk }\end{array}$ & (Epplein et al., 2013) \\
\hline
\end{tabular}




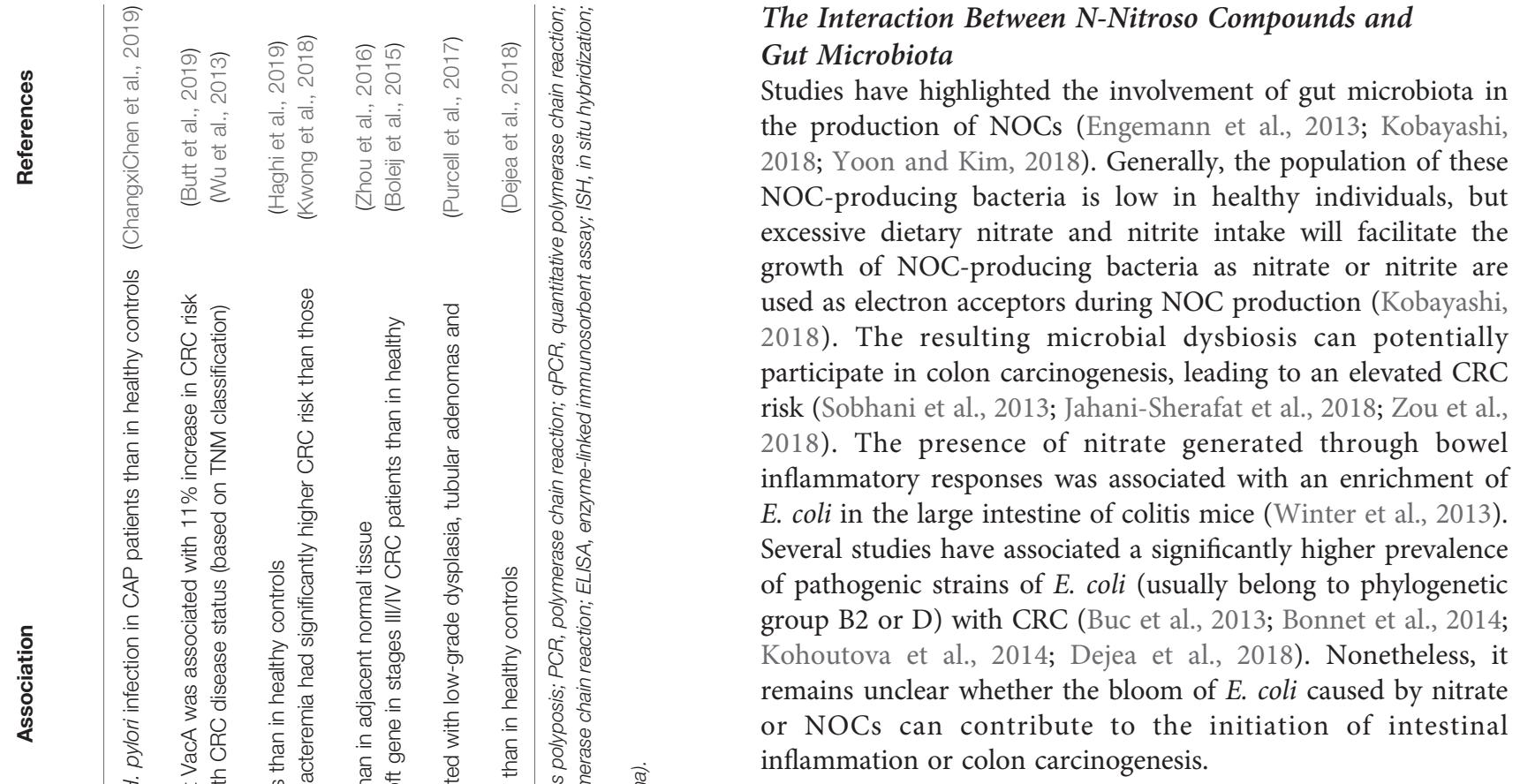

\section{Heterocyclic Amines and Polycyclic Aromatic Hydrocarbons}

When muscle meat is cooked at high temperature, its creatinine or creatine, amino acids, and sugars are converted into heterocyclic amines (HCAs) (Helmus et al., 2013). The common types of HCA in meats cooked at high temperature are 2-amino-1-methyl-6-phenylimidazo(4,5- $b$ ) pyridine (PhIP), 2-amino-3,8-dimethylimidazo(4,5-f) quinoxaline (MeIQx), 2amino-3,4-dimethylimidazo(4,5-f)quinoline (MeIQ), 2-amino3,4,8-dimethylimidazo(4,5-f) quinoxaline (DiMeIQx), and amino-3-methylimidazo(4,5-f) quinolone (IQ). PhIP, MeIQ, and MeIQx have been categorized by International Agency for Research on Cancer (IARC) as possible human carcinogens (group 2B) while IQ has been classified as probably carcinogenic to humans (group 2A) (Cascella et al., 2018). A colonoscopy-based study among Japanese reported a high MeIQ but not MeIQx and PhIP exposure to be positively associated with an increased risk of CRC in females (Budhathoki et al., 2015). However, PhIP intake but not MeIQx and DiMeIQx showed a significantly associated risk of colorectal adenoma (CRA) in an European population-based study (Rohrmann et al., 2009). Conversely, other studies have reported that a higher intake of any type of HCA (PhIP, MeIQx, and DiMeIQx) had significant associated risk for CRA (Barbir et al., 2012; Chiavarini et al., 2017). A study also reported a significant association between CRC risk and red-meat derived, but not white-meat derived HCAs and PAHs (Helmus et al., 2013). Although the definite contribution of each HCA type to colonic neoplasm remains tentative, the findings so far converge to imply that HCAs as a whole are associated with an increased CRC risk, as corroborated by mice studies (Cheung et al., 2011; Lee et al., 2013).

Incomplete combustion of organic materials from industrial processing and domestic cooking at high temperature produces 
polycyclic aromatic hydrocarbons (PAHs), which could contaminate food when they are in contact. Thus, meat cooked over an open flame is highly prone to $\mathrm{PAH}$ contamination (Zelinkova and Wenzl, 2015). Similar to HCA, PAH, primarily benzo(a)pyrene $(\mathrm{B}(a) \mathrm{P})$, could also increase the risk of CRA in humans (Sinha et al., 2005; Chiavarini et al., 2017). It has been shown experimentally that $\mathrm{B}(a) \mathrm{P}$ could bind directly to DNA to form DNA adducts, as well as induce oxidative and nitrosative stress along with increased expression of pro-inflammatory cytokines and dysregulated wnt $/ \beta$-catenin signaling in mice colon (Diggs et al., 2013; Ajayi et al., 2016). Moreover, there was a synergistic genotoxic effect of HCA and PAH with a fivefold increase in PhIP-derived DNA adducts when $\mathrm{B}(a) \mathrm{P}$ and PhIP were used in combination compared to HCA alone (Jamin et al., 2013).

\section{The Interaction Between Heterocyclic Amine and Polycyclic Aromatic Hydrocarbon and Gut Microbiota}

Exposure to PhIP (Defois et al., 2018) and B $(a) \mathrm{P}$ (Defois et al., 2017) could shift the volatile pattern of human fecal microbiota, indicating a deviation in the microbial metabolic activities that may in the long run disrupt gut homeostasis. Of note, these studies exposed microbiota to doses of HCA and PAH that were higher than expected daily consumption for a very short time $(24 \mathrm{~h})$, making the results less reflective of the actual effect of chronic HCA and $\mathrm{PAH}$ exposure. In murine models, $\mathrm{B}(a) \mathrm{P}$ also induced a shift in the abundance and composition of the gut microbiota, in addition to colonic inflammation (Khalil et al., 2010; Ribière et al., 2016). On the other hand, human colon microbiota could directly induce the bioactivations and transformations of PAH into estrogenic metabolites, influencing the toxicity of PAH (Van de Wiele et al., 2005). Human gut microbiota with beta-glucuronidase and glycerol/ diol dehydratase activity could transform HCA to HCA-M1, mitigating HCA-associated carcinogenic risk (Zhang et al., 2019). Specifically, Eulonchus halli were able to convert PhIP to PhIP-M1, whose mutagenic potency is only $5 \%$ of that of PhIP (Fekry et al., 2016). Just as HCA and PAH can induce dysbiosis to exert detrimental effect in the human body (Khalil et al., 2010; Ribière et al., 2016; Defois et al., 2017; Defois et al., 2018), there are some gut microbiota that could reduce the detrimental effects of dietary HCA and PAH (Van de Wiele et al., 2005; Fekry et al., 2016; Zhang et al., 2019).

\section{Trimethylamine-N-Oxide}

Trimethylamine-N-oxide (TMAO) is a gut microbiotadependent metabolite of saltwater fish, eggs, dairy products, and especially, red meat (Velasquez et al., 2016; Chan et al., 2019; Wang et al., 2019). In the human gut, TMAO precursors including dietary choline, phosphatidylcholine, betaine, and Lcarnitine undergo gut microbial degradation to be converted into trimethylamine (TMA). TMA is absorbed and delivered to the liver via the portal circulation, and subsequently reacts with hepatic flavin monooxygenase, primarily FMO3, to produce TMAO (Velasquez et al., 2016; Subramaniam and Fletcher, 2018; Zou et al., 2018).
Elevated TMAO level is associated with a higher mortality risk of chronic kidney disease (Tang et al., 2015; Missailidis et al., 2016), major adverse cardiovascular events such as coronary artery disease (Senthong et al., 2016), myocardial infarction (Tang et al., 2013; Suzuki et al., 2020), heart failure (Tang et al., 2014; Troseid et al., 2015), and liver cancer (Liu et al., 2018b). Besides, an epigenetic interaction network analysis indicated the role of TMAO on colon carcinogenesis, as many genetic pathways implicated in colon carcinogenesis were shared by TMAO (Xu et al., 2015). From the Women's Health Initiative (WHI) Observational Study, a higher plasma choline concentration was found to be associated with a greater risk of rectal cancer; women with low plasma vitamin B12 in particular, showed significant association between plasma TMAO level and CRC risk (Bae et al., 2014). A male matched case-control study has indicated that a higher serum concentration of choline was significantly associated with a three-fold increase CRC risk (Guertin et al., 2017). However, other studies have reported a null (de Vogel et al., 2011) and even an inverse (Nitter et al., 2014) association between plasma choline concentration and CRC risk.

TMAO has been found to promote inflammatory gene expression in both human aortic endothelial cells and smooth muscle cells via the activation of nuclear factor $-\kappa \mathrm{B}(\mathrm{NF}-\kappa \mathrm{B})$ signaling (Seldin et al., 2016); its concentration was also positively identified to be associated with the concentration of tumor necrosis factor alpha (TNF- $\alpha$ ) and its soluble receptors, both of which constitute a key regulator of inflammatory responses (Rohrmann et al., 2015). Additionally, TMAO could upregulate the expression of proinflammatory molecules such as IL-6, CXCL1, and CXCL2 in H. pylori infected-gastric epithelial cells, demonstrating the possible synergistic effect of TMAO and H. pylori in the development of gastritis or gastric ulcers $(\mathrm{Wu}$ et al., 2017). TMAO could also activate NLRP3 inflammasome and the production of reactive oxygen species (ROS) in fetal human colon cells by inhibiting ATG16L1-induced autophagy, a process that is vital for the regulation of inflammation (Yue et al., 2017). The roles of TMAO in inflammatory process implicated by these findings provide a plausible mechanism by which TMAO could contribute to colon carcinogenesis.

\section{The Interaction Between Trimethylamine-N-Oxide and Gut Microbiota}

The composition of intestinal microbiota influences the production of TMAO from its precursors (Chan et al., 2019). Following antibiotics treatment that suppressed intestinal microbiota, dietary supplementation of TMAO precursors failed to enhance TMAO synthesis in mice (Koeth et al., 2013) or healthy adults (Tang et al., 2013), implying the dependence of TMAO production on the metabolism of gut microbiota. Besides, serum TMAO level could be lowered by a natural compound known as berberine via altering the composition of gut microbiota, in particular Firmicutes and Verrucomicrobia, leading to an anti-atherosclerotic effect (Shi et al., 2018). When compared to a non-TMA producing bacterial species, TMAproducing species brought about a significantly higher serum TMAO in germ-free mice (Romano et al., 2015). In a study 
involving healthy young men, those with a higher Firmicutes to Bacteroidetes ratio demonstrated a greater response to dietary TMAO, implying the influence of gut microbiota composition on TMAO production (Cho et al., 2017). There are evidences implying the role of gut microbiota as a mediator of the association between diet, TMAO, and diseases, with alteration in the composition or structure of intestinal microbiota influencing TMAO production and hence, affecting the risk of colonic lesions (Koeth et al., 2013; Tang et al., 2013; Romano et al., 2015; Cho et al., 2017; Shi et al., 2018; Chan et al., 2019). Of note, although most of the intestinal microbiota promote TMAO production from its precursors, Eubacterium limosum was shown to be able to metabolize TMA precursors through carnitine demethylation to form a product that cannot be readily converted into TMA, revealing the potential of this gut bacterium in reducing TMAO level in the gut (Kountz et al., 2020).

\section{Heme Iron}

Red meat but not white meat, is associated with an elevated risk of CRC, and this has been linked to heme iron (Cross et al., 2010; Bastide et al., 2011; Oostindjer et al., 2014). Heme is enriched in hemoproteins including myoglobin, hemoglobin and cytochrome. Red meat in relation to white meat, has higher concentration of myoglobin, with a 10-fold higher heme content (Bastide et al., 2011). Heme-induced CRC risk is linked to two reactions catalyzed by heme, namely $\mathrm{N}$-nitrosation and lipoperoxidation. The former is characterized by the decarboxylation of amino acids by nitrosating agents to form NOCs (Bastide et al., 2011). In comparison with diet containing a negligible amount of heme, heme-rich red meat and processed meat could significantly increase fecal NOCs level, confirming the contribution of heme to endogenous NOC production (Joosen et al., 2009). Processed meat generally contains a higher amount of NOCs than fresh meat as heme iron in processed meat products is nitrosylated (curing salt contains nitrite or nitrate), resulting in the formation of nitrosyl heme (Cammack et al., 1999). In a cohort study, both nitrosylated and non-nitrosylated heme iron were found to be associated with CRA risk, but a higher risk was associated with the former, implying its higher carcinogenicity. This provides a possible explanation for the stronger link between CRC risk and processed meat intake than fresh meat intake (Bastide et al., 2016). Additionally, consumption of a large amount of red meat also results in the formation of $\mathrm{N}$-nitrosothiols, which together with nitrosyl heme, leads to the accumulation of carboxymethylated adducts (Steinberg, 2019). Indeed, the mutagenicity of NOCs has been attributed to the formation of DNA adducts such as $\mathrm{O}^{6}-\mathrm{CMG}$ and $\mathrm{O}^{6}-\mathrm{MeG}$, which could potentially accelerate the malignant transformation in the colon (Lewin et al., 2006; Bugni et al., 2009; Le Leu et al., 2015).

Lipoperoxidation is characterized by the free-radicals attack of membrane lipids which gives rise to aldehydes such as malondialdehyde (MDA) and 4-hydroxynonenal (4-HNE) (Bastide et al., 2011). Heme-induced lipoperoxidation can result in an increased fecal thiobarbituric acid reactive substances (TBARs). Previously, an increased fecal TBARs level was observed in mice (Martin et al., 2015) and human subjects (Pierre et al., 2013) who were given heme-rich diets, thus, substantiating the role of heme in promoting lipoperoxidation. In a recent study, ex vivo trapping of aldehyde counteracted inflammation and DNA damage in murine colonic epithelial cells, attributing these heme-induced deleterious effects to lipoperoxidation (Martin et al., 2019b).

In addition to NOCs and aldehydes, hemin, a porphyrin with iron bound to chloride derived from a heme group, is also related to colon tumor growth (Kim et al., 2019a). Hemin could exert cytotoxic effect on colonic epithelial cells via the production of ROS such as hydrogen peroxide (Ishikawa et al., 2010; Gemelli et al., 2014). Hemin could also mimic the effect of freeze-dried ham in inducing aberrant crypt foci and mucin depleted foci in rodent models, both of which are the precancerous lesions of the colon (Pierre et al., 2010).

\section{The Interaction Between Heme and Gut Microbiota}

The consumption of heme-rich diet was shown to alter the composition of gut microbiota in mice, which was exemplified by a reduction of Firmicutes and Deferribacteres, in addition to an increase of Proteobacteria or Bacteroidetes (IJssennagger et al., 2012; Constante et al., 2017; Martin et al., 2019b). The dysbiosis could reduce the colonic level of butyrate, a short chain fatty acid important for the digestive health, leading to adenoma formation (Constante et al., 2017). Interestingly, the dysbiosis could be ameliorated by the supplementation of calcium to heme-rich diet (Martin et al., 2019b). Other study has demonstrated the ability of gut microbiota to modulate the lipoperoxidation associated with heme-induced colon carcinogenesis (Martin et al., 2015). An antibiotic treatment was able to prevent epithelium damages and hyperproliferation in mice fed with heme-rich diet compared to antibiotics absence, substantiating the involvement of gut microbiota in enhancing heme-induced hyperproliferation and deteriorating the colonic mucus barrier (Ijssennagger et al., 2015).

\section{Other Protein Sources}

Fish consumption has no association (Engeset et al., 2007; Lee et al., 2009; Sugawara et al., 2009; Pham et al., 2013) or an inverse association (Wu et al., 2012; Aglago et al., 2019) with CRC risk. The association between egg intake and CRC risk is inconsistent, with some studies reporting a positive association (Aune et al., 2009; Lee et al., 2009) while others reported a null association (Franceschi et al., 1997; Järvinen et al., 2001). On the other hand, dairy products are associated with a decreased colon cancer risk (Huncharek et al., 2008; Aune et al., 2012), particularly cheese and milk (Lee et al., 2009; Aune et al., 2012; Murphy et al., 2013; Barnung et al., 2019).

Several studies have indicated the CRC-promoting effects in red and processed meat but not in other protein sources which also contain the CRC-inducing components found in red and processed meats. The other protein sources such as fish, eggs, and dairy products also contain the precursors of TMAO, choline, phosphatidylcholine, and L-carnitine (Velasquez et al., 2016; Subramaniam and Fletcher, 2018), while baked or grilled fish contain HCA and PAH (Alisson-Silva et al., 2016). The lack 
of a link between CRC and the consumption of protein sources other than meat may be explained by various health-promoting dietary components. For instance, studies have attributed the protective effect of fish due to its omega-3 polyunsaturated fatty acids (n-3 PUFAs) (Pietrzyk, 2017; Aglago et al., 2019). n-3 PUFAs are known to exhibit an anti-inflammatory effect through the mediation of the expression of inflammatory genes, or by modulating intracellular signaling pathways that regulate $\mathrm{T}$-cell activation, leading to a decreased risk of colon carcinogenesis (Chapkin et al., 2007; Wall et al., 2010). Calcium from dairy products is found to inhibit tumorigenesis in human colon cancer cells and CRC mouse models (Wang et al., 2011; Ju et al., 2012). The CRC-protective effect of calcium has been linked to its ability to reduce lipid peroxidation induced by heme (Hemeryck et al., 2016; Martin et al., 2019b), and to restore the upregulation of inflammatory genes induced by Western diet in the human colons (Protiva et al., 2016). Importantly, only calcium from dairy products, but not the non-dairy products, was associated with a decreased CRC risk (Murphy et al., 2013).

Although it is unclear whether certain health-promoting dietary components could counteract the harmful effects of CRC-associated dietary components, it is evident that colon carcinogenesis is not attributed to a single nutrient but a combination of them, such that the dietary impact of a particular food chemical may be influenced by the absence or presence of another (Pietrzyk, 2017). This may explain why protein sources containing the same carcinogens exhibit opposite effects in CRC.

\section{Carbohydrates}

Carbohydrates are macronutrients categorized as simple or complex carbohydrates based on their degree of polymerization (Ludwig et al., 2018). Simple carbohydrates such as monosaccharides, disaccharides, and oligosaccharides are found in sugar-sweetened food and beverage or refined plant-based food, whereas complex carbohydrates including polysaccharides such as dietary fibers and resistant starches are enriched in unrefined plant-based food (Hansen and Sams, 2018; Ludwig et al., 2018). Carbohydrate polymer length influences not only its digestion and absorption into the human body, but also the subsequent impacts on body functions (Ludwig et al., 2018). Thus, simple and complex carbohydrates will be discussed separately in terms of their contributions to CRC.

\section{Complex Carbohydrates}

The contribution of dietary fibers in reducing CRC risk has been well established in case-control studies (Dahm et al., 2010b; Luo et al., 2015), meta-analysis (Ben et al., 2014; Gianfredi et al., 2018) and European Prospective Investigation into Cancer and Nutrition (EPIC) studies (Murphy et al., 2012; Bradbury et al., 2014). The protective effect of dietary fibers is attributed to short chain fatty acids (SCFA) such as acetate, propionate, and butyrate, which are formed following the fermentation of fibers by gut microbiota along the colon tract (Wu et al., 2018). Among the different types of SCFA, butyrate has been most extensively studied for its protective efficacy against CRC. Its inhibitory effect against human colon cancer cell proliferation was shown superior compared with acetate and propionate (Zeng et al., 2020).

Butyrate exerts its anti-proliferative effect in CRC cells via several mechanisms. Firstly, butyrate decreases the expression of neuropilin-1, a receptor of vascular endothelial growth factor (VEGF) that is commonly upregulated in colon cancer cells. As VEGF is a key regulator of angiogenesis, the downregulation of neuropillin-1 exerts an inhibitory effect on the expansion of colon cancer cells (Yu et al., 2010; Yu et al., 2011). Second, butyrate induces apoptosis and suppresses the proliferation and invasion of CRC cells by regulating the expression of microRNA such as miR-92a (Hu et al., 2015) and miR-203 (Han et al., 2016). Thirdly, butyrate reduces motility of CRC cells by inhibiting the Akt/ERK signaling pathway (Li et al., 2017), revealing the potential of butyrate as part of the therapeutic strategy for blocking metastatic CRC. The protective effect of butyrate was substantiated in another study that reported a significant downregulation of free fatty acid receptor 2 (FFAR2), a butyrate receptor, in human colon cancer tissues than in healthy tissues, while mice deficient in FFAR2 also developed significantly more colon polyps than wild-type mice (Sivaprakasam et al., 2016).

Interestingly, butyrate stimulates cell growth in normal colonocytes but exerts an anti-proliferative effect in cancerous colonocytes. Such discrepancy in function was termed the "butyrate paradox." The "Butyrate paradox" is explained by the "Warburg effect" which describes the differential metabolism of butyrate in cancerous and non-cancerous cells: non-cancerous cells mainly undergo oxidative metabolism, using butyrate as a primary energy source, whereas cancerous cells favor glycolysis as a means of metabolism, resulting in an inefficient metabolism of butyrate (Donohoe et al., 2012). In cancerous colonocytes, butyrate also downregulates its own oxidation by reducing the expression of short chain acyl-CoA dehydrogenase (SCAD), an enzyme that is responsible for butyrate oxidation (Han et al., 2018). Accordingly, butyrate could accumulate and function as a histone deacetylase inhibitor to stall the proliferation of cancer cells (Donohoe et al., 2012). A corroborative study has shown that butyrate suppressed the proliferation of the underlying colonic stem cells by inhibiting histone deacetylase only in damaged colonocytes but not in normal colonocytes (Kaiko et al., 2016). Hence, although butyrate serves as a primary source of energy for the proliferation of normal colon cells, it inhibits the growth of cancerous colonocytes, which highlights the tremendous advantages of dietary fiber intake.

\section{The Interaction Between Complex Carbohydrates and Gut Microbiota}

Studies have provided evidence that dietary carbohydrates are able to modify gut microbiota and hence, could modulate the physiological conditions in the colonic environment. For instance, children from rural African villages whose diet consists of mostly fibers showed a significant enrichment in Bacteroidetes compared with Italian children. Within the Bacteroidetes phylum, several cellulose-degrading bacteria from the genus Prevotella were 
found to be completely lacking in European children (De Filippo et al., 2010). A dominance of Prevotella, along with depletion of Bacteroides was also found in the gut microbiota of Bangladeshi children compared with children from the United States (Lin et al., 2013), as well as in native Africans compared with African Americans (Ou et al., 2013). Indeed, diet serves as a driving force for shaping the intestinal microbiome, where long-term adherence to fiber-rich food leads to the abundance of Prevotella, whereas adherence to Western diet low in fiber results in abundance of Bacteroides (Wu et al., 2011; De Filippis et al., 2016; Gorvitovskaia et al., 2016). Bacteroides species, in particular Bacteroides fragilis, were found to be prevalent in the colonic mucosa of CRC patients (Boleij et al., 2015; Haghi et al., 2019). Their ability to induce DNA damage via ROS production in colonic epithelial cells (Goodwin et al., 2011) and colitis along with colon tumors in mice (Wu et al., 2009) has also been documented, indicating the possible role of Bacteroides species in promoting colonic neoplasm in individuals with low fiber intake.

On the other hand, although Prevotella is frequently linked to high fiber diet, strains such as Prevotella copri and Prevotella intestinalis have been linked to HIV-associated (Dillon et al., 2016) or intestinal inflammatory conditions (Scher et al., 2013; Iljazovic et al., 2020). Given Prevotella constitutes a large genus with great species diversity, more studies are warranted to clarify its beneficial or detrimental roles in the human body, including the mechanisms underlying its interaction with dietary components to clarify its role in the pathogenesis of CRC (Ley, 2016; Larsen, 2017). Other studies have reported the association of dietary fiber with a lower risk for F. nucleatum-positive CRC but not for $F$. nucleatum-negative CRC, suggesting the role of $F$. nucleatum as a mediator of the association between dietary fibers and colorectal neoplasms (Mehta et al., 2017; Liu et al., 2018a). Whether or not this hypothesis can be generalized to Bacteroides or Prevotella remains to be explored.

As discussed above, the protective effect of dietary fibers could be largely attributed to butyrate production. Of note, the fermentation of dietary fibers to produce butyrate is largely mediated by gut microbiota including Faecalibacterium prausnitzii, Eubacterium rectale, Roseburia faecis, E. halli, and others (Baxter et al., 2019). Thus, it is relevant to propose that the gut microbiome could influence the dietary impact of butyrate. A smaller population of butyrate-producing bacteria such as Roseburia, Clostridium, and Eubacterium was observed in advanced CRA patients along with a lower production of butyrate, highlighting the importance of gut microbiota in modulating the production of butyrate to protect hosts from colonic neoplasm (Chen et al., 2013). Conversely, butyrate could change the composition of gut microbiota to attenuate the detrimental effect of high-fat diet, resulting in an improve intestinal barrier and attenuated obesity or steatohepatitis (Zhou et al., 2017; Fang et al., 2019). Similarly, sodium butyrate supplementation was shown to beneficially restore the dysbiosis in CRC liver metastasis mouse model, resulting in a better host immune system characterized by an increase in natural killer $\mathrm{T}$ cells and $\mathrm{T}$ helper 17 cells (Ma et al., 2020). Hence, the interaction between butyrate and gut microbiota appears to be bidirectional. More investigations would need to be conducted to define the mechanistic link between dietary butyrate, gut microbiota, and CRC.

\section{Simple Carbohydrate}

A conclusive link between high sugar intake and CRC risk in healthy humans has not been reported by cohort studies (Galeone et al., 2012; Tasevska et al., 2012; Pacheco et al., 2019), but a moderately heightened risk did emerge in smaller case-control studies (Pou et al., 2012; Wang et al., 2014; Chun et al., 2015). Nonetheless, the detrimental effect of simple carbohydrates on CRC is more evident in animal studies. Sucrose supplementation aggravated colonic inflammation in colitic rats by inducing DNA changes in the colon mucosal cells (Mahmoud, 2011). Ingestion of high-fructose corn syrup could enhance colon tumorigenesis via the action of ketohexokinase, a fructose-converting enzyme that changes the tumor cell metabolism to increase the production of fatty acids needed for tumor growth. Importantly, the enhanced tumor growth was observed in the absence of obesity, supporting the detrimental role of simple sugars in the etiology of CRC independently from their effect on obesity (Goncalves et al., 2019). This finding points to the consequences of consumption of simple sugars, especially of high-fructose corn syrup that is widely used as a sweetener in carbonated drinks, condiments, and baked foods (Payne et al., 2012).

Simple carbohydrates, especially monosaccharides, are easily hydrolyzed and absorbed in the small intestine, resulting in a rapid rise in blood glucose level. Although a consistent link between total sugar intake and CRC risk has not been established, a number of studies did find a positive association between glycemic index (GI) and glycemic load (GL) with CRC risk (Gnagnarella et al., 2008; Sieri et al., 2015). The GI measures the elevation in blood sugar level following consumption of a particular food independent of quantity, while GL takes into account of both GI and the quantity of available carbohydrates in a portion of food consumed (Vega-López et al., 2018). Interestingly, GI has been significantly linked to CRC risk more frequently than GL (George et al., 2009; Choi et al., 2012; Turati et al., 2015). Two studies reported that high carbohydrate intake from high GI food was significantly associated with increased CRC risk, but high carbohydrate intake from low GI food was significantly associated with decreased CRC risk, indicating the greater dependence of CRC risk on the ability of carbohydrate-rich food to postprandially raise blood glucose level rather than the overall amount of carbohydrates consumed (Sieri et al., 2015; Sieri et al., 2017). In fact, hyperglycemia (high blood sugar level) and hyperinsulinemia (high insulin level) resulting from high GIdiet could contribute to the initiation or progression of CRC through the induction of DNA damage in colon cells (Othman et al., 2013; Othman et al., 2014), or the action of insulin-like growth factor (Aleksandrova et al., 2013) which has a known role in the pathogenesis and progression of CRC (Vigneri et al., 2015; Kasprzak and Adamek, 2019). Other etiological hypotheses for the CRC-promoting effect of high GI/GL diet 
include insulin resistance, oxidative stress and abnormal sex hormone production (Sieri et al., 2017; Li et al., 2019), but these mechanisms have not been extensively studied.

\section{The Interaction Between Simple Carbohydrates and Gut Microbiota}

The association between simple carbohydrate consumption and microbiota-mediated CRC risk remains poorly documented. Martinez-Medina et al. (2014) reported an increased colonization of adherent-invasive E. coli and mucin-degrading bacterium Ruminococcus torques in the gut of mice fed with high-fat, high-sugar Western diet. The change in microbiota composition subjected the mice to an increased susceptibility to inflammation, as reflected by the decreased mucus thickness and an increased release of pro-inflammatory cytokines (MartinezMedina et al., 2014). Of note, the study examined the combined effect of a high-fat and a high-sugar diet, hence it cannot be concluded whether the microbial dysbiosis was induced by fat or sugar exposure. Nevertheless, it has been postulated that a prolonged exposure to fructose and sugar substitutes through a Western diet can subject gut microbiota to extensive conditioning, leading to the formation of "Western gut microbiome" characterized by low microbial genetic and phylogenic diversity (Payne et al., 2012; Segata, 2015). Supporting this hypothesis, studies have shown that individuals living in non-urban settings harbor a gut microbiome of greater diversity and complexity, relative to individuals from urban-industrialized settings (Obregon-Tito et al., 2015; Rampelli et al., 2015). The loss or depletion of certain gut microbiota may in the long run lead to microbial dysbiosis or aberrant host-microbe interactions, and ultimately, disorders (Payne et al., 2012).

\section{Fat}

Epidemiological studies examining the link between dietary fat intake and CRC risk are sparse and to date, have not drawn a definitive conclusion regarding the CRC-promoting effect of dietary fats. While total dietary fat intake is infrequently linked to CRC risk (Dahm et al., 2010a; Williams et al., 2010; Kim and Park, 2018), an elevated CRC risk has been detected among individuals with a high saturated fat intake (Chun et al., 2015; Tayyem et al., 2015; Kim et al., 2017b). In contrast, consumption of n-3 polyunsaturated fat ( $\mathrm{n}-3$ PUFA) has been inversely associated with CRC (Zhong et al., 2013; Kim and Kim, 2020). A more consistent link between fat intake and colon carcinogenesis has been inferred from mice studies, that showed an associated increased risk due to an altered expression of inflammatory mediators (Padidar et al., 2012; Day et al., 2013).

Investigations of the dietary fat-associated CRC risk often cite bile acids as being responsible for increasing CRC risk. Human primary bile acids, namely cholic acid (CA) and chenodeoxycholic acid (CDCA), are synthesized in the liver from cholesterol. Conjugated with glycine and taurine, the primary bile acids are secreted into the hepatobiliary system and enter the duodenum to emulsify dietary fats after a meal.
Subsequently, the majority of the primary bile acids will be deconjugated and reabsorbed, but a small amount can escape and enter the colon, where they are biotransformed by colonic bacteria via $7 \alpha$-dehydroxylation to form secondary bile acids such as deoxycholic acid (DCA) and lithocholic acid (LCA). Most human gut microbiota that participate in the $7 \alpha$ dehydroxylation belong to the genus Clostridium (Ocvirk and O’Keefe, 2017; Zou et al., 2018).

Given bile acids are cholesterol derivatives, their synthesis is likely to be promoted by a high-fat diet that is also rich in cholesterol. A high-fat diet will upregulate bile discharge for the emulsification of excessive dietary fats, which further raises the bile acid level (Ajouz et al., 2014). A study reported an increased fecal bile acid concentration in mice fed with high-fat, low-fiber Western diet, which was observed along with a defective bile acid transport and an increased colon tumor number (Dermadi et al., 2017). Accumulation of fecal bile acid was also observed in DCAtreated mice, along with a significantly increased intestinal inflammation (Xu et al., 2020). Extending to human studies, African Americans who consumed a high-fat diet were shown to have a 3-4 times higher level of secondary bile acids than native Africans who subsisted on a low-fat diet, providing a possible explanation for the much higher CRC risk among African Americans (Ou et al., 2012). In the follow-up study that involved switching African Americans to a high-fiber, low-fat diet for 2 weeks, the dietary change led to a suppressed secondary bile acid synthesis and showed a remarkable decrease in colonic mucosal inflammation and proliferation biomarkers of cancer risk (O’Keefe et al., 2015).

Although the exact mechanism of how bile acids induce the pre-cancerous state of colonocytes is unclear, it has been hypothesized that bile acids as cholesterol derivatives with detergent-like properties, could damage the intestinal epithelium when they are present at high concentration. Such destruction will trigger inflammation and a compensatory hyperproliferation of undifferentiated cells, which drives their transition into a precancerous state (Nguyen et al., 2018). Moreover, DCA and LCA could induce cancer stem cell growth in the colonic epithelium via the modulation of M3R and $\mathrm{Wnt} / \beta$-catenin signaling. Given cancer stem cells are notorious for their ability to initiate and sustain tumor growth or proliferation, this finding provides a probable mechanism on how bile acids promote CRC (Farhana et al., 2016). Interestingly, it has been hypothesized that bile acid could exert a dichotomous effect on the apoptosis of colonocytes (Nguyen et al., 2018): a short-term exposure to high concentration of bile acid was able to induce apoptosis, primarily via the production of ROS (Ignacio Barrasa et al., 2011), whereas a prolonged exposure gave rise to colon carcinogenesis (Bernstein et al., 2011), which can be attributed to the inhibited accumulation of tumor suppressor p53 (Qiao et al., 2001), or the activation of PI3K/ Akt signaling (Raufman et al., 2008). The effect of bile acids on CRC development was shown to be mediated by the farnesoid X receptor (FXR), a primary bile acid nuclear receptor. One study reported that inactivation of FXR could increase cancer risk by inducing bile acid dysregulation (Dermadi et al., 2017). 
Conversely, in another study, the ability of DCA to compromise colonic epithelial restitution appeared to be mediated by the activation of FXR, and such effect was linked to colonic barrier dysfunction and intestinal inflammation, both of which could increase susceptibility to CRC (Mroz et al., 2018). Although the role of FXR remains incompletely defined, these studies pinpoint the importance of FXR in mediating bile acid-associated CRC risk.

Although DCA and LCA are notorious for their tumorigenic effect especially in the course of CRC development, it is vital to note that not all bile acids could cause adverse effects. Ursodeoxycholic acid (UDCA), a secondary bile acid used as the first-line therapy for primary biliary cirrhosis, is found to have profound chemopreventive effect against colorectal carcinogenesis (Serfaty et al., 2010). The antiproliferative action of UDCA in colon cancer cells has been well documented and attributed to its ability to regulate the production of ROS (Kim et al., 2017a), to suppress the proproliferative c-Myc proteins (Peiro-Jordan et al., 2012), or to sustain the hyperphosphorylation of ERK1 kinase (KrishnaSubramanian et al., 2012). UDCA could also reverse DCAinduced effect on colonic epithelial cells by inhibiting DCAinduced secretion of epithelial defensins (Lajczak et al., 2017). Evidently, while other secondary bile acids drive CRC progression, UDCA emerges as a potential chemopreventive agent for CRC. Their differential actions on CRC-related inflammatory signals or growth factors are likely to account for such contrasting effect (Serfaty et al., 2010).

\section{The Interaction Between Dietary Fat and Gut Microbiota}

Several studies have associated the prolonged intake of high-fat diet with a shift in the relative proportion of Firmicutes to Bacteroidetes ( $\mathrm{F} / \mathrm{B}$ ratio), where Firmicutes dominate at the expense of Bacteroidetes in most cases (Murphy et al., 2010; Islam et al., 2011; Taira et al., 2015). Given the shift in the F/B ratio has been repeatedly linked to obese individuals (Ferrer et al., 2013; Kasai et al., 2015; Koliada et al., 2017), it could be contended that the dysbiosis is more likely to be associated with the host obese state rather than the high-fat diet itself. However, it was found that even in the absence of an obese genotype, mice fed with high-fat diet demonstrated profound changes in microbial communities characterized by increase in Firmicutes and decrease in Bacteroidetes (Hildebrandt et al., 2009). A high-fat diet could also promote tumorigenesis in the murine small intestine independently of obesity by inducing a dysbiosis that was associated with an attenuated antimicrobial host defense (Schulz et al., 2014). These findings collectively show that microbial dysbiosis is inducible by high-fat diet alone, and such dysbiosis could promote colon carcinogenesis independently of obesity.

Moreover, a high-fat diet could increase the proportion of the phylum Actinobacteria with an accompanying increase in the expression of proinflammatory cytokines and a decrease in tight junction proteins (Kim et al., 2019b). Given Actinobacteria are known mucin-degrading bacteria (Tailford et al., 2015), an increase in abundance could induce gut barrier impairment and subsequent colonic inflammation, which may help explain the CRC-promoting effect of dietary fat in the colon. In mice, a high-fat diet also diminished the beneficial gut microbiota including Bifidobacterium, Lactobacillus, and Akkermansia (Kim et al., 2012; Lecomte et al., 2015; He et al., 2018), all of which play significant roles in mediating the intestinal metabolism and immunity (Naito et al., 2018). The high-fat diet-induced reduction of these beneficial gut microbiota could possibly increase the susceptibility to inflammation, facilitating subsequent neoplastic progression.

As conversion of bile acids into secondary bile acids involves the action of gut microbiota, changes in the composition of gut microbiota can potentially influence the metabolic effect of bile acids in the host. A dysbiosis characterized by a decrease in the ratio between Faecalibacterium prausntizii and E. coli was associated with an impaired bile acid metabolism in patients with inflammatory bowel diseases (IBD), as reflected by their higher level of fecal bile acids (Duboc et al., 2013). In a recent metagenomics analysis, a lower abundance of genes of bilemetabolizing Firmicutes was detected in the gut microbiota of IBD individuals, again linking microbial dysbiosis with the disease state (Das et al., 2019). Of note, the interaction between bile acids and gut microbiota is bidirectional as bile acids serve as antimicrobial agents that help shape the gut microbiome structure (Ridlon et al., 2016). Administration of cholic acid into rats could expand Firmicutes to approximately $95 \%$ of the total gut microbiome in relation to $54 \%$ in control rats (Islam et al., 2011). DCA treatment could induce a dysbiosis characterized by an increase in opportunistic pathogens and a decrease in Lactobacillus, Lactococcus, and Roseburia, which was linked to intestinal tumorigenesis (Cao et al., 2017). Indeed, while gut microbiota can affect the metabolism of bile acid, bile acid can shape the composition of gut microbiota.

Recently, Bilophila wadsworthia, a sulfur-metabolizing microbe that convert dietary sulfur into genotoxic hydrogen sulfide $\left(\mathrm{H}_{2} \mathrm{~S}\right)$ have been associated with the development of CRC (David et al., 2014; Ijssennagger et al., 2016; Nguyen et al., 2020). Excessive gut-derived $\mathrm{H}_{2} \mathrm{~S}$ could break down the disulfide bonds of the mucus bilayer of the gastrointestinal tract and expose gut epithelium to immunogenic luminal bacteria (Ijssennagger et al., 2016). Moreover, it could cause epithelial DNA damage, promote alterations in immune cell populations associated with inflammation and CRC. David et al. (2014) reported that participants fed with a high-meat, high-fat diet for several days showed an increase in Bilophila, which coincided with an increased abundance of microbial DNA and RNA encoding for $\mathrm{H}_{2} \mathrm{~S}$-producing enzymes (David et al., 2014). In a large cohort of patients with precancerous polyps and CRC, Yachida et al. (2019) found that DCA concentration was significantly increased in subjects with multiple polypoid (MP, more than three adenomas) adenomas with low grade dysplasia as compared to healthy controls; and Bilophila wadsworthia was the only species that was significantly associated with DCA increase in this MP group (Yachida et al., 2019). Nguyen et al. (2020) reported that long-term adherence to a dietary pattern 


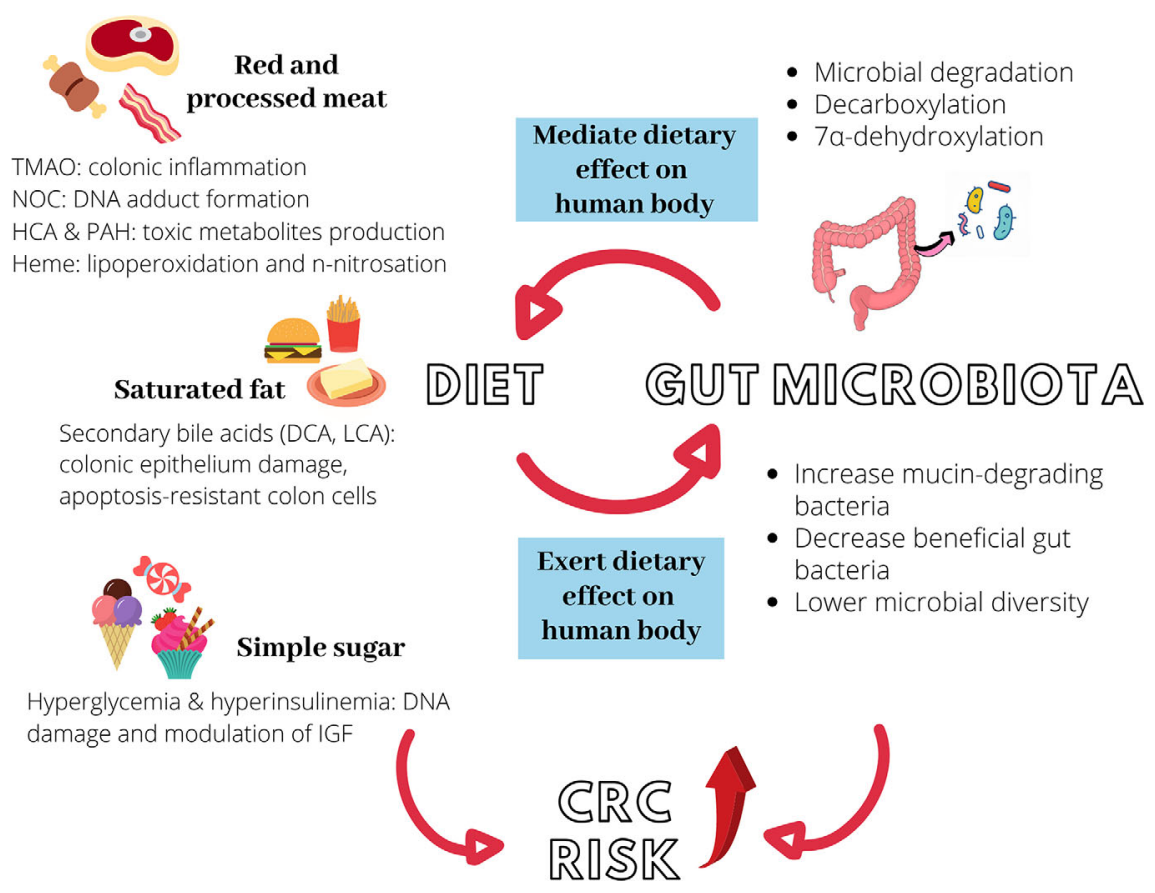

FIGURE 1 | Diet, gut microbiota, and increased colorectal cancer (CRC) risk. Red and processed meat, saturated fat, and simple sugar could independently promote colon carcinogenesis via different mechanisms. Similarly, they can induce microbial dysbiosis in the intestine, further elevating CRC risk. Gut microbiota modulates the metabolism of ingested food via different processes to produce carcinogenic metabolites such as NOC, TMAO, and secondary bile acids. The interaction between diet and gut microbiota is hence bidirectional. TMAO, trimethylamine-N-oxide; NOC, N-nitroso compounds, HCA, heterocyclic amines; PAH, polycyclic aromatic hydrocarbons; DCA, deoxycholic acid; LCA, lithocholic acid; IGF, insulin-like growth factor.

associated with sulfur-metabolizing bacteria in stool was associated with an increased risk of distal CRC in men but how this bacteria contribute to CRC pathogenesis remains unclear (Nguyen et al., 2020).

Figure 1 illustrates the interactions between diet, gut microbiota, and increased risk of CRC risk. Table 2 recapitulates the interactions between dietary compounds and gut microbiota that purportedly influence CRC risk.

\section{THE UNDERLYING MOLECULAR MECHANISMS OF COLON CARCINOGENESIS MEDIATED BY GUT MICROBIOTA}

\section{Inflammation and Host Defense Mechanism}

The connection between inflammation and malignant diseases has been well-established based on evidence from epidemiological, genetic, or pharmacological studies. In the case of colon malignancies, IBDs especially ulcerative colitis and Crohn's disease exhibit consistent association with an elevated risk of CRC (Choi et al., 2019; Zhou et al., 2019; Olén et al., 2020). IBDassociated CRC is characterized by early onset (Keller et al., 2019), increased formation of synchronous, and poorly differentiated tumors (Reynolds et al., 2017) as well as elevated mortality rate (Sebastian et al., 2014), in relation to sporadic CRC.

Importantly, recent studies have indicated the role of gut microbiota in mediating inflammatory responses during the course of colon carcinogenesis, most of which are through the activation of nuclear factor- $\kappa \mathrm{B}(\mathrm{NF}-\kappa \mathrm{B})$ signaling pathway. NF$\kappa \mathrm{B}$ are a family of transcription factors that actively regulate genes of various immune and inflammatory responses, and strong evidence has indicated its involvement in the pathogenesis of IBD and IBD-associated cancers (Liu et al., 2017). In a mice study, colon tumors with a higher abundance of Fusobacterium nucleatum had a higher nuclear translocation of the p65 NF- $\mathrm{BB}$ subunit, representing an increase in the activation of NF- $\kappa B$ pathway (Kostic et al., 2013). Importantly, the tumorigenic property of $F$. nucleatum was indicated as its administration into $\mathrm{Apc}^{\mathrm{Min} /+}$ mice and human $\mathrm{CRC}$ cell lines accelerated the colonic tumorigenesis, which was attributed to the activation of NF- $\kappa \mathrm{B}$ that in turn induced miR21 expression (Yang et al., 2017). Analysis of colonic epithelial tissue of CRC patients showed a higher expression of NF- $\mathrm{BB}$ in the $S$. gallolyticus-seropositive group compared to the S. gallolyticusseronegative group (Abdulamir et al., 2009). In the follow-up study, the colorectal tissue of $S$. gallolyticus-seropositive CRC patients had a higher expression of IL-1 and COX-2, both of which constitute the products of NF- $\mathrm{KB}$ activity (Abdulamir et al., 2010). Likewise, infection of human macrophages with 
TABLE 2 | Interactions between dietary compounds and gut microbiota that purportedly influence colorectal cancer (CRC) risk.

\begin{tabular}{|c|c|c|c|c|c|}
\hline Food type & $\begin{array}{l}\text { Compounds } \\
\text { involved }\end{array}$ & $\begin{array}{l}\text { Action of dietary compounds on gut } \\
\text { microbiota }\end{array}$ & References & $\begin{array}{l}\text { Action of gut microbiota on } \\
\text { dietary compounds }\end{array}$ & References \\
\hline \multirow[t]{4}{*}{$\begin{array}{l}\text { Red and } \\
\text { processed } \\
\text { meat }\end{array}$} & $\begin{array}{l}\text { N-nitroso } \\
\text { compounds (NOCs) }\end{array}$ & $\begin{array}{l}\text { Promote the growth of NOC-producing } \\
\text { bacteria, leading to disease- causing } \\
\text { dysbiosis }\end{array}$ & (Kobayashi, 2018) & - & - \\
\hline & $\begin{array}{l}\text { Heterocyclic amines } \\
\text { (HCAs) and } \\
\text { polycyclic aromatic } \\
\text { hydrocarbons } \\
\text { (PAHs) }\end{array}$ & $\begin{array}{l}\text { Alter the abundance, composition, or } \\
\text { metabolic activities of gut microbiota, } \\
\text { accompanied by colonic inflammation }\end{array}$ & $\begin{array}{l}\text { (Khalil et al., 2010; Ribière } \\
\text { et al., 2016; Defois et al., } \\
\text { 2017; Defois et al., 2018) }\end{array}$ & $\begin{array}{l}\text { Bioactivate and transform } \\
\text { HCAs and PAHs into } \\
\text { compounds with lower toxicity }\end{array}$ & $\begin{array}{l}\text { (Van de Wiele et al., } \\
\text { 2005; Fekry et al., } \\
\text { 2016; Zhang et al., } \\
\text { 2019) }\end{array}$ \\
\hline & $\begin{array}{l}\text { Trimethylamine- } \mathrm{N}- \\
\text { oxide (TMAO) }\end{array}$ & - & - & $\begin{array}{l}\text { Involved in TMAO synthesis; } \\
\text { microbial composition could } \\
\text { define body response toward } \\
\text { TMAO intake }\end{array}$ & $\begin{array}{l}\text { (Koeth et al., 2013; } \\
\text { Tang et al., 2013; } \\
\text { Romano et al., 2015; } \\
\text { Cho et al., 2017) }\end{array}$ \\
\hline & Heme & $\begin{array}{l}\text { Promote the enrichment of Proteobacteria } \\
\text { and Bacteroidetes; reduce Firmicutes and } \\
\text { Deferribacteres; promote adenoma formation; } \\
\text { decrease fecal butyrate level }\end{array}$ & $\begin{array}{l}\text { (IJssennagger et al., } \\
\text { 2012; Constante et al., } \\
\text { 2017; Martin et al., } \\
\text { 2019b) }\end{array}$ & $\begin{array}{l}\text { Increase heme-induced } \\
\text { lipoperoxidation, } \\
\text { hyperproliferation and } \\
\text { exacerbation of colonic mucus } \\
\text { barrier }\end{array}$ & $\begin{array}{l}\text { (ljssennagger et al., } \\
\text { 2015; Martin et al., } \\
\text { 2015) }\end{array}$ \\
\hline $\begin{array}{l}\text { Dietary } \\
\text { fibers }\end{array}$ & Butyrate & $\begin{array}{l}\text { Promote the enrichment of Bacteroidetes, } \\
\text { especially Prevotella; restore high-fat diet- } \\
\text { induced dysbiosis, resulting in an improved } \\
\text { host immune response and intestinal barrier } \\
\text { as well as attenuated obesity and } \\
\text { steatohepatitis }\end{array}$ & $\begin{array}{l}\text { (De Filippo et al., 2010; } \\
\text { Lin et al., 2013; Ou et al., } \\
\text { 2013; Zhou et al., 2017; } \\
\text { Fang et al., 2019; Ma } \\
\text { et al., 2020) }\end{array}$ & $\begin{array}{l}\text { Mediate the fermentation of } \\
\text { dietary fiber to form butyrate }\end{array}$ & $\begin{array}{l}\text { (Chen et al., 2013; } \\
\text { Baxter et al., 2019) }\end{array}$ \\
\hline $\begin{array}{l}\text { Simple } \\
\text { sugar }\end{array}$ & - & $\begin{array}{l}\text { Promote the enrichment of pathogenic and } \\
\text { mucin degrading bacteria; form "Western gut } \\
\text { microbiome" characterized by low genetic } \\
\text { and phylogenic diversity }\end{array}$ & $\begin{array}{l}\text { (Payne et al., 2012; } \\
\text { Martinez-Medina et al., } \\
\text { 2014; Segata, 2015) }\end{array}$ & - & - \\
\hline Fats & Bile acids & $\begin{array}{l}\text { Increase the Firmicutes to Bacteroidetes ratio, } \\
\text { which was linked to obesity; promote the } \\
\text { enrichment of mucin-degrading } \\
\text { Actinobacteria; decrease beneficial gut } \\
\text { microbiota such as Bifidobacterium, } \\
\text { Lactobacillus, and Akkermansia }\end{array}$ & $\begin{array}{l}\text { (Murphy et al., 2010; } \\
\text { Islam et al., 2011; Kim } \\
\text { et al., 2012; Lecomte } \\
\text { et al., 2015; Taira et al., } \\
\text { 2015; Cao et al., 2017; } \\
\text { He et al., 2018) }\end{array}$ & $\begin{array}{l}\text { Mediate the conversion of bile } \\
\text { acids into secondary bile acids; } \\
\text { dysbiosis is associated with } \\
\text { impaired bile acid metabolism } \\
\text { and inflammatory bowel } \\
\text { diseases }\end{array}$ & $\begin{array}{l}\text { (Duboc et al., 2013; } \\
\text { Zou et al., 2018; Das } \\
\text { et al., 2019) }\end{array}$ \\
\hline
\end{tabular}

CRC-associated E. coli strains promoted a sustained COX-2 expression (Raisch et al., 2015). These studies together underscore the role of gut microbiota together with the involvement of NF- $\mathrm{KB}$ during the course of colon carcinogenesis.

The infection of colonocytes by certain gut microbiota can activate a wealth of immune cells that together mediate the colonic inflammatory responses. Enterotoxigenic B. fragilis for instance, could induce distal colon tumorigenesis by recruiting polymorphonuclear immature myeloid cells following NF- $\mathrm{KB}$ activation (Chung et al., 2018). Peptostreptococcus anaerobius interacts with colonic cells via $\alpha 2 / \beta 1$ integrin, a receptor that is commonly overexpressed in CRC to promote a proinflammatory state, characterized by an expansion of tumorassociated macrophages, myeloid-derived suppressor cells, and granulocytic tumor-associated neutrophils (Long et al., 2019). Macrophages of Enterococcus faecalis-colonized mice could produce pro-inflammatory cytokine TNF- $\alpha$, which in turn increased the colon epithelial cell production of netrin-1, a neuronal guidance molecule capable of inhibiting apoptosis to accelerate malignant transformation (Yang et al., 2012).

Obesity is known to produce a chronic, low-grade state of inflammation. Some of the mediator for inflammation are cytokines and inflammation-related molecules (Hursting et al.,
2012). A study reported that increased body mass index (BMI) was associated with increase in two proinflammatory colonic cytokines, namely TNF- $\alpha$ and interleukin 6 (IL6), while obesity coincided with precancerous changes in the transcriptome (Pfalzer et al., 2018). Considering the existing correlation between obesity and gut microbiota changes (Boulangé et al., 2016), finding from Pfalzer et al. (2018) implies that inflammation may be one of the mechanisms of how obesityassociated dysbiosis contributes to increased CRC risk.

Although the above describe mainly the detrimental effects of microbiome, Parabacteroides distasonis, a commensal organism, has been shown to exert an anti-inflammatory effect. When fed to $\mathrm{BALB} / \mathrm{C}$ mice, $P$. distasonis could reduce the severity of intestinal inflammation of acute and chronic colitis (Kverka et al., 2011). Likewise, Koh et al. (2020) has reported the beneficial role of $P$. distasonis in attenuating colonic tumorigenesis and maintaining intestinal epithelial barrier in azoxymethane (AOM)-treated mice (Koh et al., 2020).

\section{Bacterial Toxin}

CRC-associated gut microbiota also exerts tumorigenic effect through the production of genotoxin, which induces DNA or 
chromosomal damage to facilitate malignant transformation. Interestingly, the production of genotoxin is not restricted to only the typically pathogenic bacteria but also commensal bacteria. E. coli constitutes a normal component of the gut microbiome, but certain strains that acquire pathogen-like features can produce cyclomodulin genotoxin including colibactin, cytotoxic necrotizing factor (CNF), and cytolethal distending toxin (CDT) (Kurnick et al., 2019), all of which have been examined for their promoting effect in CRC. The pathogenicity island encoding colibactin, known as polyketide synthase (pks), are detected in up to $66.7 \%$ of CRC patients (Arthur et al., 2012). Moreover, experimental studies show that colibactin could sustain tumor growth by generating DNA cross links in cellulo, which were later transformed into DNA doublestrand breaks (Bossuet-Greif et al., 2018; Kawanishi et al., 2019; Wilson et al., 2019), or by favoring the emergence of senescent cells (Cougnoux et al., 2014; Dalmasso et al., 2014). Senescent cells are cells with an irreversible cell cycle arrest. Although earlystage senescence usually protects cells against malignant transformation, a long-term senescence stage changes cellular microenvironment leading to cancer development (Zeng et al., 2018). In the case of CRC, colibactin-induced cellular senescence could lead to the continuous secretion of growth factors that promote tumor growth (Cougnoux et al., 2014; Dalmasso et al., 2014). On the other hand, CNF-encoding gene was found significantly more prevalent in the resection specimens of CRC patients than diverticulosis patients, suggesting the specific role of CNF in promoting colon cancer (Buc et al., 2013). Like colibactin, CNF could induce cellular senescence in human colon cells. Of note, such senescence was reversible, where the polyploid cells re-entered cell cycle, depolyploidised and eventually produced more aneuploid progeny. Given aneuploidy is the hallmark of solid tumor development, the reversible senescence induced by $\mathrm{CNF}$ is relevant to colon tumorigenesis (Zhang et al., 2018b). Likewise, CDT that are produced by pathogenic $E$. coli could drive colon carcinogenesis in genetically altered premalignant human colon epithelial cells (Graillot et al., 2016). Another gram-negative bacterium, Salmonella enterica, also produces CDT, which has been classified as typhoid toxin due to being a unique virulence factor of S. enterica subspecies enterica serotype Typhi (Miller and Wiedmann, 2016). Typhoid toxin of S. enterica was found to synergize with the loss of the adenomatous polyposis coli (APC) gene to promote microenvironment conducive for malignant transformation, purportedly through the inhibition of DNA repair and DNA damage-induced cell cycle arrest (Martin et al., 2019a).

Besides E. coli, other types of CRC-associated gut microbiota also produce CRC-promoting cytotoxins. The gene encoding $B$. fragilis toxin was detected in the colonic mucosa of both the early-stages and late-stages CRC patients, with a $100 \%$ prevalence in the latter (Boleij et al., 2015). Studies investigating the tumorigenicity of $B$. fragilis toxin reported its capability to disrupt or cleave E-cadherin, leading to barrier permeability dysfunction, activation of $\mathrm{Wnt} / \beta$ catenin and NF- $\mathrm{KB}$ signaling pathways as well as expression of IL-8 and IL-17, which altogether form a carcinogenic inflammatory cascade (Wu et al., 2007; Hwang et al., 2013; Chung et al., 2018). B. fragilis toxin could also upregulate spermine oxidase, a polyamine catabolic enzyme and subsequently led to the generation of ROS and DNA damage (Goodwin et al., 2011). Although the overall H. pylori seroprevalence was not associated with CRC risk, seropositivity to a specific $H$. pylori protein called VacA significantly increased the odds of developing CRC (Epplein et al., 2013; Butt et al., 2019). It was posited that VacA cytotoxin may contribute to CRC by disrupting the ionic equilibrium in enterocytes, primarily through the modulation of chloride concentration in the cellular microenvironment (Ponzetto and Figura, 2019). This mechanism, however, remains as a postulation; the effect of $H$. pylori on CRC is far from clear as previous studies only assessed the antibody responses against VacA in serum samples but did not confirm the presence of $H$. pylori or its associated protein in colorectal tissue samples (Epplein et al., 2013; Butt et al., 2019).

\section{Bacterial Adherence Factor}

Throughout their phylogenetic evolution, bacteria gradually attained virulence factors such as adhesins, pili, and flagella to develop their ability to breach the gut mucosal barrier, as well as to adhere to and to invade intestinal epithelial cells (Gagnière et al., 2016). Studies have elucidated the mechanism to which $F$. nucleatum utilizes its adhesins to bind to and invade host cells: Fusobacterium adhesin A ( FadA) binds and shifts away the vascular endothelial cadherin at the endothelial cell-cell junctions to enable the passage of $F$. nucleatum through the loosened junctions of endothelium (Fardini et al., 2011), whereas fibroblast activation protein 2 (Fap2) binds to the D-galactose- $\beta$ (1-3)-N-acetyl-D-galactosamine (Gal-GalNAc) carbohydrate moiety, which is overexpressed in CRC host, to promote $F$. nucleatum enrichment (Abed et al., 2016). Of note, experimental evidence has indicated that the interaction between bacterial adhesins and their receptors on host cells does not only facilitate bacterial attachment, but also its subsequent pathogenic activities via the modulation of different mechanisms. FadA could bind and interact with E-cadherin to induce $\beta$-catenin signaling, proinflammatory cytokines, and CRC tumor growth in xenograft mice (Rubinstein et al., 2013). A higher expression of FadA was detected in patients with CRC and precancerous adenomas in comparison with non-CRC individuals, further corroborated the facilitative role of FadA in F. nucleatum-associated colon carcinogenesis (Rubinstein et al., 2013; Kashani et al., 2020). Similarly, the binding of Fap2 to the human inhibitory receptor T-cell immunoreceptor with Ig and tyrosine based inhibitory motif domains (TIGIT) potentially sustain tumor growth by reducing natural killer cell cytotoxicity and tumor infiltrating lymphocyte cell activities (Gur et al., 2015).

E. coli, another CRC-associated gut microbe, also has its adherence and disease-promoting effect mediated by its afimbrial adhesin (afa). Diffusely-adhering E. coli expressing afa demonstrates the potential as a pathobiont that promotes IBD or intestinal cancer progression due to its ability to induce intestinal lesions, pro-inflammatory responses, and angiogenesis 
(Servin, 2014). A study has shown afa-possessing E. coli confer better adherence and invasion of intestinal epithelial cells than the afa-negative clones. Moreover, afa had the ability to upregulate the expression of VEGF, which could be linked to angiogenesis and tumor development (Prorok-Hamon et al., 2014). The prevalence of afa-possessing E. coli was also found to be higher in CRC as compared to healthy patients, indicating the potential role of afa in mediating the pathogenesis of E. coli (Prorok-Hamon et al., 2014; Eklof et al., 2017).

The role of pil3 pilus is essential to the attachment of $S$. gallolyticus to human mucus-producing cells or to the colonization of murine colon (Martins et al., 2015). Interestingly, pil3 bound equally well to the human mucins MUC2 which predominates in healthy colon, and to MUC5AC which is overexpressed only in cancerous colon. It was posited that the ability of S. gallolyticus to bind MUC2 mucin via pil3 facilitates commensal colonization, while binding to MUC5AC confers a growth advantage over other colon microbiota species in the tumor microenvironment. This helps explain the higher carriage rate of $S$. gallolyticus in the presence of colon tumors (Martins et al., 2016).

\section{Oxidative Stress and DNA Repair Defects}

As discussed above, dysbiotic microbiota provokes chronic gut inflammation via different mechanisms. These chronic inflammatory cells may stimulate the release of endogenous ROS and nitrogen species (RONs), which are responsible for the accumulation of different types of DNA damage including single and double strand DNA breaks, DNA crosslinks, thymine glycol, and abasic sites (Ray and Kidane, 2016). One of the gut microbiotas that is capable of triggering such detrimental inflammatory cascade is E. faecalis. E. faecalis could produce ROS such as extracellular superoxide, which induced tumor-associated chromosomal instability, anaphase bridging, and multipolar mitosis in human colonic epithelial cells (Wang and Huycke, 2007; Wang et al., 2008). P. anaerobius interacts with toll-like receptor (TLR) 2 and 4 on colon cells to stimulate an increased ROS level, rate of cholesterol biosynthesis, and colon cell proliferation (Tsoi et al., 2017). Of note, the effect of ROS in carcinogenesis is dichotomous; while it contributes to tumor growth and survival, it induces the apoptosis of cancer cells when present at excessively high level (Lin et al., 2018). There is increasing evidence that ROS involvement in various pathways can lead to the natural resolution of inflammation (Chelombitko, 2018). Hence, the microbiotainduced tumorigenic effect observed in the aforementioned studies could be interpreted as a consequence of oxidative stress, which occurs with prolonged ROS overproduction that could not be compensated by antioxidant systems, rather than the direct tumor promoting effect of ROS itself.

The DNA damage caused by ROS could be repaired by several DNA repair mechanisms including the DNA mismatch repair system (MMR) and base excision repair system (BER), both of which are highly conserved from bacteria to humans (Bridge et al., 2014). The disruption of either of these antioxidant mechanisms by dysbiotic microbiota has been shown to promote carcinogenesis by the accumulation of oxidative stress, which is responsible for the severe cellular and tissue damage as well as chronic inflammation (Chelombitko, 2018). Studies have uncovered the detrimental effect of enteropathogenic E. coli (EPEC), which has been shown to significantly reduce the expression of two key MMR proteins, namely MSH2 and MLH1 via a post-translation mechanism involving the EPEC effector protein EspF. The MMR dysfunction could also induce microsatellite instability, a phenomenon characterized by the accumulation of DNA replication errors particularly in the area of short repetitive DNA stretches (Maddocks et al., 2009; Maddocks et al., 2013). Considering the fact that microsatellite instability is detected in up to $20 \%$ of CRC (Nojadeh et al., 2018), investigations into how other gut microbiota cause MMR dysfunction become a matter of great clinical importance. Besides, it has been proposed that dysbiotic microbiota may promote the accumulation of carcinogenic BER intermediates, primarily AP sites, leading to genomic instability and colon carcinogenesis (Ray and Kidane, 2016). Moreover, the polymorphism of BER genes could modulate CRC risk, presumably, by influencing the BER processes (Brevik et al., 2010; Kabzinski et al., 2016). Nonetheless, whether or not specific gut microbiota could interfere with BER, causing its loss of biological function and subsequently influence risk of colon carcinogenesis is yet to be explored. Figure 2 summarizes the mechanisms to which dysbiosis may set the stage for colon carcinogenesis.

\section{POSSIBLE PREVENTIVE AND THERAPEUTIC STRATEGY FOR COLORECTAL CANCER: THE PROBIOTICS}

Probiotics are typically defined as living microorganisms, which when administered in adequate amounts, confer health benefits to the host. The potential contribution of probiotics to the preventative or therapeutic strategies for CRC is attributed to its ability to first, inhibit colonization by pathogenic bacteria; second, to modulate the gut immunity; and third, to strengthen the gut barrier (Fong et al., 2020). The inhibitory effect of probiotics against pathogenic bacteria has been demonstrated by several studies. The consumption of Bacillus bacteria was shown to inhibit intestinal colonization by Staphylococcus aureus via the interference of its quorum sensing signaling (Piewngam et al., 2018). Clostridium butyricum exhibited inhibitive effect against biofilm formation by enterotoxigenic $B$. fragilis, via the regulation of several $B$. fragilis virulence and efflux pump-related genes (Shi et al., 2020). Specific Lactobacillus strains, namely Lactobacillus fermentum 88 and Lactobacillus plantarum 9, demonstrated high adhesion values to the human enteric cell line HT29 while inhibiting the adhesion of E. coli to HT29 (Gharbi et al., 2019). Pre-treatment with Lactobacillus rhamnosus GG prior to the experimental induction of periodontitis in mouse model also exerted protective effect against F. nucleatum and Porphyromonas gingivalis-induced caecum dysbiosis, as well as significantly reduced intestinal inflammation (Gatej et al., 2020). 


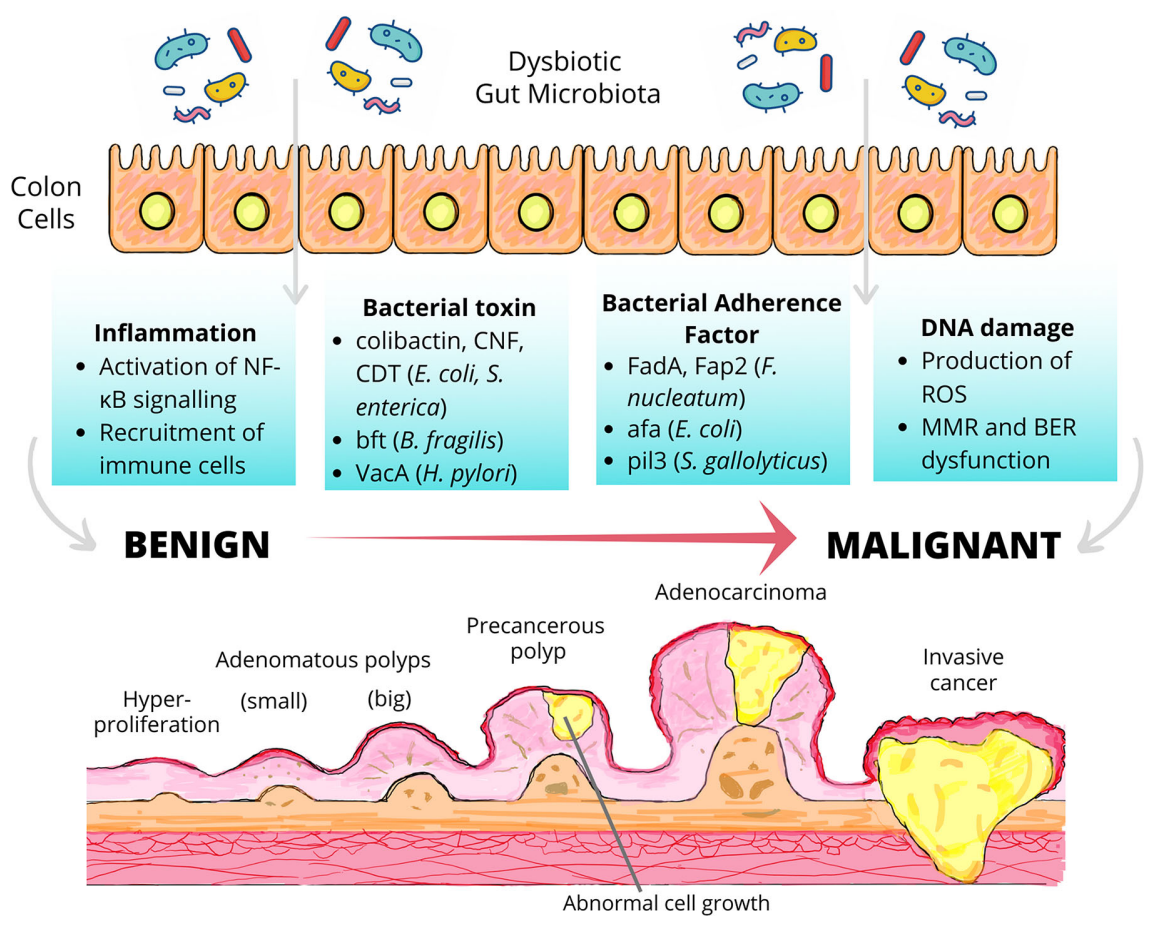

FIGURE 2 | Dysbiosis and colon carcinogenesis. Dysbiotic gut microbiota may drive the malignant transformation of colon cells via the induction of inflammation, the secretion of bacterial toxin, the action of bacterial adherence factors and the induction of DNA damage. The transformation of early neoplastic lesions (adenomatous polyps) to colorectal cancer (CRC) may take up to 15 years depending on the characteristics of the lesions and other risk factors including body weight, gender,

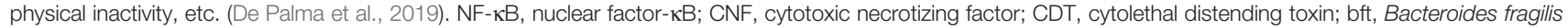
toxin; VacA, vacuolating toxin A; FadA, Fusobacterium adhesin A; Fap2, fibroblast activation protein 2; afa, afimbrial adhesin; pil3, pilus 3; ROS, reactive oxygen species; MMR, mismatch repair system, BER, base excision repair system.

As mentioned, probiotics play an immunomodulatory role in the gut and can reduce colonic inflammation. Through the suppression of $\mathrm{Wnt} / \beta$-catenin signaling, Lactobacillus species was shown to ameliorate colonic inflammation and tumor growth in azoxymethane (AOM) and dextran sulfate sodium (DSS)-induced CRC murine model (Ghanavati et al., 2020). Treatment with a specific strain of L. rhamnosus decreased tumor incidence by inhibiting inflammation and promoting apoptosis (Gamallat et al., 2016). In APCMin/+ mouse model of colon cancer, L. plantarum strain YYC-3 prevented colon tumor development, putatively by suppressing the production of inflammatory cytokines and infiltration of inflammatory cells (Yue et al., 2020). Administration of a mixture of Lactobacillus acidophilus, L. rhamnosus and Bifidobacterium bifidum decreased colitis and resulted in a $40 \%$ lower number of tumors than the control group (Mendes et al., 2018).

It is known that a dysregulation of tight junction proteins including occludin, claudins, junctional adhesion molecules, and zona occludens (ZO) can lead to a leaky epithelial barrier, setting the stage for intestinal inflammation and IBD-associated CRC (Landy et al., 2016). The ability of probiotics to enhance gut barrier integrity can hence play a preventive role. A study previously reported that the probiotic E. coli Nissle 1917 could enhance intestinal barrier function via the upregulation and redistribution of the tight junction proteins $\mathrm{ZO}-1, \mathrm{ZO}-2$, and claudin-14 (Alvarez et al., 2016). A probiotic mixture comprising Bifidobacterium, L. acidophilus, and Enterococcus attenuated colitis in mice by upregulating the expression levels of occludin and claudin-4 (Zhang et al., 2018a). In 1,2-dimethylhydrazine dihydrochloride (DMH)-induced CRC mouse model, administration of L. acidophilus, B. bifidum, and Bifidobacterium infantum enhanced TLR2 signaling and gut mucosa epithelial barrier integrity, both of which correlated with decreased tumor incidence (Kuugbee et al., 2016). Figure 3 illustrates the interactions between diet, gut microbiota, and decreased risk of CRC.

\section{CONCLUSION AND FUTURE DIRECTIONS}

This report has examined recent scientific findings that highlighted the active participation of gut microbiota in the pathogenesis of CRC via different types of mechanisms. The purported mechanisms, however, do not indicate whether the state of the gut microbiota is a cause or a consequence of colon carcinogenesis. CRC-associated microbiota have long been grouped into driver species comprising pro-carcinogenic gut bacteria that initiate CRC development, or passenger species comprising opportunistic 


\section{Probiotics}

L. fermentum, L. plantarum,

L. rhamnosus, L. acidophilus;

B. bifidum, B. infantum:

- Modulate gut immunity

- Strengthen intestinal barrier

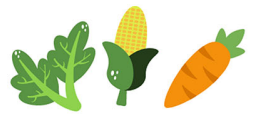

\section{Dietary fiber}

Butyrate:

- suppress CRC proliferation and invasion

- reduce CRC cell motility

- reduce the expression of receptors overexpressed in CRC
- Fermentation of fiber to form butyrate

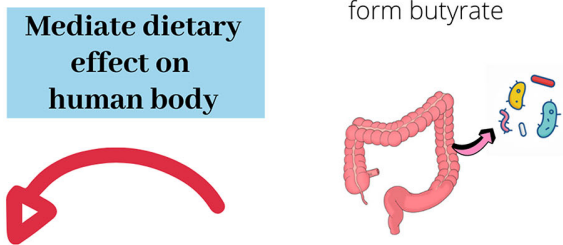

\section{DIFए GUT MLCROBLOUA

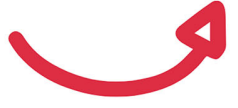 \\ Exert dietary effect on human body \\ - Prevent colonisation by pathogenic bacteria \\ - Promote enrichment of Bacteroidetes, especially Prevotella \\ - Restore high-fat diet-induced dysbiosis, obesity and steatohepatitis}

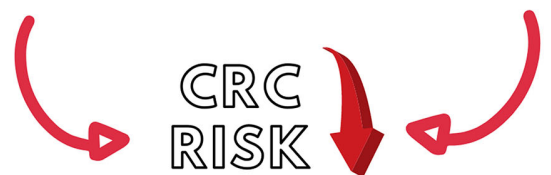

FIGURE 3 | Diet, gut microbiota, and decreased colorectal cancer (CRC) risk. The fermentation of dietary fiber by gut microbiota results in the production of butyrate. Butyrate exerts inhibitory effect against colon carcinogenesis through several mechanisms, including the restoration of gut dysbiosis induced by high-fat diet. Probiotics such as Lactobacillus and Bifidobacterium prevents gut colonization by pathogenic bacteria, modulates gut immunity, and maintains gut barrier integrity.

pathogens that outcompete the driver species in the tumor microenvironment (Tjalsma et al., 2012). In that sense, driver species can be regarded as the initiator of colon carcinogenesis while the passenger species is the consequence which further aggravates tumor progression after gaining colonization advantage in the established tumor microenvironment. Several recent studies however, redefine the roles of CRC-associated microbiota differently from what was originally proposed: E. coli, initially thought to be a driver species, may be a passenger species capable of replacing other gut microbiota through the action of colibactin (Wassenaar, 2018); S. gallolyticus, initially thought to be a passenger species, may be a driver species capable of inducing colon carcinogenesis on its own (Pasquereau-Kotula et al., 2018). Indeed, the existing scientific evidence is insufficient to provide a definitive answer for the cause-or-effect debate revolving around the role of gut microbiota in CRC. With more robust studies that could decipher the mechanisms underlying the pathogenicity of CRC-associated gut microbiota, the causative role of particular gut microbiota may one day be established, analogous to how H. pylori has been proven to be a strong risk factor for the development of gastric cancer (Wroblewski et al., 2010). Investigations into the exact effect of microbial dysbiosis on CRC development is a subject of tremendous clinical importance as gut microbiota is postulated to contribute to CRC progression and maintenance, as well as to define patients' prognosis (Mima et al., 2016; Wei et al., 2016; Chen et al., 2019) and response to anti-cancer therapies (Pouncey et al., 2018; Lin et al., 2019; Villéger et al., 2019).

Evidence from epidemiological, animal, and human cell line studies also strongly support the influence of dietary factors on CRC risk. The findings so far converge to indicate that CRC risk could be reduced by an increased intake of dietary fiber while an elevated CRC risk is associated with the excessive intake of red and processed meat, saturated fats and to a smaller extent, simple sugar. These dietary components exert their detrimental effect by altering the composition and diversity of the gut microbial community to increase dysbiosis-associated CRC risk. On the other hand, dietary impact on the human body is itself mediated by the gut microbiota activity, which means dysbiosis triggered by any factor can add to CRC risk by shifting the effect of dietary components toward promoting colonic neoplasm. In either direction of this two-way interaction, dietary components mediate the risk of malignant transformation in the colon by interacting with gut microbiota. Of note, the evidence of dietary impacts on gut microbiota obtained from animal studies must be interpreted with caution as the gut microbiota of in-bred animal may not reflect the real-life gut microbiota of humans, which is shaped by many factors other than diet (Nguyen et al., 2015). Additionally, many human studies linking dietary habits, gut microbiota and CRC risk are cross-sectional. There is a pressing need to establish more well-designed longitudinal studies that 
assess the gut microbiota composition, dietary habits and gastrointestinal health status across different life stages, in order to determine the causal effects of dysbiosis and dietary compounds on CRC development and progression. It would also be of interest to determine if a stool-based screening of microbial dysbiosis can be utilized as a non-invasive and affordable CRC screening tool, which is eminently useful in resource-poor regions where colonoscopy is not readily available. Certainly, a standardized protocol with higher specificity and sensitivity must be developed before such screening tool can be implemented.

Probiotics have long been posited as a prophylactic and even therapeutic measure in colon carcinogenesis. While probiotics have demonstrated great health benefits, it should be noted that probiotics use is accompanied by risk; host response toward gut microbiome intervention varies from individual to individual, with likelihood of adverse effect among individuals with impaired gut barrier and compromised immunity (Doron and Snydman, 2015). More studies are warranted to confirm the risk and benefits associated with probiotics use in individuals with underlying medical conditions, to ensure that only probiotics with definitive protective effects against CRC are integrated into the clinical management of CRC. A personalized microbiome therapy taking into account the host genetics, physiology, and immunity will contribute to a higher success rate of such intervention.

\section{AUTHOR CONTRIBUTIONS}

YL and MC designed the study and wrote the manuscript. YN, $\mathrm{WL}$, and SP reviewed and revised the manuscript. MC and WL acquired the funding. All authors contributed to the article and approved the submitted version.

\section{FUNDING}

This article is funded by the matched fund of Sunway Medical Centre and Sunway University: GRTEX-OTR-CBP-SMC001-2019.

\section{REFERENCES}

Abdulamir, A. S., Hafidh, R. R., Mahdi, L. K., Al-jeboori, T., and Abubaker, F. (2009). Investigation into the controversial association of Streptococcus gallolyticus with colorectal cancer and adenoma. BMC Cancer. 9, 403. doi: 10.1186/1471-2407-9-403

Abdulamir, A. S., Hafidh, R. R., and Bakar, F. A. (2010). Molecular detection, quantification, and isolation of Streptococcus gallolyticus bacteria colonizing colorectal tumors: Inflammation-driven potential of carcinogenesis via IL-1, COX-2, and IL-8. Mol. Cancer. 9, 249-249. doi: 10.1186/1476-4598-9-249

Abed, J., Emgård, J. E. M., Zamir, G., Faroja, M., Almogy, G., Grenov, A., et al. (2016). Fap2 mediates Fusobacterium nucleatum colorectal adenocarcinoma enrichment by binding to tumor-expressed Gal-GalNAc. Cell Host Microbe 20 (2), 215-225. doi: 10.1016/j.chom.2016.07.006

Aglago, E. K., Huybrechts, I., Murphy, N., Casagrande, C., Nicolas, G., Pischon, T., et al. (2019). Consumption of fish and long-chain $n-3$ polyunsaturated fatty acids is associated with reduced risk of colorectal cancer in a large European cohort. Clin. Gastroenterol. Hepatol. 18 (3), 654-666.e6. doi: 10.1016/ j.cgh.2019.06.031

Ajayi, B. O., Adedara, I. A., and Farombi, E. O. (2016). Benzo(a)pyrene induces oxidative stress, pro-inflammatory cytokines, expression of nuclear factorkappa B and deregulation of wnt/beta-catenin signaling in colons of BALB/c mice. Food Chem. Toxicol. 95, 42-51. doi: 10.1016/j.fct.2016.06.019

Ajouz, H., Mukherji, D., and Shamseddine, A. (2014). Secondary bile acids: An underrecognized cause of colon cancer. World J. Surg. Oncol. 12 (1), 164. doi: 10.1186/1477-7819-12-164

Aleksandrova, K., Nimptsch, K., and Pischon, T. (2013). Influence of obesity and related metabolic alterations on colorectal cancer risk. Curr. Nutr. Rep. 2 (1), 19. doi: 10.1007/s13668-012-0036-9

Alisson-Silva, F., Kawanishi, K., and Varki, A. (2016). Human risk of diseases associated with red meat intake: Analysis of current theories and proposed role for metabolic incorporation of a non-human sialic acid. Mol. Aspects Med. 51, 16-30. doi: 10.1016/j.mam.2016.07.002

Alvarez, C.-S., Badia, J., Bosch, M., Giménez, R., and Baldomà, L. (2016). Outer membrane vesicles and soluble factors released by probiotic Escherichia coli Nissle 1917 and commensal ECOR63 enhance barrier function by regulating expression of tight junction proteins in intestinal epithelial cells. Front. Microbiol. 7, 1981. doi: 10.3389/fmicb.2016.01981

Araghi, M., Soerjomataram, I., Bardot, A., Ferlay, J., Cabasag, C. J., Morrison, D. S., et al. (2019). Changes in colorectal cancer incidence in seven high-income countries: A population-based study. Lancet Gastroenterol. Hepatol. 4 (7), 511 518. doi: 10.1016/S2468-1253(19)30147-5

Arthur, J. C., Perez-Chanona, E., Mühlbauer, M., Tomkovich, S., Uronis, J. M., Fan, T.-J., et al. (2012). Intestinal inflammation targets cancer-inducing activity of the microbiota. Sci. (New York N.Y.) 338 (6103), 120-123. doi: 10.1126/ science. 1224820

Aune, D., De Stefani, E., Ronco, A. L., Boffetta, P., Deneo-Pellegrini, H., Acosta, G., et al. (2009). Egg consumption and the risk of cancer: A multisite case-control study in Uruguay. Asian Pac. J. Cancer Prev. 10 (5), 869-876.

Aune, D., Lau, R., Chan, D. S. M., Vieira, R., Greenwood, D. C., Kampman, E., et al. (2012). Dairy products and colorectal cancer risk: A systematic review and meta-analysis of cohort studies. Ann. Oncol. 23 (1), 37-45. doi: 10.1093/ annonc/mdr269

Bae, S., Ulrich, C. M., Neuhouser, M. L., Malysheva, O., Bailey, L. B., Xiao, L., et al. (2014). Plasma choline metabolites and colorectal cancer risk in the Women's Health Initiative Observational Study. Cancer Res. 74 (24), 7442-7452. doi: 10.1158/0008-5472.CAN-14-1835

Barbir, A., Linseisen, J., Hermann, S., Kaaks, R., Teucher, B., Eichholzer, M., et al. (2012). Effects of phenotypes in heterocyclic aromatic amine (HCA) metabolism-related genes on the association of HCA intake with the risk of colorectal adenomas. Cancer Causes Control. 23 (9), 1429-1442. doi: 10.1007/ s10552-012-0017-8

Barnung, R. B., Jareid, M., Lukic, M., Oyeyemi, S. O., Rudolfsen, J. H., Sovershaeva, E., et al. (2019). High lactose whey cheese consumption and risk of colorectal cancer The Norwegian Women and Cancer Study. Sci. Rep. 9 (1), 296. doi: 10.1038/ s41598-018-36445-6

Bastide, N. M., Pierre, F. H. F., and Corpet, D. E. (2011). Heme iron from meat and risk of colorectal cancer: A meta-analysis and a review of the mechanisms involved. Cancer Prev. Res. (Phila) 4 (2), 177-184. doi: 10.1158/19406207.CAPR-10-0113

Bastide, N., Morois, S., Cadeau, C., Kangas, S., Serafini, M., Gusto, G., et al. (2016). Heme iron intake, dietary antioxidant capacity, and risk of colorectal adenomas in a large cohort study of French women. Cancer Epidemiol. Biomarkers Prev. 25 (4), 640-647. doi: 10.1158/1055-9965.EPI-15-0724

Baxter, N. T., Schmidt, A. W., Venkataraman, A., Kim, K. S., Waldron, C., and Schmidt, T. M. (2019). Dynamics of human gut microbiota and short-chain fatty acids in response to dietary interventions with three fermentable fibers. mBio 10 (1), e02566-e02518. doi: 10.1128/mBio.02566-18

Ben, Q., Sun, Y., Chai, R., Qian, A., Xu, B., and Yuan, Y. (2014). Dietary fiber intake reduces risk for colorectal adenoma: A meta-analysis. Gastroenterology 146 (3), 689-699.e686. doi: 10.1053/j.gastro.2013.11.003 
Bernstein, C., Holubec, H., Bhattacharyya, A. K., Nguyen, H., Payne, C. M., Zaitlin, B., et al. (2011). Carcinogenicity of deoxycholate, a secondary bile acid. Arch. Toxicol. 85 (8), 863-871. doi: 10.1007/s00204-011-0648-7

Boleij, A., Hechenbleikner, E. M., Goodwin, A. C., Badani, R., Stein, E. M., Lazarev, M. G., et al. (2015). The Bacteroides fragilis toxin gene is prevalent in the colon mucosa of colorectal cancer patients. Clin. Infect. Dis. 60 (2), 208-215. doi: $10.1093 /$ cid/ciu787

Bonnet, M., Buc, E., Sauvanet, P., Darcha, C., Dubois, D., Pereira, B., et al. (2014). Colonization of the human gut by E. coli and colorectal cancer risk. Clin. Cancer Res. 20 (4), 859-867. doi: 10.1158/1078-0432.CCR-13-1343

Bossuet-Greif, N., Vignard, J., Taieb, F., Mirey, G., Dubois, D., Petit, C., et al. (2018). The colibactin genotoxin generates DNA interstrand cross-links in infected cells. mBio 9 (2), e02393-e02317. doi: 10.1128/mBio.02393-17

Boulangé, C. L., Neves, A. L., Chilloux, J., Nicholson, J. K., and Dumas, M.-E. (2016). Impact of the gut microbiota on inflammation, obesity, and metabolic disease. Genome Med. 8 (1), 42-42. doi: 10.1186/s13073-016-0303-2

Bouvard, V., Loomis, D., Guyton, K. Z., Grosse, Y., Ghissassi, F. E., BenbrahimTallaa, L., et al. (2015). Carcinogenicity of consumption of red and processed meat. Lancet Oncol. 16 (16), 1599-1600. doi: 10.1016/s1470-2045(15)00444-1

Bradbury, K. E., Appleby, P. N., and Key, T. J. (2014). Fruit, vegetable, and fiber intake in relation to cancer risk: findings from the European Prospective Investigation into Cancer and Nutrition (EPIC). Am. J. Clin. Nutr. 100 (suppl_1), 394S-398S. doi: 10.3945/ajcn.113.071357

Bray, F., Ferlay, J., Soerjomataram, I., Siegel, R. L., Torre, L. A., and Jemal, A. (2018). Global cancer statistics 2018: Globocan estimates of incidence and mortality worldwide for 36 cancers in 185 countries. CA Cancer J. Clin. 68 (6), 394-424. doi: $10.3322 /$ caac. 21492

Brevik, A., Joshi, A. D., Corral, R., Onland-Moret, N. C., Siegmund, K. D., Le Marchand, L., et al. (2010). Polymorphisms in base excision repair genes as colorectal cancer risk factors and modifiers of the effect of diets high in red meat. Cancer Epidemiol. Biomarkers Prev. 19 (12), 3167-3173. doi: 10.1158/ 1055-9965.Epi-10-0606

Bridge, G., Rashid, S., and Martin, S. A. (2014). DNA mismatch repair and oxidative DNA damage: Implications for cancer biology and treatment. Cancers (Basel) 6 (3), 1597-1614. doi: 10.3390/cancers6031597

Buc, E., Dubois, D., Sauvanet, P., Raisch, J., Delmas, J., Darfeuille-Michaud, A., et al. (2013). High prevalence of mucosa-associated E. coli producing cyclomodulin and genotoxin in colon cancer. PloS One 8 (2), e56964. doi: 10.1371/journal.pone.0056964

Budhathoki, S., Iwasaki, M., Yamaji, T., Sasazuki, S., Takachi, R., Sakamoto, H., et al. (2015). Dietary heterocyclic amine intake, NAT2 genetic polymorphism, and colorectal adenoma risk: the colorectal adenoma study in Tokyo. Cancer Epidemiol. Biomarkers Prev. 24 (3), 613-620. doi: 10.1158/1055-9965.EPI-141051

Bugni, J. M., Meira, L. B., and Samson, L. D. (2009). Alkylation-induced colon tumorigenesis in mice deficient in the Mgmt and Msh6 proteins. Oncogene 28 (5), 734-741. doi: 10.1038/onc.2008.426

Butt, J., Romero-Hernández, B., Pérez-Gómez, B., Willhauck-Fleckenstein, M., Holzinger, D., Martin, V., et al. (2016). Association of Streptococcus gallolyticus subspecies gallolyticus with colorectal cancer: Serological evidence. Int. J. Cancer. 138 (7), 1670-1679. doi: 10.1002/ijc.29914

Butt, J., Varga, M. G., Blot, W. J., Teras, L., Visvanathan, K., Le Marchand, L., et al. (2019). Serologic response to Helicobacter pylori proteins associated with risk of colorectal cancer among diverse populations in the United States. Gastroenterology 156 (1), 175-186.e172. doi: 10.1053/j.gastro.2018.09.054

Cammack, R., Joannou, C. L., Cui, X.-Y., Torres Martinez, C., Maraj, S. R., and Hughes, M. N. (1999). Nitrite and nitrosyl compounds in food preservation. Biochim. Biophys. Acta 1411 (2), 475-488. doi: 10.1016/S0005-2728(99) 00033-X

Cao, H., Xu, M., Dong, W., Deng, B., Wang, S., Zhang, Y., et al. (2017). Secondary bile acid-induced dysbiosis promotes intestinal carcinogenesis. Int. J. Cancer. 140 (11), 2545-2556. doi: 10.1002/ijc.30643

Cascella, M., Bimonte, S., Barbieri, A., Del Vecchio, V., Caliendo, D., Schiavone, V., et al. (2018). Dissecting the mechanisms and molecules underlying the potential carcinogenicity of red and processed meat in colorectal cancer (CRC): An overview on the current state of knowledge. Infect. Agent Cancer. 13, 3-3. doi: 10.1186/s13027-018-0174-9
Chan, C. W. H., Law, B. M. H., Waye, M. M. Y., Chan, J. Y. W., So, W. K. W., and Chow, K. M. (2019). Trimethylamine-N-oxide as one hypothetical link for the relationship between intestinal microbiota and cancer - where we are and where shall we go? J. Cancer 10 (23), 5874-5882. doi: 10.7150/jca.31737

ChangxiChen,, Mao, Y., Du, J., Xu, Y., Zhu, Z., and Cao, H. (2019). Helicobacter pylori infection associated with an increased risk of colorectal adenomatous polyps in the Chinese population. BMC Gastroenterol. 19 (1), 14. doi: 10.1186/ s12876-018-0918-4

Chapkin, R. S., Davidson, L. A., Ly, L., Weeks, B. R., Lupton, J. R., and McMurray, D. N. (2007). Immunomodulatory effects of (n-3) fatty acids: Putative link to inflammation and colon cancer. J. Nutr. 137 (1), 200S-204S. doi: 10.1093/jn/ 137.1.200S

Chassaing, B., Vijay-Kumar, M., and Gewirtz, A. T. (2017). How diet can impact gut microbiota to promote or endanger health. Curr. Opin. Gastroenterol. 33 (6), 417-421. doi: 10.1097/MOG.0000000000000401

Chelombitko, M. A. (2018). Role of reactive oxygen species in inflammation: A minireview. Moscow Univ. Biol. Sci. Bull. 73 (4), 199-202. doi: 10.3103/ S009639251804003X

Chen, H. M., Yu, Y. N., Wang, J. L., Lin, Y. W., Kong, X., Yang, C. Q., et al. (2013). Decreased dietary fiber intake and structural alteration of gut microbiota in patients with advanced colorectal adenoma. Am. J. Clin. Nutr. 97 (5), 10441052. doi: 10.3945/ajcn.112.046607

Chen, Y., Lu, Y., Ke, Y., and Li, Y. (2019). Prognostic impact of the Fusobacterium nucleatum status in colorectal cancers. Med. (Baltimore) 98 (39), e17221. doi: $10.1097 / \mathrm{md} .0000000000017221$

Cheung, C., Loy, S., Li, G. X., Liu, A. B., and Yang, C. S. (2011). Rapid induction of colon carcinogenesis in cypla-humanized mice by 2 -amino-1-methyl-6phenylimidazo[4,5-b]pyridine and dextran sodium sulfate. Carcinogenesis 32 (2), 233-239. doi: 10.1093/carcin/bgq235

Chiavarini, M., Bertarelli, G., Minelli, L., and Fabiani, R. (2017). Dietary intake of meat cooking-related mutagens (HCAs) and risk of colorectal adenoma and cancer: A systematic review and meta-analysis. Nutrients 9 (5), 514. doi: $10.3390 /$ nu9050514

Cho, C. E., Taesuwan, S., Malysheva, O. V., Bender, E., Tulchinsky, N. F., Yan, J., et al. (2017). Trimethylamine-N-oxide (TMAO) response to animal source foods varies among healthy young men and is influenced by their gut microbiota composition: A randomized controlled trial. Mol. Nutr. Food Res. 61 (1), 1600324. doi: 10.1002/mnfr.201600324

Choi, Y., Giovannucci, E., and Lee, J. E. (2012). Glycaemic index and glycaemic load in relation to risk of diabetes-related cancers: A meta-analysis. Br. J. Nutr. 108 (11), 1934-1947. doi: 10.1017/s0007114512003984

Choi, C.-H. R., Al Bakir, I., Ding, N.-S., Lee, G.-H., Askari, A., Warusavitarne, J., et al. (2019). Cumulative burden of inflammation predicts colorectal neoplasia risk in ulcerative colitis: A large single-centre study. Gut 68 (3), 414-422. doi: 10.1136/gutjnl-2017-314190

Chun, Y. J., Sohn, S.-K., Song, H. K., Lee, S. M., Youn, Y. H., Lee, S., et al. (2015). Associations of colorectal cancer incidence with nutrient and food group intakes in Korean adults: A case-control study. Clin. Nutr. Res. 4 (2), 110-123. doi: $10.7762 / \mathrm{cnr} .2015 .4 .2 .110$

Chung, L., Thiele Orberg, E., Geis, A. L., Chan, J. L., Fu, K., DeStefano Shields, C. E., et al. (2018). Bacteroides fragilis toxin coordinates a pro-carcinogenic inflammatory cascade via targeting of colonic epithelial cells. Cell Host Microbe 23 (2), 203-214.e205. doi: 10.1016/j.chom.2018.01.007

Constante, M., Fragoso, G., Calvé, A., Samba-Mondonga, M., and Santos, M. M. (2017). Dietary heme induces gut dysbiosis, aggravates colitis, and potentiates the development of adenomas in mice. Front. Microbiol. 8, 1809. doi: 10.3389/ fmicb.2017.01809

Corredoira, J., Grau, I., Garcia-Rodriguez, J. F., Garcia-Pais, M. J., Rabunal, R., Ardanuy, C., et al. (2017). Colorectal neoplasm in cases of Clostridium septicum and Streptococcus gallolyticus subsp. Gallolyticus bacteraemia. Eur. J. Intern. Med. 41, 68-73. doi: 10.1016/j.ejim.2017.02.009

Cougnoux, A., Dalmasso, G., Martinez, R., Buc, E., Delmas, J., Gibold, L., et al. (2014). Bacterial genotoxin colibactin promotes colon tumour growth by inducing a senescence-associated secretory phenotype. Gut 63 (12), 19321942. doi: 10.1136/gutjnl-2013-305257

Cross, A. J., Ferrucci, L. M., Risch, A., Graubard, B. I., Ward, M. H., Park, Y., et al. (2010). A large prospective study of meat consumption and colorectal cancer 
risk: An investigation of potential mechanisms underlying this association. Cancer Res. 70 (6), 2406-2414. doi: 10.1158/0008-5472.CAN-09-3929

Dahm, C. C., Keogh, R. H., Lentjes, M. A., Spencer, E. A., Key, T. J., Greenwood, D. C., et al. (2010a). Intake of dietary fats and colorectal cancer risk: Prospective findings from the UK dietary cohort consortium. Cancer Epidemiol. 34 (5), 562-567. doi: 10.1016/j.canep.2010.07.008

Dahm, C. C., Keogh, R. H., Spencer, E. A., Greenwood, D. C., Key, T. J., Fentiman, I. S., et al. (2010b). Dietary fiber and colorectal cancer risk: A nested casecontrol study using food diaries. J. Natl. Cancer Inst. 102 (9), 614-626. doi: 10.1093/jnci/djq092

Dalmasso, G., Cougnoux, A., Delmas, J., Darfeuille-Michaud, A., and Bonnet, R. (2014). The bacterial genotoxin colibactin promotes colon tumor growth by modifying the tumor microenvironment. Gut Microbes 5 (5), 675-680. doi: 10.4161/19490976.2014.969989

Das, P., Marcišauskas, S., Ji, B., and Nielsen, J. (2019). Metagenomic analysis of bile salt biotransformation in the human gut microbiome. BMC Genomics 20 (1), 517-517. doi: 10.1186/s12864-019-5899-3

David, L. A., Maurice, C. F., Carmody, R. N., Gootenberg, D. B., Button, J. E., Wolfe, B. E., et al. (2014). Diet rapidly and reproducibly alters the human gut microbiome. Nature 505 (7484), 559-563. doi: 10.1038/nature12820

Davis, C. D., and Milner, J. A. (2009). Gastrointestinal microflora, food components and colon cancer prevention. J. Nutr. Biochem. 20 (10), 743752. doi: 10.1016/j.jnutbio.2009.06.001

Day, S. D., Enos, R. T., McClellan, J. L., Steiner, J. L., Velázquez, K. T., and Murphy, E. A. (2013). Linking inflammation to tumorigenesis in a mouse model of high-fat-diet-enhanced colon cancer. Cytokine 64 (1), 454-462. doi: 10.1016/j.cyto.2013.04.031

De Almeida, C. V., de Camargo, M. R., Russo, E., and Amedei, A. (2019). Role of diet and gut microbiota on colorectal cancer immunomodulation. World J. Gastroenterol. 25 (2), 151-162. doi: 10.3748/wjg.v25.i2.151

De Filippis, F., Pellegrini, N., Vannini, L., Jeffery, I. B., La Storia, A., Laghi, L., et al. (2016). High-level adherence to a mediterranean diet beneficially impacts the gut microbiota and associated metabolome. Gut 65 (11), 1812-1821. doi: 10.1136/gutjnl-2015-309957

De Filippo, C., Cavalieri, D., Di Paola, M., Ramazzotti, M., Poullet, J. B., Massart, S., et al. (2010). Impact of diet in shaping gut microbiota revealed by a comparative study in children from Europe and rural Africa. Proc. Natl. Acad. Sci. U. S. A. 107 (33), 14691-14696. doi: 10.1073/pnas.1005963107

De Palma, F. D. E., D’Argenio, V., Pol, J., Kroemer, G., Maiuri, M. C., and Salvatore, F. (2019). The molecular hallmarks of the serrated pathway in colorectal cancer. Cancers (Basel) 11 (7), 1017. doi: 10.3390/cancers11071017

de Vogel, S., Schneede, J., Ueland, P. M., Vollset, S. E., Meyer, K., Fredriksen, Å., et al. (2011). Biomarkers related to one-carbon metabolism as potential risk factors for distal colorectal adenomas. Cancer Epidemiol. Biomarkers Prev. 20 (8), 1726-1735. doi: 10.1158/1055-9965.EPI-11-0359

Defois, C., Ratel, J., Denis, S., Batut, B., Beugnot, R., Peyretaillade, E., et al. (2017). Environmental pollutant benzo[a]pyrene impacts the volatile metabolome and transcriptome of the human gut microbiota. Front. Microbiol. 8, 1562. doi: $10.3389 /$ fmicb.2017.01562

Defois, C., Ratel, J., Garrait, G., Denis, S., Le Goff, O., Talvas, J., et al. (2018). Food chemicals disrupt human gut microbiota activity and impact intestinal homeostasis as revealed by in vitro systems. Sci. Rep. 8 (1), 11006. doi: 10.1038/s41598-018-29376-9

Dejea, C. M., Fathi, P., Craig, J. M., Boleij, A., Taddese, R., Geis, A. L., et al. (2018). Patients with familial adenomatous polyposis harbor colonic biofilms containing tumorigenic bacteria. Sci. (New York N.Y.) 359 (6375), 592-597. doi: 10.1126/science.aah3648

Demeyer, D., Mertens, B., De Smet, S., and Ulens, M. (2016). Mechanisms linking colorectal cancer to the consumption of (processed) red meat: A review. Crit. Rev. Food Sci. Nutr. 56 (16), 2747-2766. doi: 10.1080/10408398.2013.873886

Dermadi, D., Valo, S., Ollila, S., Soliymani, R., Sipari, N., Pussila, M., et al. (2017). Western diet deregulates bile acid homeostasis, cell proliferation, and tumorigenesis in colon. Cancer Res. 77 (12), 3352-3363. doi: 10.1158/00085472.Can-16-2860

Diggs, D. L., Myers, J. N., Banks, L. D., Niaz, M. S., Hood, D. B., Roberts, L. J., et al. (2013). Influence of dietary fat type on benzo(a)pyrene [b(a)p] biotransformation in a b(a)p-induced mouse model of colon cancer. J. Nutr. Biochem. 24 (12), 2051-2063. doi: 10.1016/j.jnutbio.2013.07.006
Dillon, S. M., Lee, E. J., Kotter, C. V., Austin, G. L., Gianella, S., Siewe, B., et al. (2016). Gut dendritic cell activation links an altered colonic microbiome to mucosal and systemic T-cell activation in untreated HIV-1 infection. Mucosal Immunol. 9 (1), 24-37. doi: 10.1038/mi.2015.33

Donohoe, D. R., Collins, ,.L. B., Wali, A., Bigler, R., Sun, W., and Bultman, S. J. (2012). The Warburg effect dictates the mechanism of butyrate-mediated histone acetylation and cell proliferation. Mol. Cell. 48 (4), 612-626. doi: 10.1016/j.molcel.2012.08.033

Doron, S., and Snydman, D. R. (2015). Risk and safety of probiotics. Clin. Infect. Dis. 60 Suppl 2:Suppl 2, S129-S134. doi: 10.1093/cid/civ085

Duboc, H., Rajca, S., Rainteau, D., Benarous, D., Maubert, M. A., Quervain, E., et al. (2013). Connecting dysbiosis, bile-acid dysmetabolism and gut inflammation in inflammatory bowel diseases. Gut 62 (4), 531-539. doi: 10.1136/gutjnl-2012-302578

Eklof, V., Lofgren-Burstrom, A., Zingmark, C., Edin, S., Larsson, P., Karling, P., et al. (2017). Cancer-associated fecal microbial markers in colorectal cancer detection. Int. J. Cancer. 141 (12), 2528-2536. doi: 10.1002/ijc.31011

Engemann, A., Focke, C., and Humpf, H. U. (2013). Intestinal formation of Nnitroso compounds in the pig cecum model. J. Agric. Food Chem. 61 (4), 9981005. doi: $10.1021 / \mathrm{jf} 305040 \mathrm{e}$

Engeset, D., Andersen, V., Hjartåker, A., and Lund, E. (2007). Consumption of fish and risk of colon cancer in the Norwegian women and cancer (NOWAC) study. Br. J. Nutr. 98 (3), 576-582. doi: 10.1017/S0007114507721487

Epplein, M., Pawlita, M., Michel, A., Peek, R. M. Jr., Cai, Q., and Blot, W. J. (2013). Helicobacter pylori protein-specific antibodies and risk of colorectal cancer. Cancer Epidemiol. Biomarkers Prev. 22 (11), 1964-1974. doi: 10.1158/10559965.Epi-13-0702

Ewa, B., and Danuta, M.-Š. (2017). Polycyclic aromatic hydrocarbons and pahrelated DNA adducts. J. Appl. Genet. 58 (3), 321-330. doi: 10.1007/s13353-0160380-3

Fahrer, J., and Kaina, B. (2013). O6 -methylguanine-DNA methyltransferase in the defense against $\mathrm{N}$-nitroso compounds and colorectal cancer. Carcinogenesis 34 (11), 2435-2442. doi: 10.1093/carcin/bgt275

Fang, W., Xue, H., Chen, X., Chen, K., and Ling, W. (2019). Supplementation with sodium butyrate modulates the composition of the gut microbiota and ameliorates high-fat diet-induced obesity in mice. J. Nutr. 149 (5), 747-754. doi: $10.1093 / \mathrm{jn} / \mathrm{nxy} 324$

Fardini, Y., Wang, X., Témoin, S., Nithianantham, S., Lee, D., Shoham, M., et al. (2011). Fusobacterium nucleatum adhesin FadA binds vascular endothelial cadherin and alters endothelial integrity. Mol. Microbiol. 82 (6), 1468-1480. doi: 10.1111/j.1365-2958.2011.07905.x

Farhana, L., Nangia-Makker, P., Arbit, E., Shango, K., Sarkar, S., Mahmud, H., et al. (2016). Bile acid: A potential inducer of colon cancer stem cells. Stem Cell Res. Ther. 7 (1), 181. doi: 10.1186/s13287-016-0439-4

Fekry, M. I., Engels, C., Zhang, J., Schwab, C., Lacroix, C., Sturla, S. J., et al. (2016). The strict anaerobic gut microbe Eubacterium hallii transforms the carcinogenic dietary heterocyclic amine 2-amino-1-methyl-6-phenylimidazo [4,5-b]pyridine (PhIP). Environ. Microbiol Rep. 8 (2), 201-209. doi: 10.1111/ 1758-2229.12369

Ferrer, M., Ruiz, A., Lanza, F., Haange, S. B., Oberbach, A., Till, H., et al. (2013). Microbiota from the distal guts of lean and obese adolescents exhibit partial functional redundancy besides clear differences in community structure. Environ. Microbiol. 15 (1), 211-226. doi: 10.1111/j.1462-2920.2012.02845.x

Fong, W., Li, Q., and Yu, J. (2020). Gut microbiota modulation: A novel strategy for prevention and treatment of colorectal cancer. Oncogene 39 (26), 49254943. doi: 10.1038/s41388-020-1341-1

Franceschi, S., Favero, A., La Vecchia, C., Negri, E., Conti, E., Montella, M., et al. (1997). Food groups and risk of colorectal cancer in Italy. Int. J. Cancer. 72 (1), 56-61. doi: 10.1002/(SICI) 1097-0215(19970703)72:1<56::AIDIJC8>3.0.CO;2-3

Fukugaiti, M. H., Ignacio, A., Fernandes, M. R., Ribeiro Júnior, U., Nakano, V., and Avila-Campos, M. J. (2015). High occurrence of Fusobacterium nucleatum and Clostridium difficile in the intestinal microbiota of colorectal carcinoma patients. Braz. J. Microbiol. 46 (4), 1135-1140. doi: 10.1590/S1517838246420140665

Gagnière, J., Raisch, J., Veziant, J., Barnich, N., Bonnet, R., Buc, E., et al. (2016). Gut microbiota imbalance and colorectal cancer. World J. Gastroenterol. 22 (2), 501-518. doi: 10.3748/wjg.v22.i2.501 
Galeone, C., Pelucchi, C., and La Vecchia, C. (2012). Added sugar, glycemic index and load in colon cancer risk. Curr. Opin. Clin. Nutr. Metab. Care 15 (4), 368373. doi: 10.1097/MCO.0b013e3283539f81

Gamallat, Y., Meyiah, A., Kuugbee, E. D., Hago, A. M., Chiwala, G., Awadasseid, A., et al. (2016). Lactobacillus rhamnosus induced epithelial cell apoptosis, ameliorates inflammation and prevents colon cancer development in an animal model. BioMed. Pharmacother. 83, 536-541. doi: 10.1016/j.biopha.2016.07.001

Gatej, S. M., Bright, R., Weyrich, L. S., Marino, V., Christophersen, C. T., Gibson, R. J., et al. (2020). Probiotic Lactobacillus rhamnosus GG protects against P. gingivalis and F. nucleatum gut dysbiosis. J. Int. Acad. Periodontol. 22 (2), 1827.

Gemelli, C., Dongmo, B. M., Ferrarini, F., Grande, A., and Corsi, L. (2014). Cytotoxic effect of hemin in colonic epithelial cell line: Involvement of $18 \mathrm{kDa}$ translocator protein (TSPO). Life Sci. 107 (1-2), 14-20. doi: 10.1016/ j.lfs.2014.04.026

George, S. M., Mayne, S. T., Leitzmann, M. F., Park, Y., Schatzkin, A., Flood, A., et al. (2009). Dietary glycemic index, glycemic load, and risk of cancer: A prospective cohort study. Am. J. Epidemiol. 169 (4), 462-472. doi: 10.1093/aje/ kwn347

Geravand, M., Fallah, P., Yaghoobi, M. H., Soleimanifar, F., Farid, M., Zinatizadeh, N., et al. (2019). Investigation of Enterococcus faecalis population in patients with polyp and colorectal cancer in comparison of healthy individuals. Arq Gastroenterol. 56 (2), 141-145. doi: 10.1590/s0004-2803.201900000-28

Ghanavati, R., Akbari, A., Mohammadi, F., Asadollahi, P., Javadi, A., Talebi, M., et al. (2020). Lactobacillus species inhibitory effect on colorectal cancer progression through modulating the Wnt/ $\beta$-catenin signaling pathway. Mol. Cell Biochem. 470 (1), 1-13. doi: 10.1007/s11010-020-03740-8

Gharbi, Y., Fhoula, I., Ruas-Madiedo, P., Afef, N., Boudabous, A., Gueimonde, M., et al. (2019). In-vitro characterization of potentially probiotic Lactobacillus strains isolated from human microbiota: Interaction with pathogenic bacteria and the enteric cell line HT29. Ann. Microbiol. 69 (1), 61-72. doi: 10.1007/ s13213-018-1396-1

Gianfredi, V., Salvatori, T., Villarini, M., Moretti, M., Nucci, D., and Realdon, S. (2018). Is dietary fibre truly protective against colon cancer? A systematic review and meta-analysis. Int. J. Food Sci. Nutr. 69 (8), 904-915. doi: 10.1080/ 09637486.2018.1446917

Gnagnarella, P., Gandini, S., La Vecchia, C., and Maisonneuve, P. (2008). Glycemic index, glycemic load, and cancer risk: A meta-analysis. Am. J. Clin. Nutr. 87 (6), 1793-1801. doi: 10.1093/ajcn/87.6.1793

Goncalves, M. D., Lu, C., Tutnauer, J., Hartman, T. E., Hwang, S.-K., Murphy, C. J., et al. (2019). High-fructose corn syrup enhances intestinal tumor growth in mice. Science 363 (6433), 1345-1349. doi: 10.1126/science.aat8515

Goodwin, A. C., Destefano Shields, C. E., Wu, S., Huso, D. L., Wu, X., MurrayStewart, T. R., et al. (2011). Polyamine catabolism contributes to enterotoxigenic Bacteroides fragilis-induced colon tumorigenesis. Proc. Natl. Acad. Sci. U. S. A. 108 (37), 15354-15359. doi: 10.1073/pnas.1010203108

Gorvitovskaia, A., Holmes, S. P., and Huse, S. M. (2016). Interpreting Prevotella and Bacteroides as biomarkers of diet and lifestyle. Microbiome 4 (1), 15. doi: 10.1186/s40168-016-0160-7

Graillot, V., Dormoy, I., Dupuy, J., Shay, J. W., Huc, L., Mirey, G., et al. (2016). Genotoxicity of cytolethal distending toxin (CDT) on isogenic human colorectal cell lines: Potential promoting effects for colorectal carcinogenesis. Front. Cell Infect. Microbiol. 6, 34. doi: 10.3389/fcimb.2016.00034

Guertin, K. A., Li, X. S., Graubard, B. I., Albanes, D., Weinstein, S. J., Goedert, J. J., et al. (2017). Serum trimethylamine $\mathrm{N}$-oxide, carnitine, choline, and betaine in relation to colorectal cancer risk in the alpha tocopherol, beta carotene cancer prevention study. Cancer Epidemiol. Biomarkers Prev. 26 (6), 945-952. doi: 10.1158/1055-9965.EPI-16-0948

Gur, C., Ibrahim, Y., Isaacson, B., Yamin, R., Abed, J., Gamliel, M., et al. (2015). Binding of the Fap2 protein of Fusobacterium nucleatum to human inhibitory receptor TIGIT protects tumors from immune cell attack. Immunity 42 (2), 344-355. doi: 10.1016/j.immuni.2015.01.010

Haghi, F., Goli, E., Mirzaei, B., and Zeighami, H. (2019). The association between fecal enterotoxigenic B. fragilis with colorectal cancer. BMC Cancer. 19 (1), 879. doi: 10.1186/s12885-019-6115-1

Han, R., Sun, Q., Wu, J., Zheng, P., and Zhao, G. (2016). Sodium butyrate upregulates miR-203 expression to exert anti-proliferation effect on colorectal cancer cells. Cell. Physiol. Biochem. 39 (5), 1919-1929. doi: 10.1159/000447889
Han, A., Bennett, N., Ahmed, B., Whelan, J., and Donohoe, D. R. (2018). Butyrate decreases its own oxidation in colorectal cancer cells through inhibition of histone deacetylases. Oncotarget 9 (43), 27280-27292. doi: 10.18632/ oncotarget.25546

Hansen, N. W., and Sams, A. (2018). The microbiotic highway to health-new perspective on food structure, gut microbiota, and host inflammation. Nutrients 10 (11), 1590. doi: 10.3390/nu10111590

He, C., Cheng, D., Peng, C., Li, Y., Zhu, Y., and Lu, N. (2018). High-fat diet induces dysbiosis of gastric microbiota prior to gut microbiota in association with metabolic disorders in mice. Front. Microbiol. 9, 639. doi: 10.3389/ fmicb.2018.00639

Helmus, D. S., Thompson, C. L., Zelenskiy, S., Tucker, T. C., and Li, L. (2013). Red meat-derived heterocyclic amines increase risk of colon cancer: A populationbased case-control study. Nutr. Cancer. 65 (8), 1141-1150. doi: 10.1080/ 01635581.2013.834945

Hemeryck, L. Y., Rombouts, C., Hecke, T. V., Van Meulebroek, L., Bussche, J. V., De Smet, S., et al. (2016). In vitro DNA adduct profiling to mechanistically link red meat consumption to colon cancer promotion. Toxicol. Res. (Camb) 5 (5), 1346-1358. doi: $10.1039 / \mathrm{c} 6 \mathrm{tx} 00079 \mathrm{~g}$

Hildebrandt, M. A., Hoffmann, C., Sherrill-Mix, S. A., Keilbaugh, S. A., Hamady, M., Chen, Y.-Y., et al. (2009). High-fat diet determines the composition of the murine gut microbiome independently of obesity. Gastroenterology 137 (5), 1716-1724.e1242. doi: 10.1053/j.gastro.2009.08.042

Hu, S., Liu, L., Chang, E. B., Wang, J. Y., and Raufman, J. P. (2015). Butyrate inhibits pro-proliferative miR-92a by diminishing c-myc-induced miR-17-92a cluster transcription in human colon cancer cells. Mol. Cancer. 14, 180. doi: $10.1186 / \mathrm{s} 12943-015-0450-\mathrm{x}$

Huncharek, M., Muscat, J., and Kupelnick, B. (2008). Colorectal cancer risk and dietary intake of calcium, vitamin $\mathrm{D}$, and dairy products: A meta-analysis of 26,335 cases from 60 observational studies. Nutr. Cancer. 61 (1), 47-69. doi: $10.1080 / 01635580802395733$

Hursting, S. D., Digiovanni, J., Dannenberg, A. J., Azrad, M., Leroith, D., DemarkWahnefried, W., et al. (2012). Obesity, energy balance, and cancer: New opportunities for prevention. Cancer Prev. Res. (Phila) 5 (11), 1260-1272. doi: 10.1158/1940-6207.Capr-12-0140

Hwang, S., Gwon, S.-Y., Kim, M. S., Lee, S., and Rhee, K.-J. (2013). Bacteroides fragilis toxin induces IL-8 secretion in HT29/C1 cells through disruption of ecadherin junctions. Immune Netw. 13 (5), 213-217. doi: 10.4110/ in.2013.13.5.213

Ignacio Barrasa, J., Olmo, N., Perez-Ramos, P., Santiago-Gomez, A., Lecona, E., Turnay, J., et al. (2011). Deoxycholic and chenodeoxycholic bile acids induce apoptosis via oxidative stress in human colon adenocarcinoma cells. Apoptosis 16 (10), 1054-1067. doi: 10.1007/s10495-011-0633-x

Ijssennagger, N., Belzer, C., Hooiveld, G. J., Dekker, J., van Mil, S. W. C., Müller, M., et al. (2015). Gut microbiota facilitates dietary heme-induced epithelial hyperproliferation by opening the mucus barrier in colon. Proc. Natl. Acad. Sci. U. S. A. 112 (32), 10038-10043. doi: 10.1073/pnas.1507645112

IJssennagger, N., Derrien, M., van Doorn, G. M., Rijnierse, A., van den Bogert, B., Müller, M., et al. (2012). Dietary heme alters microbiota and mucosa of mouse colon without functional changes in host-microbe cross-talk. PloS One 7 (12), e49868-e49868. doi: 10.1371/journal.pone.0049868

IJssennagger, N., van der Meer, R., and van Mil, S. W. C. (2016). Sulfide as a mucus barrier-breaker inflammatory bowel disease? Trends Mol Med. 22 (3), 190-199. doi: 10.1016/j.molmed.2016.01.002

Iljazovic, A., Roy, U., Gálvez, E. J. C., Lesker, T. R., Zhao, B., Gronow, A., et al. (2020). Perturbation of the gut microbiome by Prevotella spp. Enhances host susceptibility to mucosal inflammation. Mucosal Immunol. doi: 10.1038/ s41385-020-0296-4

Ishikawa, S.-i., Tamaki, S., Ohata, M., Arihara, K., and Itoh, M. (2010). Heme induces DNA damage and hyperproliferation of colonic epithelial cells via hydrogen peroxide produced by heme oxygenase: A possible mechanism of heme-induced colon cancer. Mol. Nutr. Food Res. 54 (8), 1182-1191. doi: $10.1002 / \mathrm{mnfr} .200900348$

Islam, K. S., Fukiya, S., Hagio, M., Fujii, N., Ishizuka, S., Ooka, T., et al. (2011). Bile acid is a host factor that regulates the composition of the cecal microbiota in rats. Gastroenterology 141 (5), 1773-1781. doi: 10.1053/j.gastro.2011.07.046

Jahani-Sherafat, S., Alebouyeh, M., Moghim, S., Ahmadi Amoli, H., and Ghasemian-Safaei, H. (2018). Role of gut microbiota in the pathogenesis of 
colorectal cancer; a review article. Gastroenterol. Hepatol Bed Bench. 11 (2), 101-109.

Jamin, E. L., Riu, A., Douki, T., Debrauwer, L., Cravedi, J.-P., Zalko, D., et al. (2013). Combined genotoxic effects of a polycyclic aromatic hydrocarbon (B(a) $\mathrm{P})$ and an heterocyclic amine (PhIP) in relation to colorectal carcinogenesis. PloS One 8 (3), e58591. doi: 10.1371/journal.pone.0058591

Järvinen, R., Knekt, P., Hakulinen, T., Rissanen, H., and Heliövaara, M. (2001). Dietary fat, cholesterol and colorectal cancer in a prospective study. Br. J. Cancer 85 (3), 357-361. doi: 10.1054/bjoc.2001.1906

Joosen, A. M. C. P., Kuhnle, G. G. C., Aspinall, S. M., Barrow, T. M., Lecommandeur, E., Azqueta, A., et al. (2009). Effect of processed and red meat on endogenous nitrosation and DNA damage. Carcinogenesis 30 (8), 1402-1407. doi: 10.1093/carcin/bgp130

Ju, J., Kwak, Y., Hao, X., and Yang, C. S. (2012). Inhibitory effects of calcium against intestinal cancer in human colon cancer cells and $\mathrm{Apc}(\mathrm{Min} /+)$ mice. Nutr. Res. Pract. 6 (5), 396-404. doi: 10.4162/nrp.2012.6.5.396

Kabzinski, J., Mucha, B., Cuchra, M., Markiewicz, L., Przybylowska, K., Dziki, A., et al. (2016). Efficiency of base excision repair of oxidative DNA damage and its impact on the risk of colorectal cancer in the Polish population. Oxid. Med. Cell Longev. 2016, 3125989. doi: 10.1155/2016/3125989

Kaiko, G. E., Ryu, S. H., Koues, O. I., Collins, P. L., Solnica-Krezel, L., Pearce, E. J., et al. (2016). The colonic crypt protects stem cells from microbiota-derived metabolites. Cell 165 (7), 1708-1720. doi: 10.1016/j.cell.2016.05.018

Kasai, C., Sugimoto, K., Moritani, I., Tanaka, J., Oya, Y., Inoue, H., et al. (2015). Comparison of the gut microbiota composition between obese and non-obese individuals in a Japanese population, as analyzed by terminal restriction fragment length polymorphism and next-generation sequencing. $B M C$ Gastroenterol. 15, 100. doi: 10.1186/s12876-015-0330-2

Kashani, N., Bezmin Abadi, A. T., Rahimi, F., and Forootan, M. (2020). FadApositive Fusobacterium nucleatum is prevalent in biopsy specimens of iranian patients with colorectal cancer. New Microbes New Infect. 34, 100651. doi: 10.1016/j.nmni.2020.100651

Kasprzak, A., and Adamek, A. (2019). Insulin-like growth factor 2 (IGF2) signaling in colorectal cancer-from basic research to potential clinical applications. Int. J. Mol. Sci. 20 (19), 4915. doi: 10.3390/ijms20194915

Kawanishi, M., Hisatomi, Y., Oda, Y., Shimohara, C., Tsunematsu, Y., Sato, M., et al. (2019). In vitro genotoxicity analyses of colibactin-producing E. coli isolated from a Japanese colorectal cancer patient. J. Toxicol. Sci. 44 (12), 871876. doi: $10.2131 /$ jts.44.871

Keller, D. S., Windsor, A., Cohen, R., and Chand, M. (2019). Colorectal cancer in inflammatory bowel disease: Review of the evidence. Tech Coloproctol. 23 (1), 3-13. doi: 10.1007/s10151-019-1926-2

Khalil, A., Villard, P. H., Dao, M. A., Burcelin, R., Champion, S., Fouchier, F., et al. (2010). Polycyclic aromatic hydrocarbons potentiate high-fat diet effects on intestinal inflammation. Toxicol. Lett. 196 (3), 161-167. doi: 10.1016/ j.toxlet.2010.04.010

Kim, Y., and Kim, J. (2020). Intake or blood levels of n-3 polyunsaturated fatty acids and risk of colorectal cancer: A systematic review and meta-analysis of prospective studies. Cancer Epidemiol. Biomarkers Prev. 29 (2), 288-299. doi: 10.1158/1055-9965.EPI-19-0931

Kim, M., and Park, K. (2018). Dietary fat intake and risk of colorectal cancer: A systematic review and meta-analysis of prospective studies. Nutrients 10 (12), 1963. doi: 10.3390/nu10121963

Kim, K.-A., Gu, W., Lee, I.-A., Joh, E.-H., and Kim, D.-H. (2012). High fat dietinduced gut microbiota exacerbates inflammation and obesity in mice via the TLR4 signaling pathway. PloS One 7 (10), e47713. doi: 10.1371/ journal.pone. 0047713

Kim, E. K., Cho, J. H., Kim, E., and Kim, Y. J. (2017a). Ursodeoxycholic acid inhibits the proliferation of colon cancer cells by regulating oxidative stress and cancer stem-like cell growth. PloS One 12 (7), e0181183. doi: 10.1371/ journal.pone. 0181183

Kim, J., Oh, S.-W., Kim, Y.-S., Kwon, H., Joh, H.-K., Lee, J.-E., et al. (2017b). Association between dietary fat intake and colorectal adenoma in Korean adults: A cross-sectional study. Med. (Baltimore) 96 (1), e5759-e5759. doi: 10.1097/MD.0000000000005759

Kim, H., Yin, K., Falcon, D. M., and Xue, X. (2019a). The interaction of Hemin and Sestrin2 modulates oxidative stress and colon tumor growth. Toxicol. Appl. Pharmacol. 374, 77-85. doi: 10.1016/j.taap.2019.04.025
Kim, S. J., Kim, S.-E., Kim, A. R., Kang, S., Park, M.-Y., and Sung, M.-K. (2019b). Dietary fat intake and age modulate the composition of the gut microbiota and colonic inflammation in C57BL/6J mice. BMC Microbiol. 19 (1), 193. doi: 10.1186/s12866-019-1557-9

Kobayashi, J. (2018). Effect of diet and gut environment on the gastrointestinal formation of N-nitroso compounds: A review. Nitric. Oxide 73, 66-73. doi: 10.1016/j.niox.2017.06.001

Koeth, R. A., Wang, Z., Levison, B. S., Buffa, J. A., Org, E., Sheehy, B. T., et al. (2013). Intestinal microbiota metabolism of l-carnitine, a nutrient in red meat, promotes atherosclerosis. Nat. Med. 19 (5), 576-585. doi: 10.1038/nm.3145

Koh, G. Y., Kane, A. V., Wu, X., and Crott, J. W. (2020). Parabacteroides distasonis attenuates tumorigenesis, modulates inflammatory markers and promotes intestinal barrier integrity in azoxymethane-treated $\mathrm{A} / \mathrm{J}$ mice. Carcinogenesis 41 (7), 909-917. doi: 10.1093/carcin/bgaa018

Kohoutova, D., Smajs, D., Moravkova, P., Cyrany, J., Moravkova, M., Forstlova, M., et al. (2014). Escherichia coli strains of phylogenetic group B2 and D and bacteriocin production are associated with advanced colorectal neoplasia. $B M C$ Infect. Dis. 14 (1), 733. doi: 10.1186/s12879-014-0733-7

Koliada, A., Syzenko, G., Moseiko, V., Budovska, L., Puchkov, K., Perederiy, V., et al. (2017). Association between body mass index and Firmicutes/ Bacteroidetes ratio in an adult Ukrainian population. BMC Microbiol. 17 (1), 120. doi: $10.1186 / \mathrm{s} 12866-017-1027-1$

Kostic, A. D., Chun, E., Robertson, L., Glickman, J. N., Gallini, C. A., Michaud, M., et al. (2013). Fusobacterium nucleatum potentiates intestinal tumorigenesis and modulates the tumor-immune microenvironment. Cell Host Microbe 14 (2), 207-215. doi: 10.1016/j.chom.2013.07.007

Kountz, D. J., Behrman, E. J., Zhang, L., and Krzycki, J. A. (2020). MtcB, a member of the MttB superfamily from the human gut acetogen Eubacterium Limosum, is a cobalamin-dependent carnitine demethylase. J. Biol. Chem. 295 (34), 11971-11981. doi: 10.1074/jbc.RA120.012934

Krishna-Subramanian, S., Hanski, M. L., Loddenkemper, C., Choudhary, B., Pagès, G., Zeitz, M., et al. (2012). UDCA slows down intestinal cell proliferation by inducing high and sustained erk phosphorylation. Int. J. Cancer. 130 (12), 2771-2782. doi: $10.1002 / \mathrm{ijc} .26336$

Kumar, R., Herold, J. L., Schady, D., Davis, J., Kopetz, S., Martinez-Moczygemba, M., et al. (2017). Streptococcus gallolyticus subsp. gallolyticus promotes colorectal tumor development. PloS Pathog. 13 (7), e1006440. doi: 10.1371/ journal.ppat. 1006440

Kurnick, S. A., Mannion, A. J., Feng, Y., Madden, C. M., Chamberlain, P., and Fox, J. G. (2019). Genotoxic Escherichia coli strains encoding colibactin, cytolethal distending toxin, and cytotoxic necrotizing factor in laboratory rats. Comp. Med. 69 (2), 103-113. doi: 10.30802/aalas-cm-18-000099

Kuugbee, E. D., Shang, X., Gamallat, Y., Bamba, D., Awadasseid, A., Suliman, M. A., et al. (2016). Structural change in microbiota by a probiotic cocktail enhances the gut barrier and reduces cancer via TLR2 signaling in a rat model of colon cancer. Dig Dis. Sci. 61 (10), 2908-2920. doi: 10.1007/s10620-0164238-7

Kverka, M., Zakostelska, Z., Klimesova, K., Sokol, D., Hudcovic, T., Hrncir, T., et al. (2011). Oral administration of Parabacteroides distasonis antigens attenuates experimental murine colitis through modulation of immunity and microbiota composition. Clin. Exp. Immunol. 163 (2), 250-259. doi: 10.1111/ j.1365-2249.2010.04286.x

Kwong, T. N. Y., Wang, X., Nakatsu, G., Chow, T. C., Tipoe, T., Dai, R. Z. W., et al. (2018). Association between bacteremia from specific microbes and subsequent diagnosis of colorectal cancer. Gastroenterology 155 (2), $383-$ 390.e388. doi: 10.1053/j.gastro.2018.04.028

Lajczak, N. K., Saint-Criq, V., O’dwyer, A. M., Perino, A., Adorini, L., Schoonjans, K., et al. (2017). Bile acids deoxycholic acid and ursodeoxycholic acid differentially regulate human $\beta$-defensin-1 and- 2 secretion by colonic epithelial cells. FASEB J. 31 (9), 3848-3857. doi: 10.1096/fj.201601365R

Landy, J., Ronde, E., English, N., Clark, S. K., Hart, A. L., Knight, S. C., et al. (2016). Tight junctions in inflammatory bowel diseases and inflammatory bowel disease associated colorectal cancer. World J. Gastroenterol. 22 (11), 31173126. doi: 10.3748/wjg.v22.i11.3117

Larsen, J. M. (2017). The immune response to Prevotella bacteria in chronic inflammatory disease. Immunology 151 (4), 363-374. doi: 10.1111/imm.12760

Le Leu, R. K., Winter, J. M., Christophersen, C. T., Young, G. P., Humphreys, K. J., $\mathrm{Hu}$, Y., et al. (2015). Butyrylated starch intake can prevent red meat-induced 
o6-methyl-2-deoxyguanosine adducts in human rectal tissue: A randomised clinical trial. Br. J. Nutr. 114 (2), 220-230. doi: 10.1017/s0007114515001750

Lecomte, V., Kaakoush, N. O., Maloney, C. A., Raipuria, M., Huinao, K. D., Mitchell, H. M., et al. (2015). Changes in gut microbiota in rats fed a high fat diet correlate with obesity-associated metabolic parameters. PloS One 10 (5), e0126931. doi: 10.1371/journal.pone.0126931

Lee, S.-A., Shu, X. O., Yang, G., Li, H., Gao, Y.-T., and Zheng, W. (2009). Animal origin foods and colorectal cancer risk: A report from the Shanghai women's health study. Nutr. Cancer. 61 (2), 194-205. doi: 10.1080/01635580802419780

Lee, Y. J., Hong, Y.-J., Kim, J. Y., Lee, K. W., and Kwon, O. (2013). Dietary Chlorella protects against heterocyclic amine-induced aberrant gene expression in the rat colon by increasing fecal excretion of unmetabolized PhIP. Food Chem. Toxicol. 56, 272-277. doi: 10.1016/j.fct.2013.01.028

Lewin, M. H., Bailey, N., Bandaletova, T., Bowman, R., Cross, A. J., Pollock, J., et al. (2006). Red meat enhances the colonic formation of the DNA adduct o6carboxymethyl guanine: Implications for colorectal cancer risk. Cancer Res. 66 (3), 1859-1865. doi: 10.1158/0008-5472.Can-05-2237

Ley, R. E. (2016). Gut microbiota in 2015: Prevotella in the gut: Choose carefully. Nat. Rev. Gastroenterol. Hepatol 13 (2), 69-70. doi: 10.1038/nrgastro.2016.4

Li, Y.-Y., Ge, Q.-X., Cao, J., Zhou, Y.-J., Du, Y.-L., Shen, B., et al. (2016). Association of Fusobacterium nucleatum infection with colorectal cancer in Chinese patients. World J. Gastroenterol. 22 (11), 3227-3233. doi: 10.3748/ wjg.v22.i11.3227

Li, Q., Ding, C., Meng, T., Lu, W., Liu, W., Hao, H., et al. (2017). Butyrate suppresses motility of colorectal cancer cells via deactivating Akt/ERK signaling in histone deacetylase dependent manner. J. Pharmacol. Sci. 135 (4), 148-155. doi: 10.1016/j.jphs.2017.11.004

Li, W., Zhang, X., Sang, H., Zhou, Y., Shang, C., Wang, Y., et al. (2019). Effects of hyperglycemia on the progression of tumor diseases. J. Exp. Clin. Cancer Res. 38 (1), 327. doi: 10.1186/s13046-019-1309-6

Lin, A., Bik, E. M., Costello, E. K., Dethlefsen, L., Haque, R., Relman, D. A., et al. (2013). Distinct distal gut microbiome diversity and composition in healthy children from Bangladesh and the United States. PloS One 8 (1), e53838e53838. doi: 10.1371/journal.pone.0053838

Lin, S., Li, Y., Zamyatnin, A. A. Jr, Werner, J., and Bazhin, A. V. (2018). Reactive oxygen species and colorectal cancer. J. Cell. Physiol. 233 (7), 5119-5132. doi: $10.1002 /$ jcp. 26356

Lin, C., Cai, X., Zhang, J., Wang, W., Sheng, Q., Hua, H., et al. (2019). Role of gut microbiota in the development and treatment of colorectal cancer. Digestion 100 (1), 72-78. doi: 10.1159/000494052

Liu, T., Zhang, L., Joo, D., and Sun, S.-C. (2017). Nf-kb signaling in inflammation. Signal Transduct Target Ther. 2 (1), 17023. doi: 10.1038/sigtrans.2017.23

Liu, L., Tabung, F. K., Zhang, X., Nowak, J. A., Qian, Z. R., Hamada, T., et al. (2018a). Diets that promote colon inflammation associate with risk of colorectal carcinomas that contain Fusobacterium nucleatum. Clin. Gastroenterol. Hepatol. 16 (10), 1622-1631.e1623. doi: 10.1016/j.cgh. 2018.04.030

Liu, Z.-Y., Tan, X.-Y., Li, Q.-J., Liao, G.-C., Fang, A.-P., Zhang, D.-M., et al. (2018b). Trimethylamine $\mathrm{N}$-oxide, a gut microbiota-dependent metabolite of choline, is positively associated with the risk of primary liver cancer: A casecontrol study. Nutr. Metab. (Lond). 15, 81. doi: 10.1186/s12986-018-0319-2

Loh, Y. H., Jakszyn, P., Luben, R. N., Mulligan, A. A., Mitrou, P. N., and Khaw, K.-T. (2011). N-nitroso compounds and cancer incidence: The European Prospective Investigation into Cancer and Nutrition (EPIC)-Norfolk study. Am. J. Clin. Nutr. 93 (5), 1053-1061. doi: 10.3945/ajcn.111.012377

Long, X., Wong, C. C., Tong, L., Chu, E. S. H., Ho Szeto, C., Go, M. Y. Y., et al. (2019). Peptostreptococcus anaerobius promotes colorectal carcinogenesis and modulates tumour immunity. Nat. Microbiol. 4 (12), 2319-2330. doi: 10.1038/ s41564-019-0541-3

Ludwig, D. S., Hu, F. B., Tappy, L., and Brand-Miller, J. (2018). Dietary carbohydrates: Role of quality and quantity in chronic disease. BMJ 361, k2340. doi: 10.1136/bmj.k2340

Luo, W.-P., Fang, Y.-J., Lu, M.-S., Zhong, X., Chen, Y.-M., and Zhang, C.-X. (2015). High consumption of vegetable and fruit colour groups is inversely associated with the risk of colorectal cancer: A case-control study. Br. J. Nutr. 113 (7), 1129-1138. doi: 10.1017/S0007114515000331

Ma, X., Zhou, Z., Zhang, X., Fan, M., Hong, Y., Feng, Y., et al. (2020). Sodium butyrate modulates gut microbiota and immune response in colorectal cancer liver metastatic mice. Cell Biol. Toxicol. 36 (5), 509-515. doi: 10.1007/s10565020-09518-4

Maddocks, O. D. K., Short, A. J., Donnenberg, M. S., Bader, S., and Harrison, D. J. (2009). Attaching and effacing Escherichia coli downregulate DNA mismatch repair protein in vitro and are associated with colorectal adenocarcinomas in humans. PloS One 4 (5), e5517-e5517. doi: 10.1371/journal.pone.0005517

Maddocks, O. D. K., Scanlon, K. M., and Donnenberg, M. S. (2013). An Escherichia coli effector protein promotes host mutation via depletion of DNA mismatch repair proteins. mBio 4 (3), e00152. doi: 10.1128/ mBio.00152-13

Mahmoud, R. H. (2011). The impact of vitamin B6 supplementation on experimental colitis and colonic mucosal DNA content in female rats fed high-sucrose diet. Aust. J. Basic Appl. Sci. 5, 1051-1060.

Martin, O. C., Lin, C., Naud, N., Tache, S., Raymond-Letron, I., Corpet, D. E., et al. (2015). Antibiotic suppression of intestinal microbiota reduces heme-induced lipoperoxidation associated with colon carcinogenesis in rats. Nutr. Cancer. 67 (1), 119-125. doi: 10.1080/01635581.2015.976317

Martin, O. C. B., Bergonzini, A., D’Amico, F., Chen, P., Shay, J. W., Dupuy, J., et al. (2019a). Infection with genotoxin-producing Salmonella Enterica synergises with loss of the tumour suppressor APC in promoting genomic instability via the PI3K pathway in colonic epithelial cells. Cell Microbiol. 21 (12), e13099. doi: $10.1111 / \mathrm{cmi} .13099$

Martin, O. C. B., Olier, M., Ellero-Simatos, S., Naud, N., Dupuy, J., Huc, L., et al. (2019b). Haem iron reshapes colonic luminal environment: Impact on mucosal homeostasis and microbiome through aldehyde formation. Microbiome 7 (1), 72. doi: 10.1186/s40168-019-0685-7

Martinez-Medina, M., Denizot, J., Dreux, N., Robin, F., Billard, E., Bonnet, R., et al. (2014). Western diet induces dysbiosis with increased E coli in CEABAC10 mice, alters host barrier function favouring AIEC colonisation. Gut 63 (1), 116-124. doi: 10.1136/gutjnl-2012-304119

Martins, M., Aymeric, L., du Merle, L., Danne, C., Robbe-Masselot, C., Trieu-Cuot, P., et al. (2015). Streptococcus gallolyticus pil3 pilus is required for adhesion to colonic mucus and for colonization of mouse distal colon. J. Infect. Dis. 212 (10), 1646-1655. doi: 10.1093/infdis/jiv307

Martins, M., Porrini, C., du Merle, L., Danne, C., Robbe-Masselot, C., Trieu-Cuot, P., et al. (2016). The pil3 pilus of Streptococcus gallolyticus binds to intestinal mucins and to fibrinogen. Gut Microbes 7 (6), 526-532. doi: 10.1080/19490976. 2016.1239677

McCoy, A. N., Araújo-Pérez, F., Azcárate-Peril, A., Yeh, J. J., Sandler, R. S., and Keku, T. O. (2013). Fusobacterium is associated with colorectal adenomas. PloS One 8 (1), e53653-e53653. doi: 10.1371/journal.pone.0053653

Mehta, R. S., Nishihara, R., Cao, Y., Song, M., Mima, K., Qian, Z. R., et al. (2017), Association of dietary patterns with risk of colorectal cancer subtypes classified by Fusobacterium nucleatum in tumor tissue. JAMA Oncol. 3 (7), 921-927. doi: 10.1001/jamaoncol.2016.6374

Mendes, M. C. S., Paulino, D. S., Brambilla, S. R., Camargo, J. A., Persinoti, G. F., and Carvalheira, J. B. C. (2018). Microbiota modification by probiotic supplementation reduces colitis associated colon cancer in mice. World $\mathrm{J}$. Gastroenterol. 24 (18), 1995-2008. doi: 10.3748/wjg.v24.i18.1995

Miller, R., and Wiedmann, M. (2016). Dynamic duo-the Salmonella cytolethal distending toxin combines ADP-ribosyltransferase and nuclease activities in a novel form of the cytolethal distending toxin. Toxins (Basel) 8 (5), 121. doi: 10.3390/toxins8050121

Mima, K., Nishihara, R., Qian, Z. R., Cao, Y., Sukawa, Y., Nowak, J. A., et al. (2016). Fusobacterium nucleatum in colorectal carcinoma tissue and patient prognosis. Gut 65 (12), 1973-1980. doi: 10.1136/gutjnl-2015-310101

Missailidis, C., Hallqvist, J., Qureshi, A. R., Barany, P., Heimburger, O., Lindholm, B., et al. (2016). Serum trimethylamine- $\mathrm{N}$-oxide is strongly related to renal function and predicts outcome in chronic kidney disease. PloS One 11 (1), e0141738. doi: 10.1371/journal.pone.0141738

Mroz, M. S., Lajczak, N. K., Goggins, B. J., Keely, S., and Keely, S. J. (2018). The bile acids, deoxycholic acid and ursodeoxycholic acid, regulate colonic epithelial wound healing. Am. J. Physiol. Gastrointest. Liver Physiol. 314 (3), G378-G387. doi: 10.1152/ajpgi.00435.2016

Murphy, E. F., Cotter, P. D., Healy, S., Marques, T. M., O'Sullivan, O., Fouhy, F., et al. (2010). Composition and energy harvesting capacity of the gut microbiota: Relationship to diet, obesity and time in mouse models. Gut 59 (12), 1635-1642. doi: 10.1136/gut.2010.215665 
Murphy, N., Norat, T., Ferrari, P., Jenab, M., Bueno-de-Mesquita, B., Skeie, G., et al. (2012). Dietary fibre intake and risks of cancers of the colon and rectum in the European Prospective Investigation into Cancer and Nutrition (EPIC). PloS One 7 (6), e39361. doi: 10.1371/journal.pone.0039361

Murphy, N., Norat, T., Ferrari, P., Jenab, M., Bueno-de-Mesquita, B., Skeie, G., et al. (2013). Consumption of dairy products and colorectal cancer in the European Prospective Investigation into Cancer and Nutrition (EPIC). PloS One 8 (9), e72715-e72715. doi: 10.1371/journal.pone.0072715

Naito, Y., Uchiyama, K., and Takagi, T. (2018). A next-generation beneficial microbe: Akkermansia muciniphila. J. Clin. Biochem. Nutr. 63 (1), 33-35. doi: $10.3164 /$ jcbn.18-57

Nguyen, T. L., Vieira-Silva, S., Liston, A., and Raes, J. (2015). How informative is the mouse for human gut microbiota research? Dis. Model Mech. 8 (1), 1-16. doi: $10.1242 / \mathrm{dmm} .017400$

Nguyen, T. T., Ung, T. T., Kim, N. H., and Jung, Y. D. (2018). Role of bile acids in colon carcinogenesis. World J. Clin. cases 6 (13), 577-588. doi: 10.12998/ wjcc.v6.i13.577

Nguyen, L. H., Ma, W., Wang, D. D., Cao, Y., Mallick, H., Gerbaba, T. K., et al. (2020). Association between sulfur-metabolizing bacterial communities in stool and risk of distal colorectal cancer in men. Gastroenterology 158 (5), 1313-1325. doi: 10.1053/j.gastro.2019.12.029

Nitter, M., Norgård, B., de Vogel, S., Eussen, S. J. P. M., Meyer, K., Ulvik, A., et al. (2014). Plasma methionine, choline, betaine, and dimethylglycine in relation to colorectal cancer risk in the European Prospective Investigation into Cancer and Nutrition (EPIC). Ann. Oncol. 25 (8), 1609-1615. doi: 10.1093/annonc/ mdu185

Nojadeh, J. N., Behrouz Sharif, S., and Sakhinia, E. (2018). Microsatellite instability in colorectal cancer. EXCLI J. 17, 159-168. doi: 10.17179/excli2017-948

Obregon-Tito, A. J., Tito, R. Y., Metcalf, J., Sankaranarayanan, K., Clemente, J. C., Ursell, L. K., et al. (2015). Subsistence strategies in traditional societies distinguish gut microbiomes. Nat. Commun. 6 (1), 6505. doi: 10.1038/ncomms7505

Ocvirk, S., and O'Keefe, S. J. (2017). Influence of bile acids on colorectal cancer risk: Potential mechanisms mediated by diet - gut microbiota interactions. Curr. Nutr. Rep. 6 (4), 315-322. doi: 10.1007/s13668-017-0219-5

Olén, O., Erichsen, R., Sachs, M. C., Pedersen, L., Halfvarson, J., Askling, J., et al. (2020). Colorectal cancer in Crohn's disease: A Scandinavian population-based cohort study. Lancet Gastroenterol. Hepatol. 5 (5), 475-484. doi: 10.1016/ S2468-1253(20)30005-4

Oostindjer, M., Alexander, J., Amdam, G. V., Andersen, G., Bryan, N. S., Chen, D., et al. (2014). The role of red and processed meat in colorectal cancer development: A perspective. Meat Sci. 97 (4), 583-596. doi: 10.1016/ j.meatsci.2014.02.011

O’Keefe, S. J. D., Li, J. V., Lahti, L., Ou, J., Carbonero, F., Mohammed, K., et al. (2015). Fat, fibre and cancer risk in African Americans and rural Africans. Nat. Commun. 6 (1), 6342. doi: 10.1038/ncomms7342

Othman, E. M., Leyh, A., and Stopper, H. (2013). Insulin mediated DNA damage in mammalian colon cells and human lymphocytes in vitro. Mutat. Res. 745746, 34-39. doi: 10.1016/j.mrfmmm.2013.03.006

Othman, E. M., Hintzsche, H., and Stopper, H. (2014). Signaling steps in the induction of genomic damage by insulin in colon and kidney cells. Free Radic. Biol. Med. 68, 247-257. doi: 10.1016/j.freeradbiomed.2013.12.010

Ou, J., DeLany, J. P., Zhang, M., Sharma, S., and O'Keefe, S. J. (2012). Association between low colonic short-chain fatty acids and high bile acids in high colon cancer risk populations. Nutr. Cancer. 64 (1), 34-40. doi: 10.1080/ 01635581.2012 .630164

Ou, J., Carbonero, F., Zoetendal, E. G., DeLany, J. P., Wang, M., Newton, K., et al. (2013). Diet, microbiota, and microbial metabolites in colon cancer risk in rural Africans and African Americans. Am. J. Clin. Nutr. 98 (1), 111-120. doi: 10.3945/ajen.112.056689

Pacheco, L. S., Anderson, C. A. M., Lacey, J. V.Jr., Giovannucci, E. L., Lemus, H., Araneta, M. R. G., et al. (2019). Sugar-sweetened beverages and colorectal cancer risk in the California Teachers Study. PloS One 14 (10), e0223638. doi: 10.1371/journal.pone.0223638

Padidar, S., Farquharson, A. J., Williams, L. M., Kearney, R., Arthur, J. R., and Drew, J. E. (2012). High-fat diet alters gene expression in the liver and colon: Links to increased development of aberrant crypt foci. Dig. Dis. Sci. 57 (7), 1866-1874. doi: 10.1007/s10620-012-2092-9
Parnaud, G., Pignatelli, B., Peiffer, G., Taché, S., and Corpet, D. E. (2000). Endogenous N-nitroso compounds, and their precursors, present in bacon, do not initiate or promote aberrant crypt foci in the colon of rats. Nutr. Cancer. 38 (1), 74-80. doi: 10.1207/S15327914NC381_11

Pasquereau-Kotula, E., Martins, M., Aymeric, L., and Dramsi, S. (2018). Significance of Streptococcus gallolyticus subsp. gallolyticus association with colorectal cancer. Front. Microbiol. 9, 614. doi: 10.3389/fmicb.2018.00614

Payne, A. N., Chassard, C., and Lacroix, C. (2012). Gut microbial adaptation to dietary consumption of fructose, artificial sweeteners and sugar alcohols: Implications for host-microbe interactions contributing to obesity. Obes Rev. 13 (9), 799-809. doi: 10.1111/j.1467-789X.2012.01009.x

Peiro-Jordan, R., Krishna-Subramanian, S., Hanski, M. L., Luscher-Firzlaff, J., Zeitz, M., and Hanski, C. (2012). The chemopreventive agent ursodeoxycholic acid inhibits proliferation of colon carcinoma cells by suppressing c-Myc expression. Eur. J. Cancer Prev. 21 (5), 413-422. doi: 10.1097/CEJ.0b013 e32834ef16f

Pfalzer, A. C., Leung, K., Crott, J. W., Kim, S. J., Tai, A. K., Parnell, L. D., et al. (2018). Incremental elevations in TNF $\alpha$ and IL6 in the human colon and procancerous changes in the mucosal transcriptome accompany adiposity. Cancer Epidemiol. Biomarkers Prev. 27 (12), 1416-1423. doi: 10.1158/10559965.Epi-18-0121

Pham, N. M., Mizoue, T., Tanaka, K., Tsuji, I., Tamakoshi, A., Matsuo, K., et al. (2013). Fish consumption and colorectal cancer risk: An evaluation based on a systematic review of epidemiologic evidence among the Japanese population. Jpn. J. Clin. Oncol. 43 (9), 935-941. doi: 10.1093/jjco/hyt094

Pierre, F. H., Santarelli, R. L., Allam, O., Tache, S., Naud, N., Gueraud, F., et al. (2010). Freeze-dried ham promotes azoxymethane-induced mucin-depleted foci and aberrant crypt foci in rat colon. Nutr. Cancer. 62 (5), 567-573. doi: $10.1080 / 01635580903532408$

Pierre, F. H. F., Martin, O. C. B., Santarelli, R. L., Taché, S., Naud, N., Guéraud, F., et al. (2013). Calcium and $\alpha$-tocopherol suppress cured-meat promotion of chemically induced colon carcinogenesis in rats and reduce associated biomarkers in human volunteers. Am. J. Clin. Nutr. 98 (5), 1255-1262. doi: 10.3945/ajcn.113.061069

Pietrzyk, Ł. (2017). Food properties and dietary habits in colorectal cancer prevention and development. Int. J. Food Prop. 20 (10), 2323-2343. doi: $10.1080 / 10942912.2016 .1236813$

Piewngam, P., Zheng, Y., Nguyen, T. H., Dickey, S. W., Joo, H.-S., Villaruz, A. E., et al. (2018). Pathogen elimination by probiotic Bacillus via signalling interference. Nature 562 (7728), 532-537. doi: 10.1038/s41586-018-0616-y

Ponzetto, A., and Figura, N. (2019). Colon cancer risk and vaca toxin of helicobacter pylori. Gastroenterology 156 (8), 2356. doi: 10.1053/ j.gastro.2018.11.083

Pou, S. A., Diaz Mdel, P., and Osella, A. R. (2012). Applying multilevel model to the relationship of dietary patterns and colorectal cancer: An ongoing casecontrol study in Cordoba, Argentina. Eur. J. Nutr. 51 (6), 755-764. doi: 10.1007/s00394-011-0255-7

Pouncey, A. L., Scott, A. J., Alexander, J. L., Marchesi, J., and Kinross, J. (2018). Gut microbiota, chemotherapy and the host: The influence of the gut microbiota on cancer treatment. Ecancermedicalscience 12, 868. doi: 10.3332/ ecancer. 2018.868

Prorok-Hamon, M., Friswell, M. K., Alswied, A., Roberts, C. L., Song, F., Flanagan, P. K., et al. (2014). Colonic mucosa-associated diffusely adherent afaC+ Escherichia coli expressing lpfA and pks are increased in inflammatory bowel disease and colon cancer. Gut 63 (5), 761-770. doi: 10.1136/gutjnl2013-304739

Protiva, P., Pendyala, S., Nelson, C., Augenlicht, L. H., Lipkin, M., and Holt, P. R. (2016). Calcium and 1,25-dihydroxyvitamin D3 modulate genes of immune and inflammatory pathways in the human colon: A human crossover trial. Am. J. Clin. Nutr. 103 (5), 1224-1231. doi: 10.3945/ajen.114.105304

Purcell, R. V., Pearson, J., Aitchison, A., Dixon, L., Frizelle, F. A., and Keenan, J. I. (2017). Colonization with enterotoxigenic Bacteroides fragilis is associated with early-stage colorectal neoplasia. PloS One 12 (2), e0171602-e0171602. doi: 10.1371/journal.pone.0171602

Qiao, D., Gaitonde, S. V., Qi, W., and Martinez, J. D. (2001). Deoxycholic acid suppresses $\mathrm{p} 53$ by stimulating proteasome-mediated $\mathrm{p} 53$ protein degradation. Carcinogenesis 22 (6), 957-964. doi: 10.1093/carcin/22.6.957 
Raisch, J., Rolhion, N., Dubois, A., Darfeuille-Michaud, A., and Bringer, M.-A. (2015). Intracellular colon cancer-associated Escherichia coli promote protumoral activities of human macrophages by inducing sustained COX-2 expression. Lab. Invest. 95 (3), 296-307. doi: 10.1038/labinvest.2014.161

Rampelli, S., Schnorr, S. L., Consolandi, C., Turroni, S., Severgnini, M., Peano, C., et al. (2015). Metagenome sequencing of the Hadza hunter-gatherer gut microbiota. Curr. Biol. 25 (13), 1682-1693. doi: 10.1016/j.cub.2015.04.055

Raufman, J.-P., Shant, J., Guo, C. Y., Roy, S., and Cheng, K. (2008). Deoxycholyltaurine rescues human colon cancer cells from apoptosis by activating EGFR-dependent PI3K/Akt signaling. J. Cell. Physiol. 215 (2), 538-549. doi: $10.1002 /$ jcp. 21332

Rawla, P., Sunkara, T., and Barsouk, A. (2019). Epidemiology of colorectal cancer: Incidence, mortality, survival, and risk factors. Prz Gastroenterol. 14 (2), 89103. doi: $10.5114 /$ pg.2018.81072

Ray, D., and Kidane, D. (2016). Gut microbiota imbalance and base excision repair dynamics in colon cancer. J. Cancer. 7 (11), 1421-1430. doi: 10.7150/jca.15480

Reynolds, I. S., O'Toole, A., Deasy, J., McNamara, D. A., and Burke, J. P. (2017). A meta-analysis of the clinicopathological characteristics and survival outcomes of inflammatory bowel disease associated colorectal cancer. Int. J. Colorectal Dis. 32 (4), 443-451. doi: 10.1007/s00384-017-2754-3

Rezasoltani, S., Asadzadeh Aghdaei, H., Dabiri, H., Akhavan Sepahi, A., Modarressi, M. H., and Nazemalhosseini Mojarad, E. (2018). The association between fecal microbiota and different types of colorectal polyp as precursors of colorectal cancer. Microb. Pathog. 124, 244-249. doi: 10.1016/ j.micpath.2018.08.035

Ribière, C., Peyret, P., Parisot, N., Darcha, C., Déchelotte, P. J., Barnich, N., et al. (2016). Oral exposure to environmental pollutant benzo[a]pyrene impacts the intestinal epithelium and induces gut microbial shifts in murine model. Sci. Rep. 6, 31027. doi: 10.1038/srep31027

Ridlon, J. M., Harris, S. C., Bhowmik, S., Kang, D.-J., and Hylemon, P. B. (2016). Consequences of bile salt biotransformations by intestinal bacteria. Gut Microbes. 7 (1), 22-39. doi: 10.1080/19490976.2015.1127483

Rohrmann, S., Hermann, S., and Linseisen, J. (2009). Heterocyclic aromatic amine intake increases colorectal adenoma risk: Findings from a prospective European cohort study. Am. J. Clin. Nutr. 89 (5), 1418-1424. doi: 10.3945/ ajcn.2008.26658

Rohrmann, S., Linseisen, J., Allenspach, M., von Eckardstein, A., and Müller, D. (2015). Plasma concentrations of trimethylamine- $\mathrm{N}$-oxide are directly associated with dairy food consumption and low-grade inflammation in a German adult population. J. Nutr. 146 (2), 283-289. doi: 10.3945/ jn. 115.220103

Romano, K. A., Vivas, E. I., Amador-Noguez, D., and Rey, F. E. (2015). Intestinal microbiota composition modulates choline bioavailability from diet and accumulation of the proatherogenic metabolite trimethylamine- $\mathrm{N}$-oxide. mBio 6 (2), e02481-e02414. doi: 10.1128/mBio.02481-14

Rubinstein, M. R., Wang, X., Liu, W., Hao, Y., Cai, G., and Han, Y. W. (2013). Fusobacterium nucleatum promotes colorectal carcinogenesis by modulating E-cadherin/ $\beta$-catenin signaling via its FadA adhesin. Cell Host Microbe 14 (2), 195-206. doi: 10.1016/j.chom.2013.07.012

Scher, J. U., Sczesnak, A., Longman, R. S., Segata, N., Ubeda, C., Bielski, C., et al. (2013). Expansion of intestinal Prevotella copri correlates with enhanced susceptibility to arthritis. Elife 2, e01202-e01202. doi: 10.7554/eLife.01202

Schulz, M. D., Atay, Ç., Heringer, J., Romrig, F. K., Schwitalla, S., Aydin, B., et al. (2014). High-fat-diet-mediated dysbiosis promotes intestinal carcinogenesis independently of obesity. Nature 514 (7523), 508-512. doi: 10.1038/ nature 13398

Sebastian, S., Hernández, H. V., Myrelid, P., Kariv, R., Tsianos, E., Toruner, M., et al. (2014). Colorectal cancer in inflammatory bowel disease: results of the $3 \mathrm{rd}$ ECCO pathogenesis scientific workshop (I). J. Crohns Colitis 8 (1), 5-18. doi: $10.1016 /$ j.crohns.2013.04.008

Segata, N. (2015). Gut microbiome: Westernization and the disappearance of intestinal diversity. Curr. Biol. 25 (14), R611-R613. doi: 10.1016/ j.cub.2015.05.040

Seldin, M. M., Meng, Y., Qi, H., Zhu, W., Wang, Z., Hazen, S. L., et al. (2016). Trimethylamine $\mathrm{N}$-oxide promotes vascular inflammation through signaling of mitogen-activated protein kinase and nuclear factor- $\mathrm{\kappa B}$. J. Am. Heart Assoc. 5 (2), e002767. doi: 10.1161/jaha.115.002767
Senthong, V., Wang, Z., Li Xinmin, S., Fan, Y., Wu, Y., Wilson Tang, W. H., et al. (2016). Intestinal microbiota-generated metabolite trimethylamine- $\mathrm{N}$-oxide and 5-year mortality risk in stable coronary artery disease: The contributory role of intestinal microbiota in a COURAGE-like patient cohort. J. Am. Heart Assoc. 5 (6), e002816. doi: 10.1161/JAHA.115.002816

Serfaty, L., Bissonnette, M., and Poupon, R. (2010). Ursodeoxycholic acid and chemoprevention of colorectal cancer. Gastroenterol. Clin. Biol. 34 (10), 516522. doi: 10.1016/j.gcb.2010.05.005

Servin, A. L. (2014). Pathogenesis of human diffusely adhering Escherichia coli expressing Afa/Dr adhesins (Afa/Dr DAEC): Current insights and future challenges. Clin. Microbiol. Rev. 27 (4), 823-869. doi: 10.1128/CMR.00036-14

Shi, Y., Hu, J., Geng, J., Hu, T., Wang, B., Yan, W., et al. (2018). Berberine treatment reduces atherosclerosis by mediating gut microbiota in apoE-/- mice. Biomed. Pharmacother. 107, 1556-1563. doi: 10.1016/j.biopha.2018.08.148

Shi, D.-S., Rhee, K.-J., and Eom, Y.-B. (2020). Effect of probiotic Clostridium butyricum NCTC 7423 supernatant on biofilm formation and gene expression of Bacteroides Fragilis. J. Microbiol Biotechnol. 30 (3), 368-377. doi: 10.4014/ jmb.2001.01027

Siegel, R. L., Torre, L. A., Soerjomataram, I., Hayes, R. B., Bray, F., Weber, T. K., et al. (2019). Global patterns and trends in colorectal cancer incidence in young adults. Gut 68 (12), 2179. doi: 10.1136/gutjnl-2019-319511

Sieri, S., Krogh, V., Agnoli, C., Ricceri, F., Palli, D., Masala, G., et al. (2015). Dietary glycemic index and glycemic load and risk of colorectal cancer: Results from the EPIC-Italy study. Int. J. Cancer. 136 (12), 2923-2931. doi: 10.1002/ijc.29341

Sieri, S., Agnoli, C., Pala, V., Grioni, S., Brighenti, F., Pellegrini, N., et al. (2017). Dietary glycemic index, glycemic load, and cancer risk: Results from the EPICItaly study. Sci. Rep. 7 (1), 9757. doi: 10.1038/s41598-017-09498-2

Sinha, R., Peters, U., Cross, A. J., Kulldorff, M., Weissfeld, J. L., Pinsky, P. F., et al. (2005). Meat, meat cooking methods and preservation, and risk for colorectal adenoma. Cancer Res. 65 (17), 8034-8041. doi: 10.1158/0008-5472.CAN-043429

Sivaprakasam, S., Gurav, A., Paschall, A. V., Coe, G. L., Chaudhary, K., Cai, Y., et al. (2016). An essential role of Ffar2 (Gpr43) in dietary fibre-mediated promotion of healthy composition of gut microbiota and suppression of intestinal carcinogenesis. Oncogenesis 5 (6), e238. doi: 10.1038/oncsis.2016.38

Sobhani, I., Amiot, A., Le Baleur, Y., Levy, M., Auriault, M.-L., Van Nhieu, J. T., et al. (2013). Microbial dysbiosis and colon carcinogenesis: Could colon cancer be considered a bacteria-related disease? Therap Adv. Gastroenterol. 6 (3), 215229. doi: $10.1177 / 1756283 \times 12473674$

Steinberg, P. (2019). Red meat-derived nitroso compounds, lipid peroxidation products and colorectal cancer. Foods 8 (7), 252. doi: 10.3390/foods8070252

Subramaniam, S., and Fletcher, C. (2018). Trimethylamine N-oxide: Breathe new life. Br. J. Pharmacol. 175 (8), 1344-1353. doi: 10.1111/bph.13959

Sugawara, Y., Kuriyama, S., Kakizaki, M., Nagai, M., Ohmori-Matsuda, K., Sone, T., et al. (2009). Fish consumption and the risk of colorectal cancer: The Ohsaki Cohort Study. Br. J. Cancer 101 (5), 849-854. doi: 10.1038/sj.bjc.6605217

Suzuki, T., Heaney, L. M., Jones, D. J. L., and Ng, L. L. (2020). Trimethylamine Noxide and risk stratification after acute myocardial infarction. Clin. Chem. 63 (1), 420-428. doi: 10.1373/clinchem.2016.264853

Tahara, T., Yamamoto, E., Suzuki, H., Maruyama, R., Chung, W., Garriga, J., et al. (2014). Fusobacterium in colonic flora and molecular features of colorectal carcinoma. Cancer Res. 74 (5), 1311-1318. doi: 10.1158/0008-5472.CAN-131865

Tailford, L. E., Crost, E. H., Kavanaugh, D., and Juge, N. (2015). Mucin glycan foraging in the human gut microbiome. Front. Genet. 6, 81:81. doi: 10.3389/ fgene.2015.00081

Taira, T., Yamaguchi, S., Takahashi, A., Okazaki, Y., Yamaguchi, A., Sakaguchi, H., et al. (2015). Dietary polyphenols increase fecal mucin and immunoglobulin a and ameliorate the disturbance in gut microbiota caused by a high fat diet. J. Clin. Biochem. Nutr. 57 (3), 212-216. doi: 10.3164/jcbn.15-15

Tang, W. H. W., Wang, Z., Levison, B. S., Koeth, R. A., Britt, E. B., Fu, X., et al. (2013). Intestinal microbial metabolism of phosphatidylcholine and cardiovascular risk. N. Engl. J. Med. 368 (17), 1575-1584. doi: 10.1056/ NEJMoal 109400

Tang, W. H., Wang, Z., Fan, Y., Levison, B., Hazen, J. E., Donahue, L. M., et al. (2014). Prognostic value of elevated levels of intestinal microbe-generated metabolite trimethylamine- $\mathrm{N}$-oxide in patients with heart failure: Refining the 
gut hypothesis. J. Am. Coll. Cardiol. 64 (18), 1908-1914. doi: 10.1016/ j.jacc.2014.02.617

Tang, W. H., Wang, Z., Kennedy, D. J., Wu, Y., Buffa, J. A., Agatisa-Boyle, B., et al. (2015). Gut microbiota-dependent trimethylamine N-oxide (TMAO) pathway contributes to both development of renal insufficiency and mortality risk in chronic kidney disease. Circ. Res. 116 (3), 448-455. doi: 10.1161/ circresaha. 116.305360

Tasevska, N., Jiao, L., Cross, A. J., Kipnis, V., Subar, A. F., Hollenbeck, A., et al. (2012). Sugars in diet and risk of cancer in the NIH-AARP Diet and Health Study. Int. J. Cancer. 130 (1), 159-169. doi: 10.1002/ijc.25990

Tayyem, R. F., Bawadi, H. A., Shehadah, I. N., Abu-Mweis, S. S., Agraib, L. M., Bani-Hani, K. E., et al. (2015). Macro- and micronutrients consumption and the risk for colorectal cancer among Jordanians. Nutrients 7 (3), 1769-1786. doi: $10.3390 /$ nu7031769

Teimoorian, F., Ranaei, M., Hajian-Tilaki, K., Shokri Shirvani, J., and Vosough, Z. (2018). Association of Helicobacter pylori infection with colon cancer and adenomatous polyps. Iran J. Pathol. 13 (3), 325-332.

Tjalsma, H., Boleij, A., Marchesi, J. R., and Dutilh, B. E. (2012). A bacterial driverpassenger model for colorectal cancer: Beyond the usual suspects. Nat. Rev. Microbiol. 10 (8), 575-582. doi: 10.1038/nrmicro2819

Troseid, M., Ueland, T., Hov, J. R., Svardal, A., Gregersen, I., Dahl, C. P., et al. (2015). Microbiota-dependent metabolite trimethylamine-N-oxide is associated with disease severity and survival of patients with chronic heart failure. J. Intern. Med. 277 (6), 717-726. doi: 10.1111/joim.12328

Tsoi, H., Chu, E. S. H., Zhang, X., Sheng, J., Nakatsu, G., Ng, S. C., et al. (2017). Peptostreptococcus anaerobius induces intracellular cholesterol biosynthesis in colon cells to induce proliferation and causes dysplasia in mice. Gastroenterology 152 (6), 1419-1433.e1415. doi: 10.1053/j.gastro.2017.01.009

Tunsiø, H. S., Gundersen, G., Rangnes, F., Noone, J. C., Endres, A., and Bemanian, V. (2019). Detection of Fusobacterium nucleatum in stool and colonic tissues from norwegian colorectal cancer patients. Eur. J. Clin. Microbiol. Infect. Dis. 38 (7), 1367-1376. doi: 10.1007/s10096-019-03562-7

Turati, F., Galeone, C., Gandini, S., Augustin, L. S., Jenkins, D. J., Pelucchi, C., et al. (2015). High glycemic index and glycemic load are associated with moderately increased cancer risk. Mol. Nutr. Food Res. 59 (7), 1384-1394. doi: 10.1002/ mnfr.201400594

Van de Wiele, T., Vanhaecke, L., Boeckaert, C., Peru, K., Headley, J., Verstraete, W., et al. (2005). Human colon microbiota transform polycyclic aromatic hydrocarbons to estrogenic metabolites. Environ. Health Perspect. 113 (1), 610. doi: $10.1289 /$ ehp.7259

Vega-López, S., Venn, B. J., and Slavin, J. L. (2018). Relevance of the glycemic index and glycemic load for body weight, diabetes, and cardiovascular disease. Nutrients 10 (10), 1361. doi: 10.3390/nu10101361

Velasquez, M. T., Ramezani, A., Manal, A., and Raj, D. S. (2016). Trimethylamine N-oxide: The good, the bad and the unknown. Toxins (Basel) 8 (11), 326. doi: 10.3390/toxins8110326

Vigneri, P. G., Tirrò, E., Pennisi, M. S., Massimino, M., Stella, S., Romano, C., et al. (2015). The insulin/IGF system in colorectal cancer development and resistance to therapy. Front. Oncol. 5, 230. doi: 10.3389/fonc.2015.00230

Viljoen, K. S., Dakshinamurthy, A., Goldberg, P., and Blackburn, J. M. (2015). Quantitative profiling of colorectal cancer-associated bacteria reveals associations between Fusobacterium spp., enterotoxigenic Bacteroides fragilis (ETBF) and clinicopathological features of colorectal cancer. PloS One 10 (3), e0119462-e0119462. doi: 10.1371/journal.pone.0119462

Villéger, R., Lopès, A., Carrier, G., Veziant, J., Billard, E., Barnich, N., et al. (2019). Intestinal microbiota: A novel target to improve anti-tumor treatment? Int. J. Mol. Sci. 20 (18), 4584. doi: 10.3390/ijms20184584

Vuik, F. E. R., Nieuwenburg, S. A. V., Bardou, M., Lansdorp-Vogelaar, I., DinisRibeiro, M., Bento, M. J., et al. (2019). Increasing incidence of colorectal cancer in young adults in Europe over the last 25 years. Gut 68 (10), 1820. doi: 10.1136/gutjnl-2018-317592

Wall, R., Ross, R. P., Fitzgerald, G. F., and Stanton, C. (2010). Fatty acids from fish: The anti-inflammatory potential of long-chain omega-3 fatty acids. Nutr. Rev. 68 (5), 280-289. doi: 10.1111/j.1753-4887.2010.00287.x

Wang, X., and Huycke, M. M. (2007). Extracellular superoxide production by Enterococcus faecalis promotes chromosomal instability in mammalian cells. Gastroenterology 132 (2), 551-561. doi: 10.1053/j.gastro.2006.11.040
Wang, X., Allen, T. D., May, R. J., Lightfoot, S., Houchen, C. W., and Huycke, M. M. (2008). Enterococcus faecalis induces aneuploidy and tetraploidy in colonic epithelial cells through a bystander effect. Cancer Res. 68 (23), 9909-9917. doi: 10.1158/0008-5472.CAN-08-1551

Wang, J.-L., Lin, Y.-W., Chen, H.-M., Kong, X., Xiong, H., Shen, N., et al. (2011). Calcium prevents tumorigenesis in a mouse model of colorectal cancer. PloS One 6 (8), e22566-e22566. doi: 10.1371/journal.pone.0022566

Wang, Z., Uchida, K., Ohnaka, K., Morita, M., Toyomura, K., Kono, S., et al. (2014). Sugars, sucrose and colorectal cancer risk: The Fukuoka colorectal cancer study. Scand. J. Gastroenterol. 49 (5), 581-588. doi: 10.3109/ 00365521.2013 .822091

Wang, Z., Bergeron, N., Levison, B. S., Li, X. S., Chiu, S., Jia, X., et al. (2019). Impact of chronic dietary red meat, white meat, or non-meat protein on trimethylamine $\mathrm{N}$-oxide metabolism and renal excretion in healthy men and women. Eur. Heart J. 40 (7), 583-594. doi: 10.1093/eurheartj/ehy799

Wassenaar, T. M. (2018). E. coli and colorectal cancer: A complex relationship that deserves a critical mindset. Crit. Rev. Microbiol. 44 (5), 619-632. doi: 10.1080/ 1040841X.2018.1481013

Wei, Z., Cao, S., Liu, S., Yao, Z., Sun, T., Li, Y., et al. (2016). Could gut microbiota serve as prognostic biomarker associated with colorectal cancer patients survival? A pilot study on relevant mechanism. Oncotarget 7 (29), 4615846172. doi: 10.18632/oncotarget.10064

Williams, C. D., Satia, J. A., Adair, L. S., Stevens, J., Galanko, J., Keku, T. O., et al. (2010). Associations of red meat, fat, and protein intake with distal colorectal cancer risk. Nutr. Cancer. 62 (6), 701-709. doi: 10.1080/01635581003605938

Wilson, M. R., Jiang, Y., Villalta, P. W., Stornetta, A., Boudreau, P. D., Carrá, A., et al. (2019). The human gut bacterial genotoxin colibactin alkylates DNA. Science 363 (6428), eaar7785. doi: 10.1126/science.aar7785

Winter, S. E., Winter, M. G., Xavier, M. N., Thiennimitr, P., Poon, V., Keestra, A. M., et al. (2013). Host-derived nitrate boosts growth of E. coli in the inflamed gut. Science 339 (6120), 708-711. doi: 10.1126/science.1232467

World Cancer Research Fund/American Institute for Cancer Research (2018). Diet, Nutrition, Physical Activity and Cancer: A Global Perspective. Continuous Update Project Expert Report. Available at: dietandcancerreport.org.

Wroblewski, L. E., Peek, R. M. Jr., and Wilson, K. T. (2010). Helicobacter pylori and gastric cancer: Factors that modulate disease risk. Clin. Microbiol. Rev. 23 (4), 713-739. doi: 10.1128/CMR.00011-10

Wu, S., Rhee, K.-J., Zhang, M., Franco, A., and Sears, C. L. (2007). Bacteroides fragilis toxin stimulates intestinal epithelial cell shedding and gammasecretase-dependent E-cadherin cleavage. J. Cell. Sci. 120 (Pt 11), 1944-1952. doi: $10.1242 /$ jcs. 03455

Wu, S., Rhee, K.-J., Albesiano, E., Rabizadeh, S., Wu, X., Yen, H.-R., et al. (2009). A human colonic commensal promotes colon tumorigenesis via activation of $\mathrm{T}$ helper type $17 \mathrm{~T}$ cell responses.1. Nat. Med. 15 (9), 1016-1022. doi: 10.1038/ nm.2015

Wu, G. D., Chen, J., Hoffmann, C., Bittinger, K., Chen, Y.-Y., Keilbaugh, S. A., et al. (2011). Linking long-term dietary patterns with gut microbial enterotypes. Science 334 (6052), 105. doi: 10.1126/science.1208344

Wu, S., Feng, B., Li, K., Zhu, X., Liang, S., Liu, X., et al. (2012). Fish consumption and colorectal cancer risk in humans: A systematic review and meta-analysis. Am. J. Med. 125 (6), 551-559.e555. doi: 10.1016/j.amjmed.2012.01.022

Wu, N., Yang, X., Zhang, R., Li, J., Xiao, X., Hu, Y., et al. (2013). Dysbiosis signature of fecal microbiota in colorectal cancer patients. Microb. Ecol. 66 (2), 462-470. doi: 10.1007/s00248-013-0245-9

Wu, D., Cao, M., Peng, J., Li, N., Yi, S., Song, L., et al. (2017). The effect of trimethylamine $\mathrm{N}$-oxide on Helicobacter pylori-induced changes of immunoinflammatory genes expression in gastric epithelial cells. Int. Immunopharmacol. 43, 172-178. doi: 10.1016/j.intimp.2016.11.032

Wu, X., Wu, Y., He, L., Wu, L., Wang, X., and Liu, Z. (2018). Effects of the intestinal microbial metabolite butyrate on the development of colorectal cancer. J. Cancer. 9 (14), 2510-2517. doi: 10.7150/jca.25324

Xu, R., Wang, Q., and Li, L. (2015). A genome-wide systems analysis reveals strong link between colorectal cancer and trimethylamine $\mathrm{N}$-oxide (TMAO), a gut microbial metabolite of dietary meat and fat. BMC Genomics 16 Suppl 7, S4. doi: 10.1186/1471-2164-16-s7-s4

Xu, M., Cen, M., Shen, Y., Zhu, Y., Cheng, F., Tang, L., et al. (2020). Deoxycholic acid-induced gut dysbiosis disrupts bile acid enterohepatic circulation and 
promotes intestinal inflammation. Dig. Dis. Sci. doi: 10.1007/s10620-02006208-3

Yachida, S., Mizutani, S., Shiroma, H., Shiba, S., Nakajima, T., Sakamoto, T., et al. (2019). Metagenomic and metabolomic analyses reveal distinct stage-specific phenotypes of the gut microbiota in colorectal cancer. Nat. Med. 25 (6), 968976. doi: 10.1038/s41591-019-0458-7

Yang, J., and Yu, J. (2018). The association of diet, gut microbiota and colorectal cancer: What we eat may imply what we get. Protein Cell. 9 (5), 474-487. doi: 10.1007/s13238-018-0543-6

Yang, Y., Wang, X., Moore, D. R., Lightfoot, S. A., and Huycke, M. M. (2012). Tnf$\alpha$ mediates macrophage-induced bystander effects through Netrin-1. Cancer Res. 72 (20), 5219-5229. doi: 10.1158/0008-5472.CAN-12-1463

Yang, Y., Weng, W., Peng, J., Hong, L., Yang, L., Toiyama, Y., et al. (2017). Fusobacterium nucleatum increases proliferation of colorectal cancer cells and tumor development in mice by activating toll-like receptor 4 signaling to nuclear factor- $\mathrm{kb}$, and up-regulating expression of microRNA-21. Gastroenterology 152 (4), 851-866.e824. doi: 10.1053/j.gastro.2016.11.018

Yoon, K., and Kim, N. (2018). The effect of microbiota on colon carcinogenesis. J. Cancer Prev. 23 (3), 117-125. doi: 10.15430/JCP.2018.23.3.117

Yu, D. C., Waby, J. S., Chirakkal, H., Staton, C. A., and Corfe, B. M. (2010). Butyrate suppresses expression of neuropilin I in colorectal cell lines through inhibition of Sp1 transactivation. Mol. Cancer. 9, 276. doi: 10.1186/1476-45989-276

Yu, D. C., Bury, J. P., Tiernan, J., Waby, J. S., Staton, C. A., and Corfe, B. M. (2011). Short-chain fatty acid level and field cancerization show opposing associations with enteroendocrine cell number and neuropilin expression in patients with colorectal adenoma. Mol. Cancer. 10, 27. doi: 10.1186/1476-4598-10-27

Yu, J., Feng, Q., Wong, S. H., Zhang, D., Liang, Q. Y., Qin, Y., et al. (2017). Metagenomic analysis of faecal microbiome as a tool towards targeted noninvasive biomarkers for colorectal cancer. Gut 66 (1), 70-78. doi: 10.1136/ gutjnl-2015-309800

Yue, C., Yang, X., Li, J., Chen, X., Zhao, X., Chen, Y., et al. (2017). Trimethylamine $\mathrm{N}$-oxide prime NLRP3 inflammasome via inhibiting ATG16L1-induced autophagy in colonic epithelial cells. Biochem. Biophys. Res. Commun. 490 (2), 541-551. doi: 10.1016/j.bbrc.2017.06.075

Yue, Y., Ye, K., Lu, J., Wang, X., Zhang, S., Liu, L., et al. (2020). Probiotic strain Lactobacillus plantarum YYC-3 prevents colon cancer in mice by regulating the tumour microenvironment. BioMed. Pharmacother. 127, 110159. doi: 10.1016/j.biopha.2020.110159

Zelinkova, Z., and Wenzl, T. (2015). The occurrence of 16 EPA PAHs in food - a review. Polycycl Aromat Compd. 35 (2-4), 248-284. doi: 10.1080/ 10406638.2014.918550

Zeller, G., Tap, J., Voigt, A. Y., Sunagawa, S., Kultima, J. R., Costea, P. I., et al. (2014). Potential of fecal microbiota for early-stage detection of colorectal cancer. Mol. Syst. Biol. 10 (11), 766. doi: 10.15252/msb.20145645

Zeng, S., Shen, W. H., and Liu, L. (2018). Senescence and cancer. Cancer Transl. Med. 4 (3), 70-74. doi: 10.4103/ctm.ctm_22_18

Zeng, H., Hamlin, S., Safratowich, B., Cheng, W.-H., and Johnson, L. (2020). Superior inhibitory efficacy of butyrate over propionate and acetate against human colon cancer cell proliferation via cell cycle arrest and apoptosis. Curr. Dev. Nutr. 4 (suppl 2), 364-364. doi: 10.1093/cdn/nzaa044063

Zhang, Y., Hoffmeister, M., Weck, M. N., Chang-Claude, J., and Brenner, H. (2012). Helicobacter pylori infection and colorectal cancer risk: Evidence from a large population-based case-control study in Germany. Am. J. Epidemiol. 175 (5), 441-450. doi: 10.1093/aje/kwr331

Zhang, Y., Zhao, X., Zhu, Y., Ma, J., Ma, H., and Zhang, H. (2018a). Probiotic mixture protects dextran sulfate sodium-induced colitis by altering tight junction protein expressions and increasing Tregs. Mediators Inflamm. 2018, 9416391. doi: 10.1155/2018/9416391

Zhang, Z., Aung, K. M., Uhlin, B. E., and Wai, S. N. (2018b). Reversible senescence of human colon cancer cells after blockage of mitosis/cytokinesis caused by the CNF1 cyclomodulin from Escherichia coli. Sci. Rep. 8 (1), 17780. doi: 10.1038/ s41598-018-36036-5

Zhang, J., Lacroix, C., Wortmann, E., Ruscheweyh, H.-J., Sunagawa, S., Sturla, S. J., et al. (2019). Gut microbial beta-glucuronidase and glycerol/diol dehydratase activity contribute to dietary heterocyclic amine biotransformation. $B M C$ Microbiol. 19 (1), 99. doi: 10.1186/s12866-019-1483-X

Zhao, Z., Feng, Q., Yin, Z., Shuang, J., Bai, B., Yu, P., et al. (2017). Red and processed meat consumption and colorectal cancer risk: A systematic review and meta-analysis. Oncotarget 8 (47), 83306-83314. doi: 10.18632/ oncotarget.20667

Zheng, Y., Luo, Y., Lv, Y., Huang, C., Sheng, Q., Zhao, P., et al. (2017). Clostridium difficile colonization in preoperative colorectal cancer patients. Oncotarget 8 (7), 11877-11886. doi: 10.18632/oncotarget.14424

Zhong, X., Fang, Y.-J., Pan, Z.-Z., Li, B., Wang, L., Zheng, M.-C., et al. (2013). Dietary fat, fatty acid intakes and colorectal cancer risk in Chinese adults: A case-control study. Eur. J. Cancer Prev. 22 (5), 438-447. doi: 10.1097/ CEJ.0b013e32835e88c4

Zhou, Y., He, H., Xu, H., Li, Y., Li, Z., Du, Y., et al. (2016). Association of oncogenic bacteria with colorectal cancer in South China. Oncotarget 7 (49), 80794-80802. doi: 10.18632/oncotarget.13094

Zhou, D., Pan, Q., Xin, F.-Z., Zhang, R.-N., He, C.-X., Chen, G.-Y., et al. (2017). Sodium butyrate attenuates high-fat diet-induced steatohepatitis in mice by improving gut microbiota and gastrointestinal barrier. World J. Gastroenterol. 23 (1), 60-75. doi: 10.3748/wjg.v23.i1.60

Zhou, Q., Shen, Z.-F., Wu, B.-S., Xu, C.-B., He, Z.-Q., Chen, T., et al. (2019). Risk of colorectal cancer in ulcerative colitis patients: A systematic review and metaanalysis. Gastroenterol. Res. Pract. 2019, 5363261. doi: 10.1155/2019/5363261

Zhu, Y., Wang, P. P., Zhao, J., Green, R., Sun, Z., Roebothan, B., et al. (2014). Dietary N-nitroso compounds and risk of colorectal cancer: A case-control study in Newfoundland and Labrador and Ontario, Canada. Br. J. Nutr. 111 (6), 1109-1117. doi: 10.1017/S0007114513003462

Zou, S., Fang, L., and Lee, M.-H. (2018). Dysbiosis of gut microbiota in promoting the development of colorectal cancer. Gastroenterol. Rep. (Oxf) 6 (1), 1-12. doi: 10.1093/gastro/gox031

Conflict of Interest: The authors declare that the research was conducted in the absence of any commercial or financial relationships that could be construed as a potential conflict of interest.

Copyright $\odot 2020$ Loke, Chew, Ngeow, Lim and Peh. This is an open-access article distributed under the terms of the Creative Commons Attribution License (CC BY). The use, distribution or reproduction in other forums is permitted, provided the original author(s) and the copyright owner(s) are credited and that the original publication in this journal is cited, in accordance with accepted academic practice. No use, distribution or reproduction is permitted which does not comply with these terms. 